
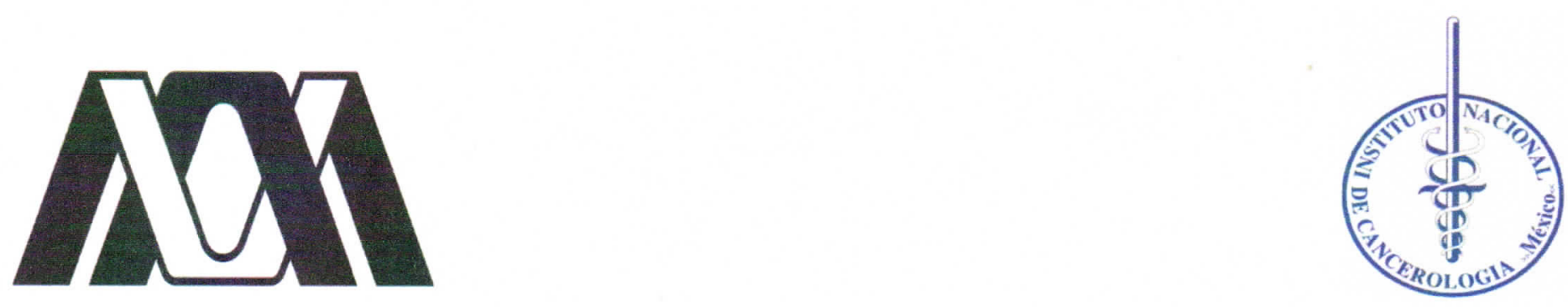

UNIVERSIDAD AUTÓNOMA METROPOLITANA

DIVISIÓN DE CIENCIAS BÁSICAS E INGENIERÍA

INSTITUTO NACIONAL DE CANCEROLOGÍA

\title{
CARACTERIZACIÓN DEL PERFIL DEL HAZ DE PROTONES DE UN CICLOTRÓN IBA 18/9 CON PELÍCULAS RADIOCRÓMICAS EBT3
}

\section{IDÓNEA COMUNICACIÓN DE RESULTADOS}

QUE PARA OBTENER EL GRADO DE

ESPECIALISTA EN FÍSICA MÉDICA CLÍNICA

\section{PRESENTA}

ALÍ CÉSAR MEDRANO SANDOVAL

Director de Tesis: Dr Juan Azorín Nieto

Tutor Clínico: Fís. Esteban Barrera García
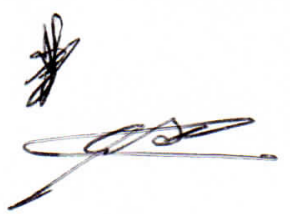

Miembro de Comité Tutorial. Dr en C. Héctor Francisco Valdovinos Uribe

Miembro de Comité Tutorial: M. en C. Jonathan Elizalde Cabrera

Miembro de Comité Tutorial. M. en C. Adolfo Zárate Morales

Miembro de Comité Tutorial. M. en C. José Alfredo Herrera González

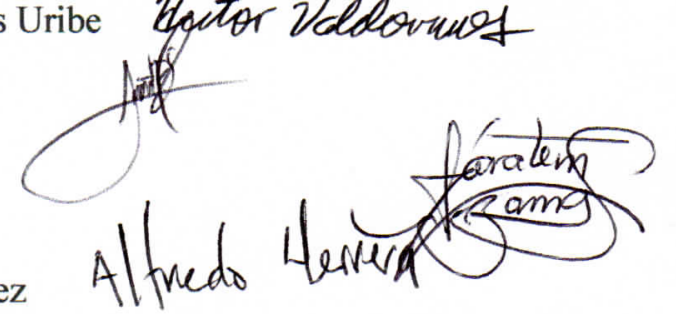


«No hay que olvidar que cuando se descubrió el radio, nadie sabía que resultaría útil en los hospitales. Se trataba de trabajo de ciencia pura. Y esta es una prueba de que la actividad científica no debe valorarse desde el punto de vista de su utilidad directa, sino que hay que llevarla a cabo por sí misma, por su belleza...»

-Marie Curie. 
A la Universidad Autónoma Metropolitana Unidad Iztapalapa por el apoyo al estímulo económico recibido durante la realización de esta tesina.

Al Instituto Nacional de Cancerología por impulsar esta primera generación en esta especialización.

Al Departamento de Medicina Nuclear, lugar en específico donde pude completar mi formación como Físico Médico.

A La Unidad de Ciclotrón \& Radiofarmacia por facilitar la creación de este proyecto. 
A mi familia, que durante complicados momentos, nunca nos separamos. A mi compañera de especialidad y después amiga Marlene que prácticamente estuvimos todo el tiempo juntos, aprendiendo uno del otro.

Al físico Esteban Barrera por aceptar ser el tutor de este trabajo en la parte clínica y tener la paciencia necesaria para la infinidad de pruebas que realizamos.

A la Dra. Silvia Hidalgo, Al Dr. Juan Azorín y al Dr. Ramón González por darme la oportunidad de haberme aceptado en dicha especialidad y sobre todo darnos las herramientas necesarias para el ingreso al INCan.

A la M. en C. Vanessa Izquierdo por las recomendaciones y sugerencias cuando necesitaba su apoyo en la parte química y uso del TLC.

A mis sinodales: el Dr. Héctor Valdovinos y el M. en C. Adolfo Zárate por sus acertadas correcciones en dicha tesina.

A los M. en C. Jonathan Elizalde y Alfredo Herrera primeramente por aportar sus observaciones y correcciones en dicho trabajo y además por permitir hacer uso del escáner para la digitalización de las películas EBT.

Al M. en C. Miguel Rodríguez por el préstamo de las películas EBT3, un elemento valioso para cumplir los objetivos de la tesis.

A la Lic. Ivonne por prácticamente estar a cargo del apoyo económico durante nuestra estancia en el INCan.

Gracias a INCan y UAM-I por permitir ser su estudiante. 


\section{Índice General}

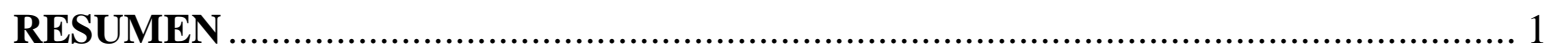

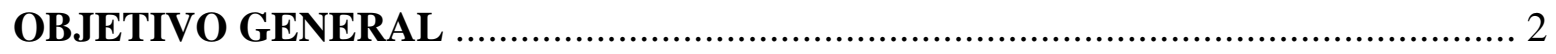

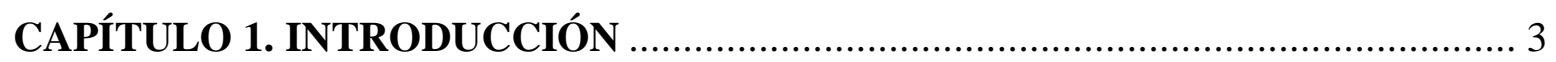

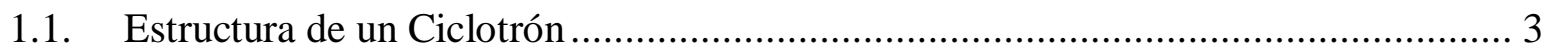

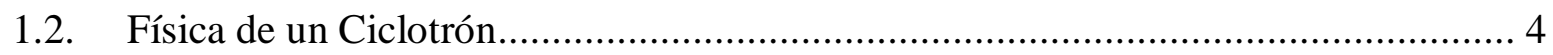

1.2.1. Condición de resonancia y aceleración .......................................................... 5

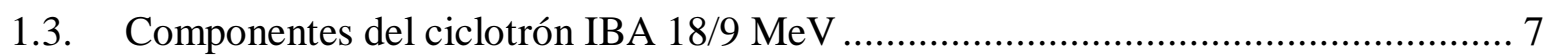

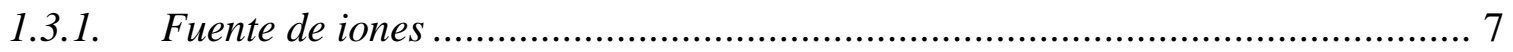

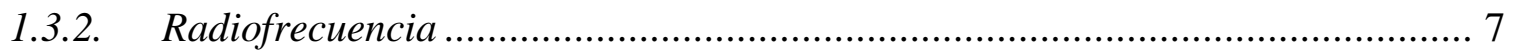

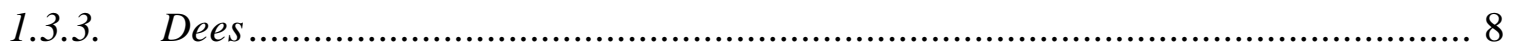

1.3.4. Campo Magnético ………………………….......................................... 9

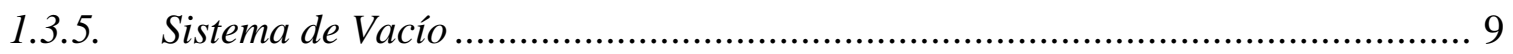

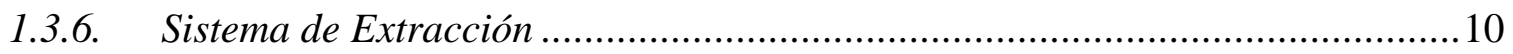

1.3.7. Características comunes de los distintos tipos de aceleradores cíclicos............11

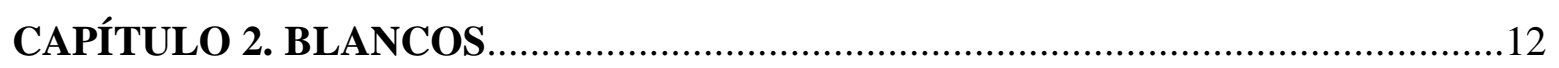

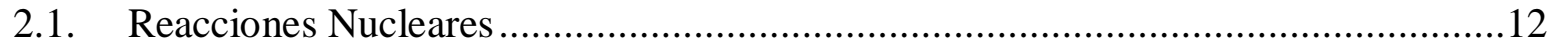

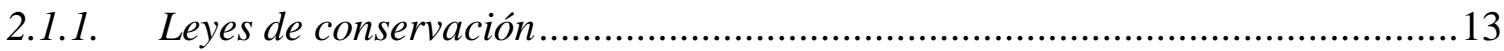

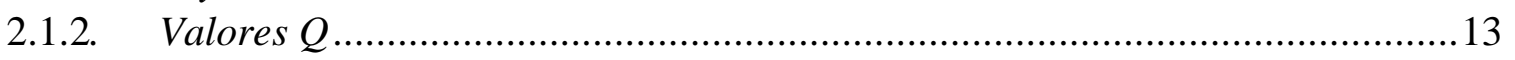

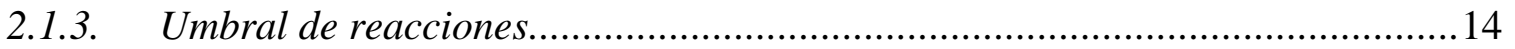

2.1.4. Sección Eficaz: Ecuaciones fundamentales para la producción de

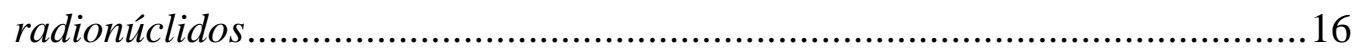

2.1.5. Sección eficaz: rapidez de producción de un radionúclido................................17

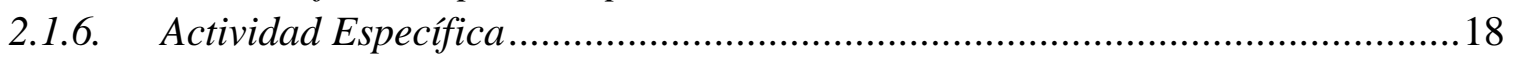

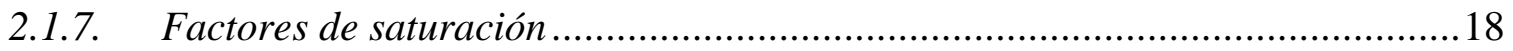

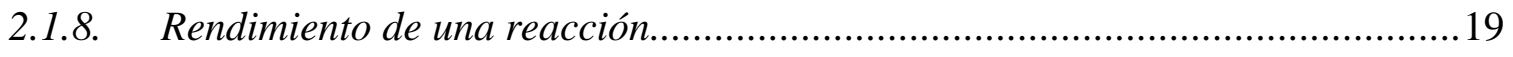

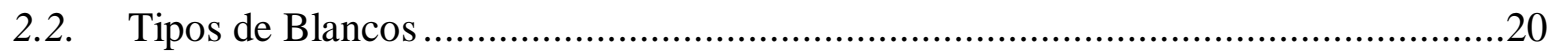

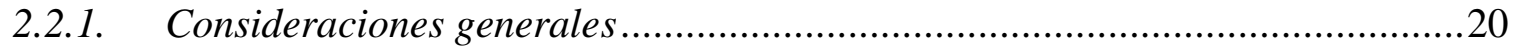

2.2.2 Transporte del haz de radiación. Perfiles ...................................................22

CAPÍTULO 3. MÉTODOS PARA LA CARACTERIZACIÓN DEL PERFIL DE UN

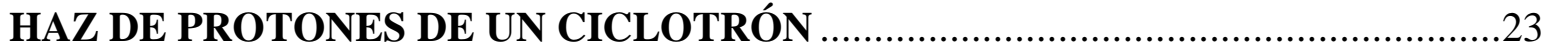

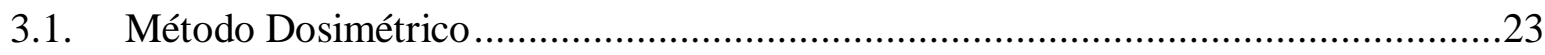

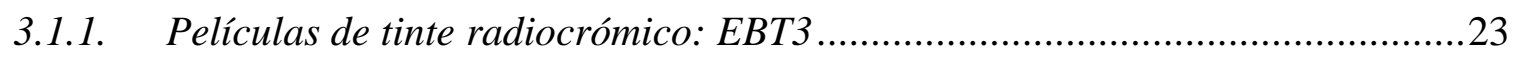

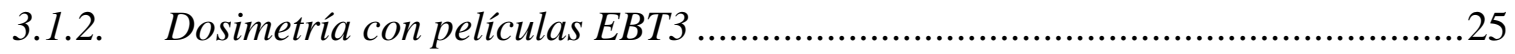


3.2. Método con lector de distribución de actividad usado en cromatografía de capa

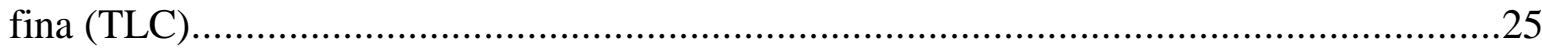

3.2.1. Principios de funcionamiento de lector de tiras usadas en un TLC .................25

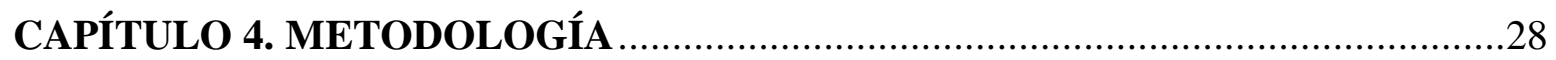

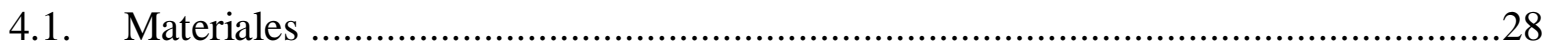

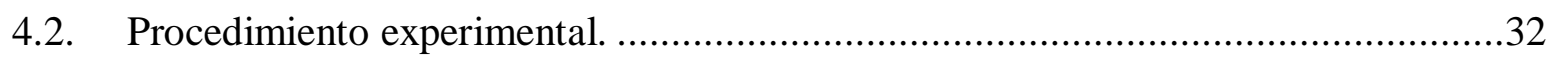

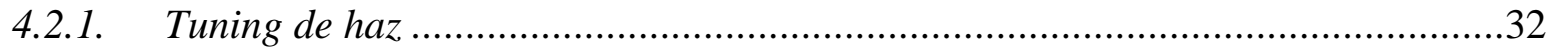

4.2.2. Montaje de película EBT3 en blanco de prueba .................................................33

4.2.3. Proceso de Irradiación .........................................................................................34

4.2.4. Productos de activación. Lector de tiras de TLC y calibrador de dosis ...............35

4.2.5. Proceso de Digitalización ....................................................................................36

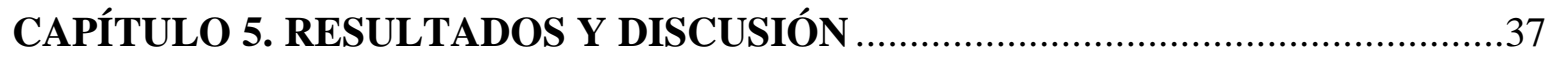

5.1. Tamaño del haz. Técnica Dosimétrica y con lector de tiras de TLC .......................37

5.2. Perfil de haz sobre Blanco de Flúor ...............................................................40

5.3. Productos de Activación ......................................................................... 42

5.4. Tamaño del haz. Técnica con lector de tiras de TLC...........................................43

5.5. Parámetros que influyen en el perfil del haz.................................................44

5.6. Cálculo de la dosis absorbida .........................................................................48

5.7. Tamaño de haz en diversos materiales...........................................................48

DISCUSIÓN

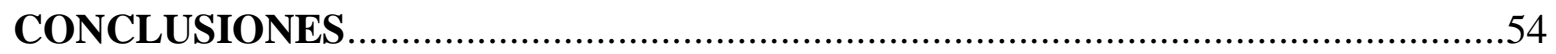

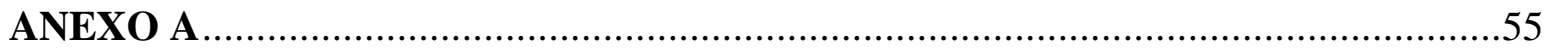

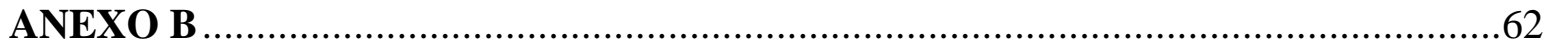

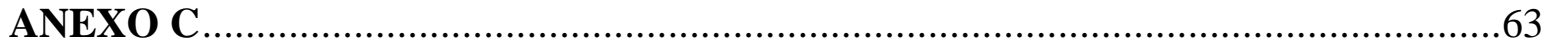

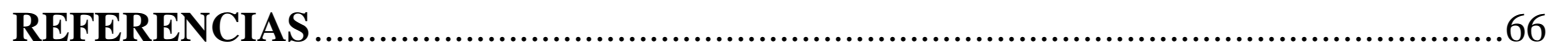


En el presente trabajo se proponen dos métodos para estimar el tamaño del haz de protones de un acelerador de partículas tipo Ciclotrón marca IBA 18/9 MeV perteneciente a la unidad de Ciclotrón \& Radiofarmacia del Instituto Nacional de Cancerología.

En los capítulos 1 y 2 se describen las bases físicas necesarias para el funcionamiento de un ciclotrón y la parte correspondiente a la teoría de blancos.

En el capítulo 3 se habla sobre los métodos para conocer con certeza el ancho del haz del ciclotrón. El primer método se basa en la dosimetría mediante el uso de películas radiocrómicas EBT3 muy utilizadas en la verificación de dosis en tratamientos de radioterapia. Esta técnica consiste en hacer incidir el haz directamente sobre la película, sin necesidad de degradadores de haz para, posteriormente obtener una imagen perfil de la proyección del haz por medio de su digitalización en un escáner de transmisión. El segundo método propone una nueva alternativa para estimar las dimensiones del haz de protones haciendo uso de un lector de cromatografía de capa fina (TLC), que obtendrá el perfil de la distribución de actividad presente en la película debido a los productos de activación al término de la irradiación.

En el capítulo 4 se describe el proceso experimental para la irradiación de las películas radiocrómicas, desde la manipulación para su corte hasta su lectura en el TLC, y escáner.

En la sección de resultados, se comprueba la tendencia constante del tamaño de haz para tres factores que influyen en una típica irradiación: tiempo, intensidad de corriente y vacío. El tamaño promedio del eje mayor del perfil elipse formado para estas pruebas fue de $10 \pm 1 \mathrm{~mm}$ mientras que para el eje menor fue de $6 \pm 0.1 \mathrm{~mm}$. Los perfiles de la distribución de actividad producto de la activación del ${ }^{16} \mathrm{O}$ obtenidos mediante TLC, reportan a partir del FWHM un tamaño de haz de $12 \mathrm{~mm}$. El aumento de tamaño podría corresponder a la dispersión de haz que se lleva a cabo al momento de impactar el filme y que propiamente activará una mayor región misma que el área efectiva (elipse formada). Dichos resultados nos ayudan a conocer cómo se comporta el haz de radiación; ya que se puede visualizar si se encuentra centrado, lo que permite al momento de una irradiación, aumentar la eficiencia de producción. Además de que se evita una mayor activación en los colimadores del blanco. Por otra parte, saber las dimensiones del haz de irradiación permitirá conocer el área del material blanco para su electrodeposición cuando se inicien pruebas para la implementación de blancos sólidos en el Ciclotrón. 


\section{OBJETIVO GENERAL}

Caracterizar el perfil del haz de protones de $18 \mathrm{MeV}$ de un Ciclotrón IBA 18/9 haciendo uso de películas radiocrómicas EBT3.

\section{OBJETIVOS ESPECÍFICOS}

- Encontrar los parámetros bajo los cuales se tiene un haz de irradiación fino (tunnig) mediante el ajuste del tiempo de irradiación, intensidad de corriente, movimiento del stripper e intensidad del campo magnético.

- Analizar el perfil y ancho de haz de protones a la máxima y mínima corriente mediante su digitalización en un escáner de transmisión.

- Medir el ancho del haz mediante el uso de un lector de tiras usadas en un TLC.

- Estimar la dosis absorbida en la película EBT3. 


\section{CAPÍTULO 1 \\ INTRODUCCIÓN}

La medicina junto con la física se correlacionan desde tiempos memorables. La aplicación de los conceptos físicos es esencial en el desarrollo de dispositivos capaces de satisfacer necesidades en el ámbito clínico tales como la obtención de imágenes anatómicas detalladas del interior de un paciente con el desarrollo del primer tomógrafo en 1974 [Cristerna, 1995], cuyas bases matemáticas fueron descritas por Johan Radon en 1917 mediante el principio que rige la reconstrucción de imágenes y/o el primer equipo PET para la obtención de imágenes metabólicas a través de la recopilación de información de la biodistribución de un determinado radiofármaco. Dichos temas son los que se abordan en física médica la cual involucra la aplicación de modelos físicos en el control, diagnóstico y tratamiento de las enfermedades [OIEA, 2010]. Como parte de los modelos físicos aplicados podemos encontrar el desarrollo de los denominados aceleradores (circulares o lineales), que se basan en una complicada teoría de onda pero que en la práctica dichos conceptos pueden ser simplificados para obtener un beneficio clínico. E. Lawrence desarrolló en 1930 el primer acelerador tipo ciclotrón y con ello el nuevo inicio en la investigación de los primeros radionúclidos.

\subsection{Estructura de un Ciclotrón}

El acelerador de partículas cargadas o Ciclotrón es uno de los ejemplos de aceleradores circulares cuya finalidad es producir reacciones nucleares (capítulo 2), mediante el impacto de partículas tales como: protones o deuterones sobre un material blanco de número $\mathrm{Z}$ a velocidades no relativistas y a altas energías (10-20 MeV) capaz de romper la barrera coulombiana del núcleo blanco. El radionúclido de interés puede ser producido mediante dos de las reacciones nucleares básicas: la reacción protón ${ }_{Z}^{A} X(p, n){ }_{Z+1}^{A} Y$ y la reacción deuterón ${ }_{Z}^{A} X(d, n){ }_{Z+1}^{A+1} Y$. La tabla 1.1 muestra una variedad de radionúclidos que se producen en un ciclotrón basándose en las reacciones anteriores [Cherry et al., 2012].

Tabla 1.1. Radionúclidos que son generados en un Ciclotrón

\begin{tabular}{|c|c|c|c|c|}
\hline Producto & $\begin{array}{c}\text { Modo de } \\
\text { decaimiento }\end{array}$ & $\begin{array}{c}\text { Reacción Nuclear } \\
\text { común }\end{array}$ & $\begin{array}{c}\text { Valor } Q^{*} \\
(\mathrm{MeV})\end{array}$ & $\begin{array}{c}\text { Umbral de Energía* } \\
(\mathrm{MeV})\end{array}$ \\
\hline \multirow[t]{2}{*}{${ }^{11} C$} & $\beta^{+}, E C$ & ${ }^{14} N(p, \alpha){ }^{11} C$ & -3.0 & 3.1 \\
\hline & & ${ }^{10} B(d, n){ }^{11} C$ & 6.4 & 0 \\
\hline \multirow[t]{2}{*}{${ }^{13} \mathrm{~N}$} & $\beta^{+}$ & ${ }^{16} O(p, \alpha){ }^{13} N$ & -5.2 & 5.5 \\
\hline & & ${ }^{12} C(d, n){ }^{13} N$ & -0.3 & 0.3 \\
\hline \multirow[t]{2}{*}{${ }^{15} \mathrm{O}$} & $\beta^{+}$ & ${ }^{14} N(d, n){ }^{15} \mathrm{O}$ & 5.0 & 0.6 \\
\hline & & ${ }^{15} N(p, n){ }^{15} O$ & -3.5 & 3.8 \\
\hline \multirow[t]{2}{*}{${ }^{18} F$} & $\beta^{+}, E C$ & ${ }^{18} O(p, n){ }^{18} F$ & -2.4 & 3.0 \\
\hline & & ${ }^{20} N(d, \alpha){ }^{18} F$ & 8.0 & 0 \\
\hline
\end{tabular}

* Valores obtenidos de la base de datos del Brookhaven National Laboratory 
El esquema general de los componentes de un acelerador de partículas cargadas se puede ver en la figura 1.1 [Powsner.R \& Powsner.E, 2006].

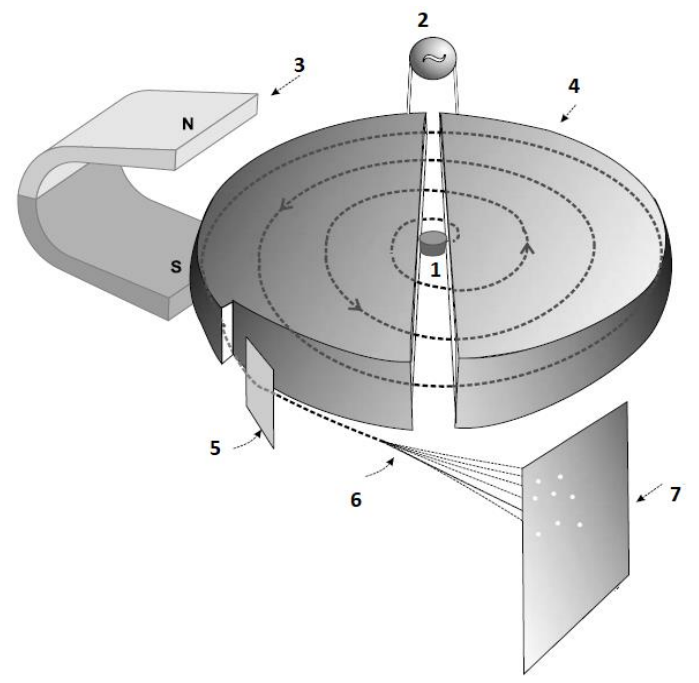

Figura 1.1. Componentes generales de un acelerador tipo ciclotrón.

1) Fuente de iones

2) Potencial oscilante o RF

3) Campo magnético

4) Dee

5) Sistema de extracción del haz

6) Haz de partículas

7) Blanco (sólido, líquido o gaseoso)

\subsection{Física de un Ciclotrón}

El principio básico del funcionamiento de un ciclotrón se basa en el movimiento circular de una partícula cargada inmersa en un campo magnético. De acuerdo a la teoría de la electrodinámica, la frecuencia rotacional de una partícula viajando a través de este campo es independiente del radio de su órbita [Resnick et al., 1994].Consideremos la segunda ley de Newton para la partícula moviéndose a través de una trayectoria circular de radio (r) en un campo magnético (B) perpendicular al plano de movimiento y que experimenta una fuerza de Lorenz de magnitud $(q \vee v B)$ entonces:

$$
q v B=\frac{v^{2}}{r} m
$$

Dónde: $q$ es la carga de la partícula, $v$ es la velocidad de la partícula, $B$ es el campo magnético, $r$ es la órbita circular durante una revolución y $m$ es la masa de la partícula en cuestión. El cociente del cuadrado de la velocidad y el radio es la denominada aceleración centrípeta.

De aquí podemos escribir a (1.1) como: 


$$
r=\frac{m v}{|q| B_{z}}
$$

La velocidad angular de una partícula en un movimiento circular podemos relacionarla con (1.2):

$$
\omega=\frac{v}{r}=\frac{q B}{m}
$$

Ahora la frecuencia de resonancia de dicha partícula es:

$$
v=\frac{\omega}{2 \pi}=\frac{q B}{2 \pi m}
$$

Estas ecuaciones son fundamentales para la operación de un ciclotrón. Como en la figura (1.1), la cámara de aceleración es colocada entre dos polos que originan un campo magnético homogéneo perpendicular a dos estructuras metálicas llamadas Dees; en el centro de estas Dees se encuentra una fuente de iones de hidrógeno (también para deuterones). Las estructuras son sometidas a un potencial oscilante (RF) el cual permitirá al ion comenzar su aceleración y ser extraído de dicha fuente por efecto del campo magnético, el ion entra primeramente a una de las Dees donde el campo eléctrico en el interior es cero pero por la acción del campo magnético lo obligará a sentir una fuerza (fuerza de Lorenz), que seguirá una trayectoria semicircular con radio r. A la salida de esta "Dee" justo el campo eléctrico en la brecha cambia de polaridad por lo que el ion es acelerado hacia el interior de la segunda dee (figura 1.2) y siguiendo de nuevo una trayectoria semicircular con una velocidad y radio mayor al primero. Cabe mencionar que en cada aceleración el ion presenta una ganancia de energía que está descrita por la siguiente relación:

$$
E_{K}=\frac{q^{2} B^{2} R^{2}}{2 m}
$$

\subsubsection{Condición de resonancia y aceleración}

La condición de aceleración del ion de hidrógeno radica en que la frecuencia del potencial alternante debe de ser proporcional a su frecuencia de resonancia. De aquí se obtiene una expresión analítica denominada modos harmónicos:

$$
H \bullet f_{i o n}=f_{R F}
$$

Dónde: $f_{R F}, f_{i o n}$ denotan las frecuencias de la radiofrecuencia (potencial oscilante) y de la partícula y $\mathrm{H}$ el modo harmónico (figura 1.3). 

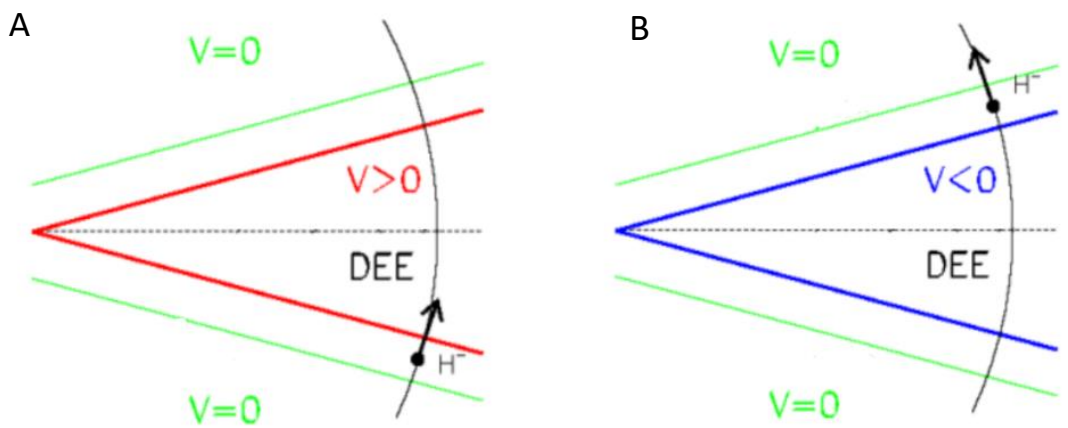

Figura 1.2.A) Ion de hidrógeno entrando a la primera Dee donde el voltaje es diferente de cero y en la cual experimenta una atracción. B) el potencial cambia de polaridad repeliendo o empujando al ion que por ende entrará a la segunda Dee para de nuevo ser acelerado.

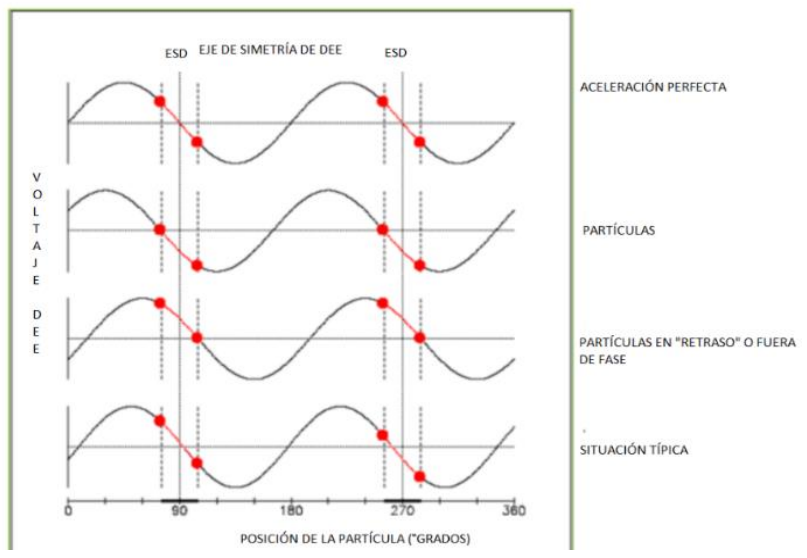

Figura 1.3. Los modos harmónicos de las frecuencias de oscilación del potencial alternante y la partícula.

Los modos harmónicos pares (figura 1.4), proporcionarán un reforzamiento de onda mientras que modos harmónicos impares proporcionarán un desfase que conlleva a la no aceleración de la partícula

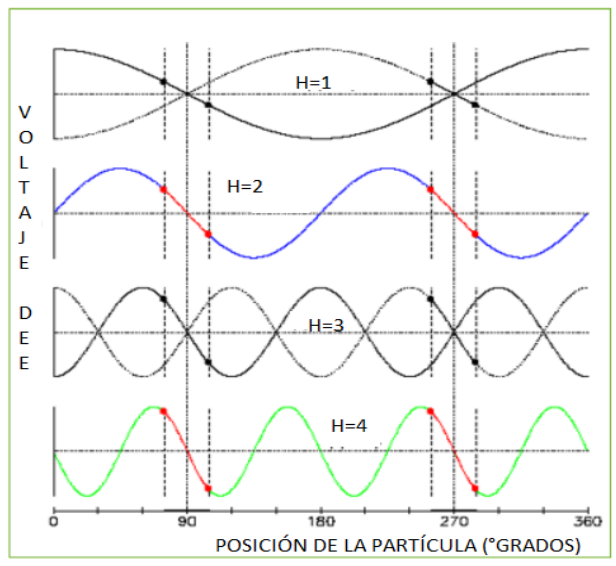

Figura 1.4. El modo $\mathrm{H}=2$ y $\mathrm{H}=4$ favorecen la aceleración de la partícula. 


\subsection{Componentes del ciclotrón IBA 18/9 MeV}

Los siguientes parámetros técnicos son datos precisos del ciclotrón del departamento de Medicina Nuclear e imagen Molecular del Instituto Nacional de Cancerología (INCan).

\subsubsection{Fuente de iones}

La fuente de iones se encuentra en el centro del acelerador (figura 1.5 A) justo en la brecha que separa a las Dees. El equipo cuenta con dos fuentes las cuales son alimentadas por $\mathrm{H}^{-}$que se encuentra a una diferencia de potencial de $\mathbf{3 4} \mathrm{kV}$. La corriente generada por la ionización en cadena es de $\mathbf{4 0} \mathrm{mA}$. La descarga eléctrica que se le aplica al gas crea los iones de hidrógeno (figura $1.5 \mathrm{~B}$ ). Una vez que se crea el plasma entre el ánodo y cátodo, se tiene una distribución de energías de los iones que al ser extraídos por el campo magnético comenzarán su primera aceleración no sin antes pasar a través de la "pop-up probe" que registrará la corriente efectiva dado que sólo se tiene una pequeña porción de iones del plasma original.
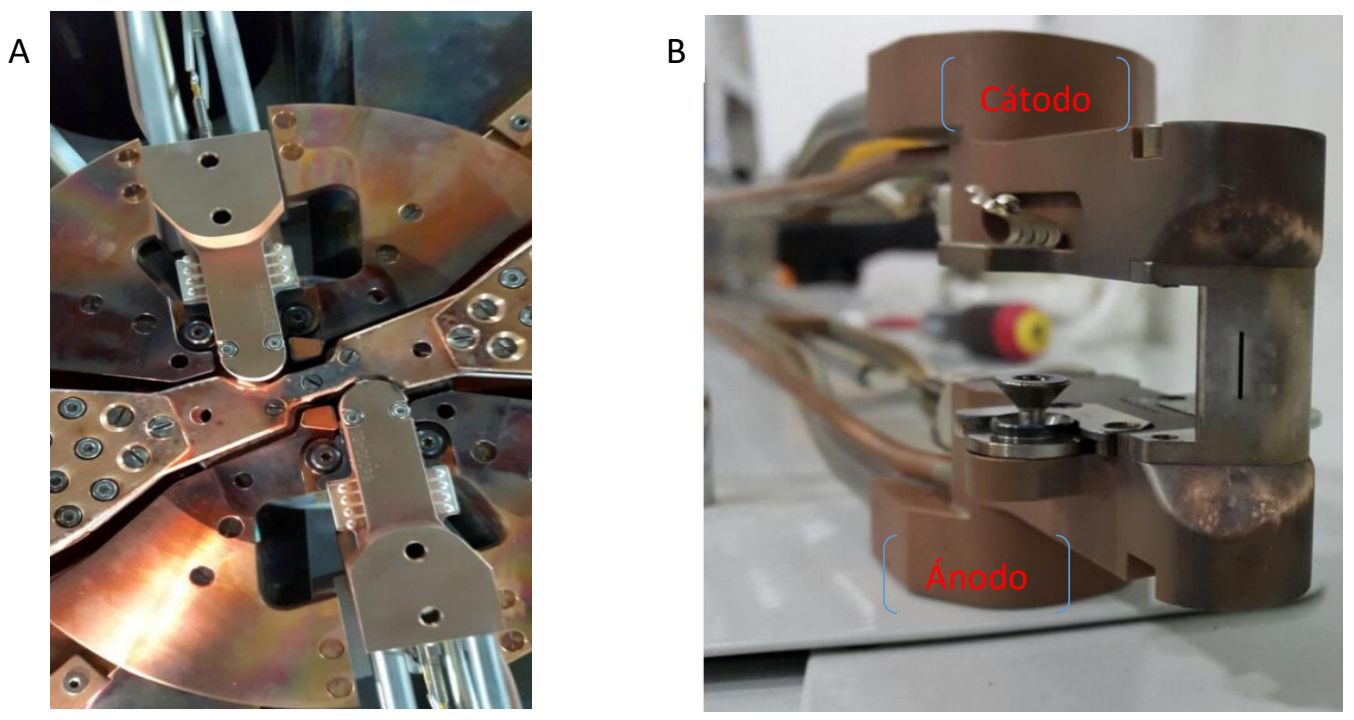

Figura 1.5. A) Sistema de dos fuentes de hidrógeno. B) Fuente de iones donde se puede visualizar a los electrodos y la apertura donde son extraídos los iones.

\subsubsection{Radiofrecuencia}

Cuando la radiofrecuencia es acoplada en las Dees, gradientes de campo eléctrico son producidos. El valor de dicha frecuencia es de $42 \mathrm{MHz}$. Los "gaps crossings" o las veces que el ion es atraído o repelido, es igual a dos veces el número de electrodos que contenga el ciclotrón y que conlleva a una ganancia de energía del ion que dependerá directamente de la amplitud de la diferencia de potencial, los modos harmónicos y la longitud azimutal entre los electrodos [OIEA, 2008]. Consideremos la siguiente relación:

$$
\Delta E_{K}=V_{D E E} N \bullet q \bullet \operatorname{sen}\left(\frac{h \varphi}{2}\right)
$$


Dónde: $\Delta E_{K}$ es la ganancia de energía, $\mathrm{V}_{\mathrm{DEE}}$ es la diferencia de potencial que se genera en las Dees a partir del suministro de una alta radiofrecuencia, $\mathrm{N}$ es el número de "saltos o pasos" que experimenta el ion al acelerarse entre los electrodos, $q$ es la carga del ion (igual a 1), h es el modo harmónico y $\varphi$ es la longitud azimutal que recorre el ion que para el modelo iba $18 / 9$ es de $30^{\circ}$. Entonces, la ganancia que adquiere el ion cada que sufre una aceleración es de $\mathbf{6 0} \mathrm{keV}$. El número de revoluciones que se tiene para alcanzar la energía de $18 \mathrm{MeV}$ es de 300. La energía final también se puede calcular a partir de la relación (1.5) considerando el radio de la Dee.

\subsubsection{Dees}

Son electrodos en forma parecida a una D (aunque en realidad no lo son) y separados por una brecha, con radio aproximado de $0.94 \mathrm{~cm}$ y en el centro se encuentran dos fuentes de iones de hidrógeno $\mathrm{H}^{-}$. A altas energías, se tienen que considerar aproximaciones relativistas dado que con el aumento de la masa del ion la condición de resonancia se pierde. Además en la práctica también se presenta un problema. La frecuencia de la órbita no se mantiene "del todo" constante debido a la disminución de la intensidad del campo magnético que siente el ion con el aumento del radio. Para solucionar este problema se construyeron regiones entre los magnetos donde se tiene una variación de campo llamada variación azimutal del campo magnético (AVF). Estas regiones se llaman "hills" y "valleys" (figura 1.6). La AVF también proporciona el denominado efecto de enfoque axial que "enfoca" a los posibles iones que se desvíen del plano medio axial de aceleración.

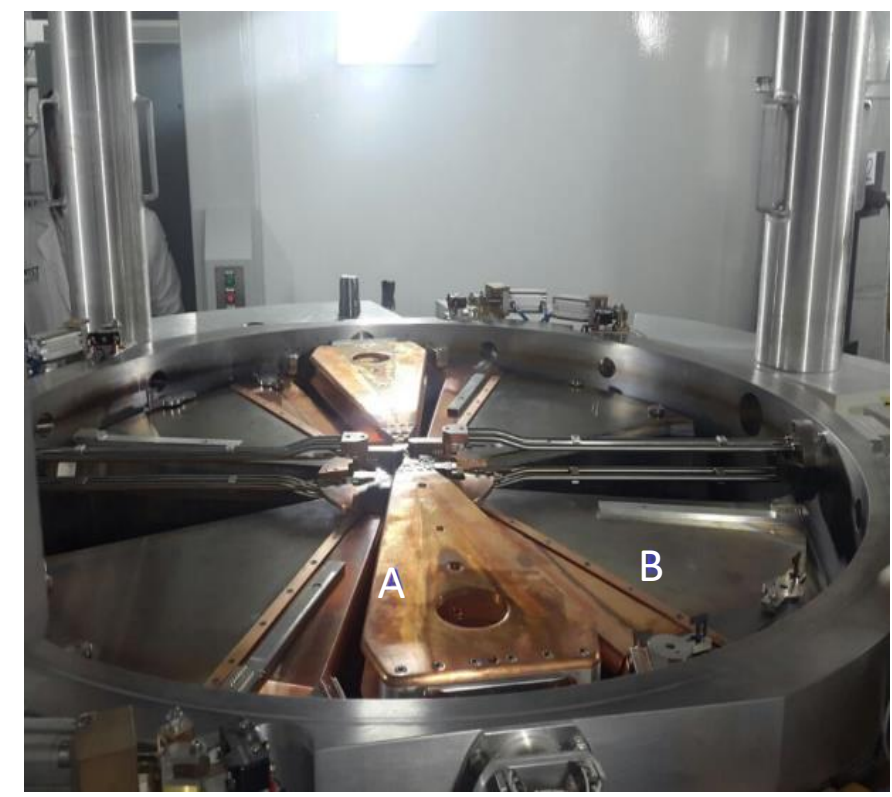

Figura 1.6. Interior del tanque del ciclotrón del INCan en donde se pueden apreciar A) los Hills y B) los valleys. 


\subsubsection{Campo Magnético}

El campo magnético de un ciclotrón extrae al ion de la fuente y lo confina a mantenerse en órbita. La magnitud de dicho campo magnético es de 1.3 T. La figura 1.7 A muestra la región dónde se encuentra la bobina que da origen al mismo. Las líneas de campo son perpendiculares al plano de aceleración.
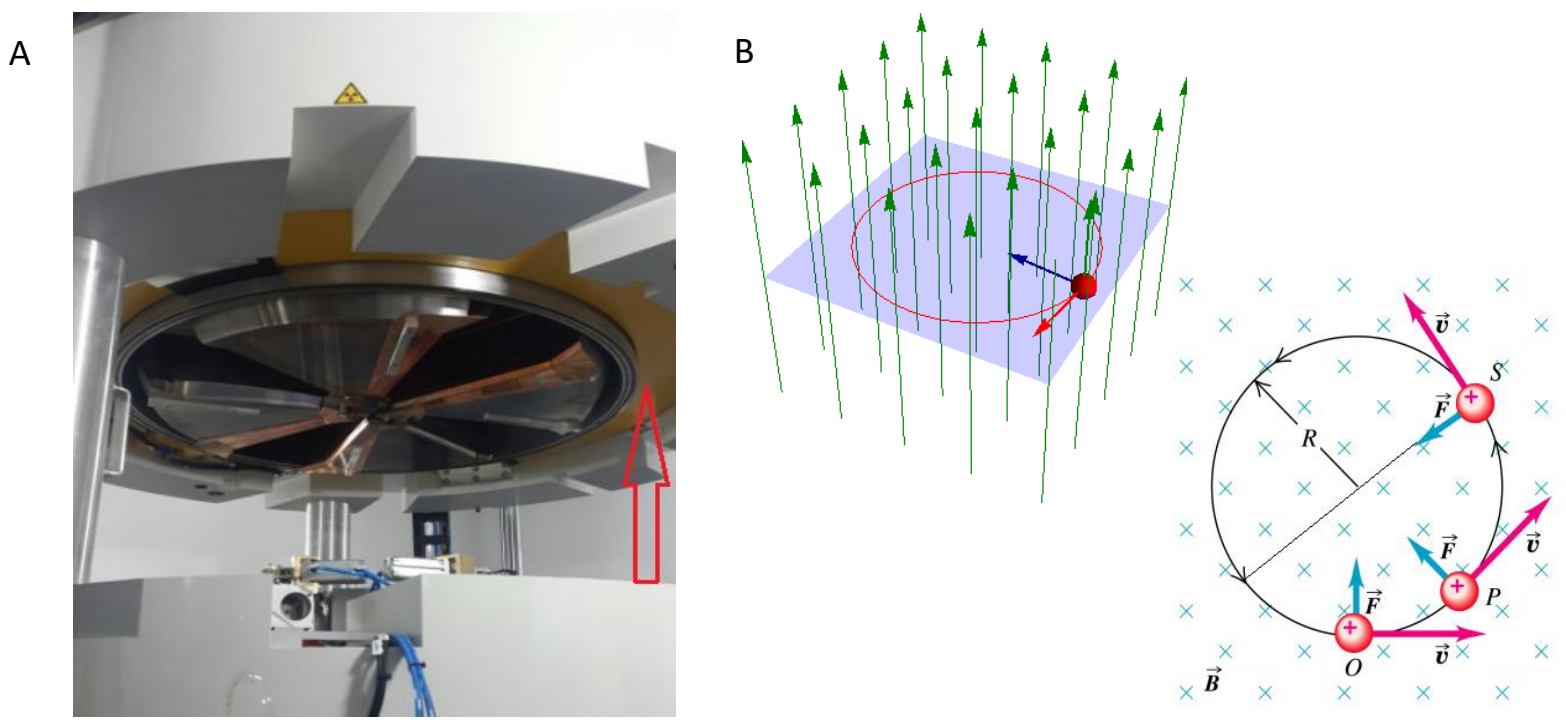

Figura 1.7. A) Ubicación del embobinado en el equipo IBA18/9. B) líneas de campo homogéneas al plano de aceleración del ion $\mathrm{H}^{-}$. F representa la fuerza que siente la partícula con una velocidad $\boldsymbol{v}$ en el plano de aceleración $\mathrm{S}$ de radio $\mathrm{R}$ (radio de la Dee) e inmerso en un campo magnético $\mathbf{B}$.

\subsubsection{Sistema de Vacío}

El vacío permite tener un camino libre para que el haz tenga una menor perdida al interaccionar con la menor cantidad posible de partículas en el tanque del Ciclotrón antes de impactar al denominado sistema de extracción que transformará dicho haz en un flujo de protones. Dicho vacío se puede lograr mediante el empleo de bombas de difusión que atrapan las moléculas de gas que estén contenidas en la cámara de aceleración. En particular este ciclotrón cuenta con 4 bombas de difusión.

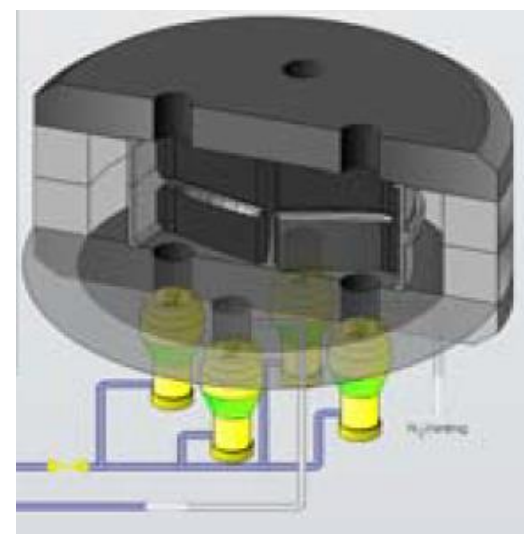

Figura 1.8. Corte transversal del equipo Iba 18/9 donde se muestran las 4 bombas de difusión. 


\subsubsection{Sistema de Extracción}

La función del sistema de extracción es convertir el haz de iones en un haz de protones de manera continua y colimada [Cárcamo, 2013]. Una vez que las partículas han completado su recorrido al radio máximo de la Dee y ganado la energía necesaria $(18 \mathrm{MeV})$ impactan a una lámina de material (comúnmente carbono de espesor $30 \mu \mathrm{m}$ ), y que al interceptar el haz de iones $\mathrm{H}^{-}$le arranca los dos electrones orbitales dejando pasar solamente los protones; es decir, la polaridad del haz cambia deflectándose hacia uno de los 8 blancos que tiene el equipo.

La lámina de carbono se encuentra montada en un dispositivo llamado carrusel (ver figura 1.9), el cual posee un movimiento angular que permitirá centrar al haz de protones en dicho blanco. Este procedimiento es parte del proceso llamado tuning del haz.

A

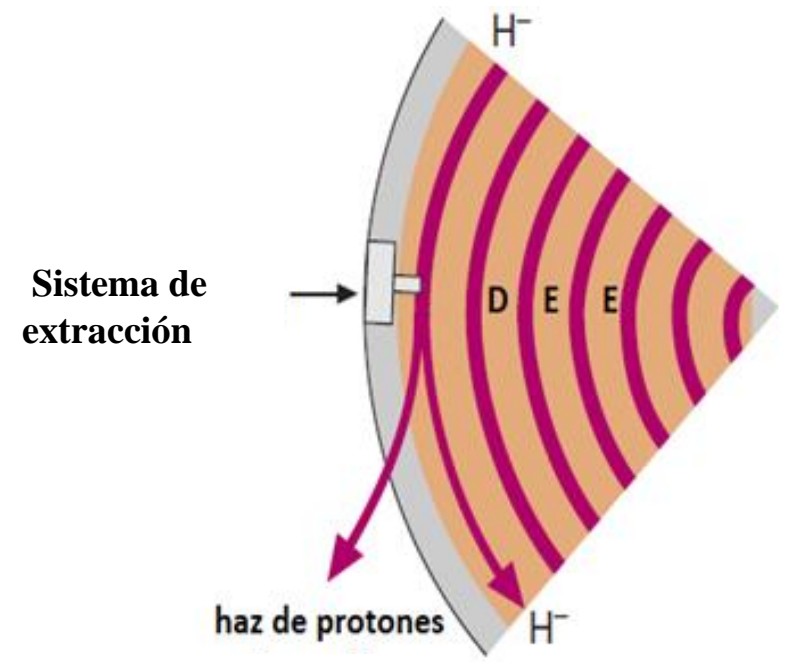

Blanco
B

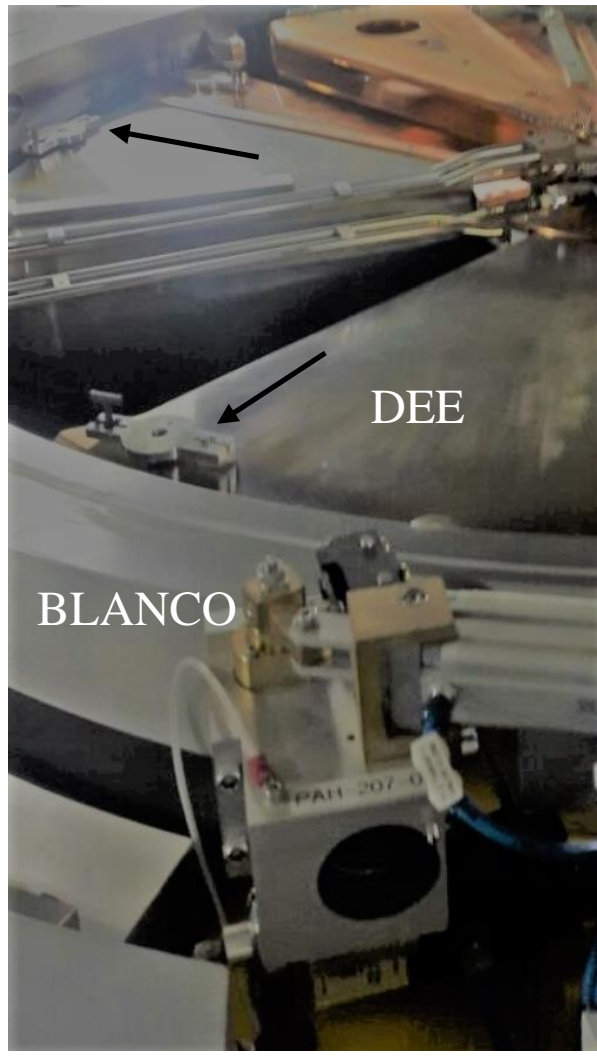

Figura 1.9. A) Diagrama que ejemplifica el sistema de extracción. B) Ubicación del sistema de extracción en el ciclotrón Iba 18/9. 


\subsubsection{Características comunes de los distintos tipos de aceleradores cíclicos}

De acuerdo a las aplicaciones, los diferentes tipos de aceleradores se pueden clasificar como se ejemplifican en la tabla 1.2 [NCRP, 2003].

Tabla 1.2 Diversos aceleradores

$\begin{array}{ccccccc}\text { Acelerador } & \begin{array}{c}\text { Partículas } \\ \text { aceleradas }\end{array} & \begin{array}{c}\text { Radio de } \\ \text { la órbita }\end{array} & \text { RF } & \begin{array}{c}\text { Campo } \\ \text { Magnético }\end{array} & \begin{array}{c}\text { Salida } \\ \text { del haz } \\ \text { fino }\end{array} & \begin{array}{c}\text { Límite de } \\ \text { Energía }\end{array} \\ \begin{array}{c}\text { Betatrón } \\ \text { Ciclotrón }\end{array} & \begin{array}{c}\text { Electrones } \\ \text { Iones }\end{array} & \begin{array}{c}\text { Constante } \\ \text { Incremento }\end{array} & \begin{array}{c}\text { No } \\ \text { Constante }\end{array} & \begin{array}{c}\text { Incremento } \\ \text { Constante }\end{array} & \begin{array}{c}\text { Pulsado } \\ \text { Continuo }\end{array} & <300 \mathrm{MeV} \\ \begin{array}{c}\text { Sincrociclotrón } \\ \text { Sincrotrón }\end{array} & \begin{array}{c}\text { Iones } \\ \text { Electrones } \\ \text { y iones }\end{array} & \begin{array}{c}\text { Incremento } \\ \text { Constante }\end{array} & \begin{array}{c}\text { Modulado } \\ \text { Constante } \\ \text { Constate }\end{array} & \begin{array}{c}\text { Pulsado } \\ \text { Incremento }\end{array} & \begin{array}{c}\text { Pulsado } \\ \text { Pul }\end{array} & \sim 10^{5} \mathrm{GeV} \\ \text { Microtrón } & \text { Electrones } & \text { Incremento } & \begin{array}{c}\text { modulado } \\ \text { Constante }\end{array} & \text { Constante } & \text { Continuo } & <300 \mathrm{MeV}\end{array}$




\subsection{Reacciones Nucleares}

Es posible la modificación de la estructura de un núcleo atómico por medio de un "bombardeo" de partículas hacia el mismo. Llamamos a esta interacción una reacción nuclear dado que en la modificación o transmutación del núcleo se producen dos o más partículas ligeras o fotones gamma [Azorín, 1997]. Una de las primeras reacciones nucleares fue producida en el laboratorio de Rutherford donde se utilizaron partículas $\alpha$ provenientes de una fuente radiactiva y que al mismo tiempo se comprobó la existencia de un núcleo dada por la dispersión elástica de éstas. Dicha reacción nuclear realizada en 1919 fue la siguiente:

$$
{ }^{14} N+\alpha \rightarrow{ }^{17} O+p
$$

Y la primera reacción producida en un acelerador fue en 1930 por los físicos Cockroft y Walton la cual es [Kenneth, 1988]:

$$
{ }^{7} \mathrm{Li}+p \rightarrow{ }^{4} \mathrm{He}+\alpha
$$

Típicamente, una reacción nuclear ocurre cuando una partícula incidente $\tau$ impacta a un núcleo $\mathrm{X}$ (blanco) visto desde el marco de laboratorio produciendo otra partícula ligera $\tau^{\prime} y$ un núcleo Y. Expresando esto de una manera simplificada tenemos que:

$$
\begin{aligned}
& X+\tau=Y+\tau^{\prime} \\
& X\left(\tau, \tau^{\prime}\right) Y
\end{aligned}
$$

Se hace referencia a las partículas ligeras como el neutrón, protón, deuterón, partícula $\alpha$ y el fotón $\gamma$. El ejemplo práctico de una reacción nuclear es el caso del bombardeo de ${ }^{18} \mathrm{O}$ con protones produciendo un neutrón y el núcleo radiactivo ${ }^{18} \mathrm{~F}$. El estudio de las reacciones nucleares se centra en recordar la definición del centro de masa y en el concepto de colisiones elásticas e inelásticas ya que a partir del análisis energético de la interacción de la partícula incidente con el núcleo blanco se obtienen como resultado los denominados valores $\mathrm{Q}$ y el valor umbral ( $\left.\mathrm{E}_{\text {Treshold }}\right)$ que hace posible una reacción nuclear.

Existen varios tipos de reacciones nucleares dependiendo de la partícula proyectil que se clasifican en:

- Reacciones fotonucleares: la partícula incidente es un fotón; $X\left(\gamma, \tau^{\prime}\right) Y$

- Captura radiactiva: cuando la partícula resultante es un fotón; $X(\tau, \gamma) Y$

- Dispersión: cuando la partícula emitida es idéntica a la capturada. 


\subsubsection{Leyes de conservación}

Consideremos la siguiente reacción nuclear en donde tenemos la formación de un núcleo compuesto [Evans, 1950]:

$$
{ }_{5}^{10} B+\alpha \rightarrow\left(7^{14} N\right) \rightarrow{ }_{1}^{1} H+{ }_{6}^{13} C+Q
$$

- Conservación del número de protones y de neutrones. Al principio y al final de una reacción el número de nucleones debe permanecer igual. Esto es consecuencia de un proceso energético bajo [Kenneth, 1988].

- Conservación de la carga. La suma de las cargas implicadas debe de ser la misma antes y después de la reacción;

- Conservación de la energía y el momento lineal. Teniendo en cuenta este punto, teóricamente se puede estimar la energía de la partícula resultante o la diferencia de masas entre el núcleo padre y el núcleo hijo o en su caso predecir si la reacción es energéticamente posible [Azorín, 1997]. Ahora bien si la partícula blanco está en reposo, el momento lineal se "reparte" en los productos de la reacción. En el marco del centro de masa, el momento lineal es cero en todo momento.

- Conservación del momento angular. Permanece constante.

- Conservación de la paridad y de la estadística. La estadística de Bose-Einstein y la de FermiDirac se mantienen constantes.

- Conservación masa-energía. Se conserva el total de estas dos cantidades. El valor de la energía cinética liberada $Q$ es la resta de las masas en reposo de los constituyentes de toda la reacción nuclear.

\subsubsection{Valores $Q$}

Dada la conservación del momento lineal y de la energía, haciendo un análisis que involucra la energía y las masas en reposo de las partículas antes y después de la reacción, se obtiene un valor denominado valor $\mathbf{Q}$ de la reacción o "valor de la energía de desintegración nuclear". El delta de energía de las partículas en la reacción es igual a la diferencia de masa en reposo de las partículas antes y después de la reacción, es decir se tiene que:

$$
\begin{aligned}
& \Delta E=\Delta M_{\text {reposo }} \\
& Q=\Delta E=\left[\left(E_{\tau^{\prime}}+E_{Y}\right)-\left(E_{\tau}+E_{X}\right)\right]=\left[\left(M_{x}+M_{\tau}\right)-\left(M_{\tau^{\prime}}+M_{Y}\right)\right] c^{2} M e V
\end{aligned}
$$

Se le denomina reacción nuclear exotérmica cuando los valores de Q son positivos y endotérmica cuando tales valores son negativos. Cuando $\mathrm{Q}=0$ entonces se considera que hay una dispersión elástica, es decir que no hay modificación de los elementos del sistema (ver figura 2.1) 


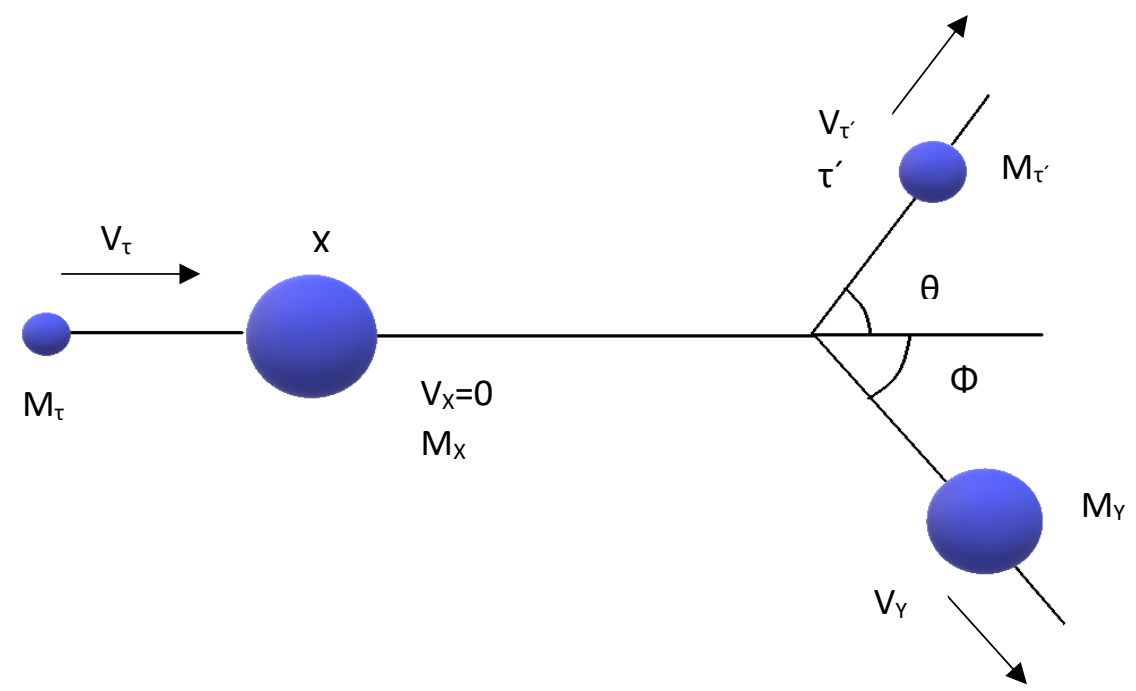

Figura 2.1. Esquema típico de los componentes que intervienen en una reacción nuclear. A partir de la conservación de momento lineal y de la energía es posible encontrar una expresión analítica para el valor Q. Imagen modificada de [Evans, 1950].

Una expresión general que se obtiene para el valor Q que es aplicado a la interacción de dos cuerpos no relativistas es [Azorín, 1997]:

$$
Q=E_{\tau^{\prime}}\left[1+\frac{M_{\tau^{\prime}}}{M_{Y}}\right]-E_{\tau}\left[1-\frac{M_{\tau}}{M_{X}}\right]-\frac{2}{M_{Y}}\left(M_{\tau} E_{\tau} M_{\tau^{\prime}} E_{\tau^{\prime}}\right)^{1 / 2} \cos \theta
$$

\subsubsection{Umbral de reacciones}

El umbral de una reacción es cuando $\frac{d^{2} Q}{d E_{\tau}{ }^{2}}=0$ y haciendo $\theta=0$ en (2.7) resulta:

$$
E_{\tau \min }=-Q \frac{M_{\tau}+M_{X}}{M_{X}}
$$

Es decir que para reacciones endoenergéticas, existe un valor de energía mínimo indispensable para que la reacción nuclear pueda llevarse a cabo o en otras palabras se debe cumplir la relación

$$
E_{\tau^{\prime}}=f\left(E_{t}, \theta\right)
$$

Para valores de $\mathrm{E}^{\prime \prime}$ negativos no hay emisión de partículas. La relación anterior gráficamente ejemplifica la reacción. En el caso de reacciones endoenergéticas, la gráfica de distribución de energía (figura 2.2) para la reacción ${ }^{3} \mathrm{H}(\mathrm{p}, \mathrm{n}){ }^{3} \mathrm{He}$ tiene la forma: 


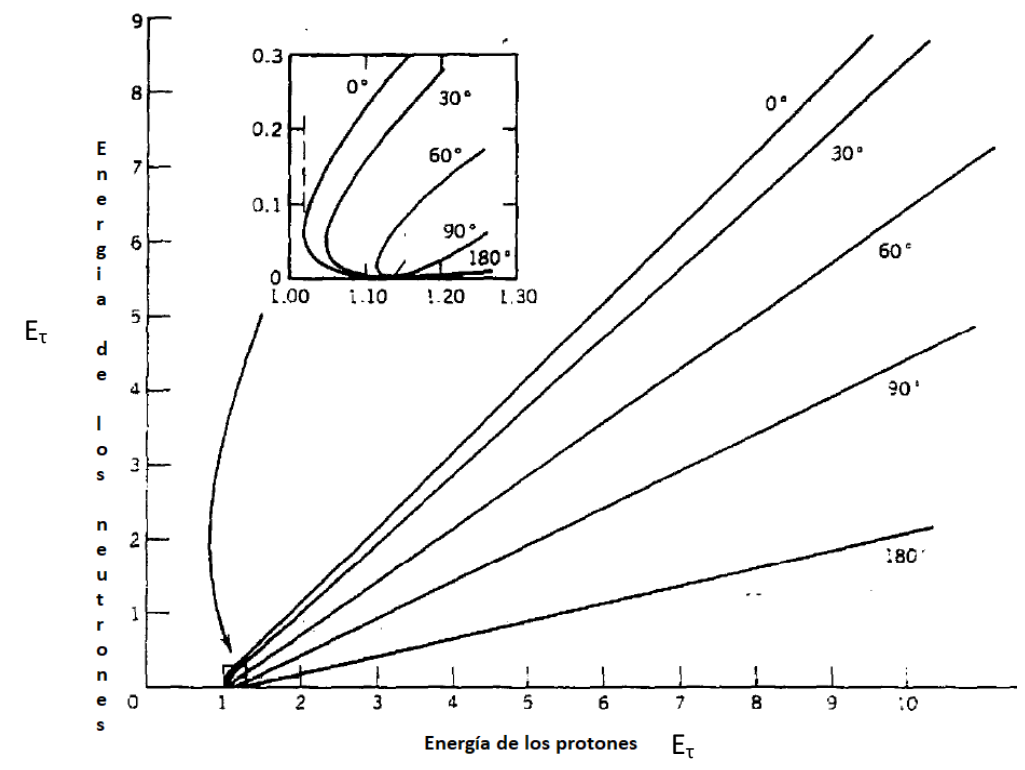

Figura 2.2. Distribución de energía de los neutrones emitidos en la reacción ${ }^{3} \mathrm{H}(\mathrm{p}, \mathrm{n}){ }^{3} \mathrm{He}$ con un valor para $\mathrm{Q}=-763.75 \mathrm{keV}$ emitidos en diferentes ángulos. Nótese que las curvas que siguen la relación (2.7) convergen a un solo punto llamado el umbral de energía. En el caso de reacciones exoenergéticas cualquiera que sea el valor de $\mathrm{E}_{\tau}$ la reacción se llevará a cabo. Imagen de [Kenneth,

1988].

Para bajos valores de la energía de la partícula incidente $\left(0.1 \mathrm{MeV}<\mathbf{E}_{\boldsymbol{\tau}} 1<\mathrm{MeV}\right)$ se considera la formación del denominado núcleo compuesto (tabla 2.1) cuya probabilidad de descomponerse depende de un proceso estadístico y de la denominada sección eficaz discutida en la siguiente sección.

Tabla 2.1. Ejemplos de los diferentes mecanismos o vías de salida para la desintegración del núcleo compuesto ${ }^{16} \mathrm{O}$ resultado del bombardeo al núcleo target de ${ }^{14} \mathrm{~N}$ con deuterones.

\begin{tabular}{|c|c|c|c|c|c|}
\hline $\begin{array}{c}\text { Vía de } \\
\text { entrada }\end{array}$ & $\begin{array}{c}\text { Núcleo } \\
\text { Compuesto }\end{array}$ & Vía de salida & $\begin{array}{c}\text { Valor } Q \\
(\mathrm{MeV})\end{array}$ & $\begin{array}{l}\text { Valor Umbral } \\
\quad(\mathrm{MeV})\end{array}$ & $\begin{array}{l}\text { Tipo de } \\
\text { reacción }\end{array}$ \\
\hline \multirow{4}{*}{$d+{ }^{14} N$} & & $\left(\mathrm{n} \rightarrow{ }^{15} \mathrm{O}\right)$ & 5.1 & 0 & exoenergética \\
\hline & ${ }^{16} \mathrm{O}$ & $\left(\alpha \longrightarrow{ }^{12} \mathrm{C}\right)$ & 13.6 & 0 & exoenergética \\
\hline & & $\left(\mathrm{n}+\mathrm{p} \rightarrow{ }^{14} \mathrm{~N}\right)$ & -2.2 & 2.5 & endoenergética \\
\hline & & $\left(\gamma \rightarrow{ }^{16} \mathrm{O}\right)$ & 20.7 & 0 & exoenergética \\
\hline
\end{tabular}




\subsubsection{Sección Eficaz: Ecuaciones fundamentales para la producción de radionúclidos}

La cantidad de actividad producida cuando una muestra y/o material es irradiada por un determinado haz de partículas depende de varios factores como: la intensidad del haz, el número de núcleos que conforman el blanco y la probabilidad de interacción que se pueda presentar con dicho material (sección transversal o eficaz) [Cherry et al., 2012].

La sección eficaz se define como la caracterización de la probabilidad de interacción de una reacción nuclear [Azorín, 1997] y su unidad es el mili barn $(\mathrm{mb})$ equivalente a $10^{-31} \mathrm{~m}^{2}$. Para cualquier tipo de reacción, la sección eficaz se representa de la siguiente manera:

$$
\sigma_{i}=\sigma_{n c m}\left(\frac{P_{i}}{\sum P_{j}}\right)[\mathrm{mb}]
$$

Donde:

$\sigma_{i}=$ Sección transversal para los productos formados [mb].

$\sigma_{n c m}=$ Sección transversal para el núcleo compuesto [mb].

$P_{i}=$ Probabilidad de la formación de los productos.

$P_{j}=$ Suma de las probabilidades de todos los procesos involucrados.

En la figura 2.3 se ilustra la manera más sencilla de entender el concepto de sección eficaz. La probabilidad de choque de la partícula incidente con uno de los núcleos blanco está dada por: $P=\sigma \delta x n$ donde n es el número de núcleos por unidad de volumen. El número de núcleos radiactivos que se forman son entonces: $\Delta \phi P=\phi n \sigma \delta x$

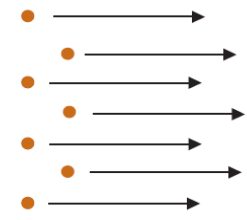

Densidad de flujo del haz de partículas $\varphi$

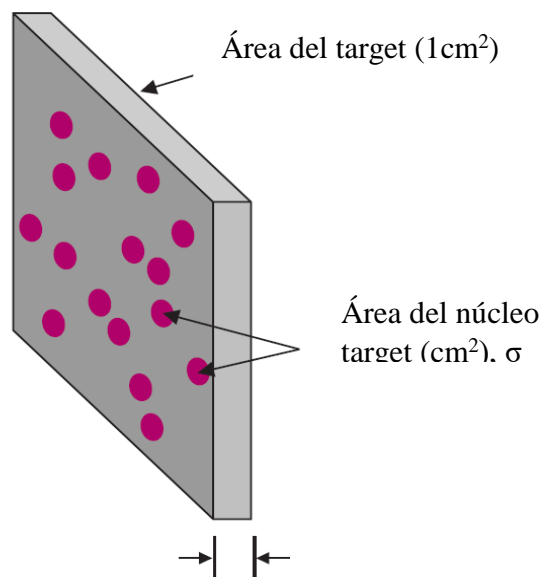

Espesor del material $\delta \mathrm{x}$

Figura 2.3. Representación esquemática de la sección transversal en una reacción nuclear. Imagen modificada de [Cherry et al., 2012]. 
Para el caso de los blancos gruesos la sección transversal es

$$
\sigma=\frac{1}{n \delta x} \ln \frac{N_{0}}{N(\chi)}
$$

Dónde $\mathrm{N}_{0}$ denota la afluencia de partículas inicial y $\mathrm{N}(\chi)$ la afluencia a la profundidad $\chi$.

\subsubsection{Sección eficaz: rapidez de producción de un radionúclido}

La rapidez de producción de un radionúclido es dependiente de factores como:

- Sección transversal en función de la energía

- La energía de la partícula incidente

- El espesor del blanco

- Flujo de las partículas incidentes

De manera general, la ecuación para la rapidez de producción de un determinado radionúclido es la siguiente [OIEA, 2008]:

$$
R=-n I\left(1-e^{-\lambda t}\right) \int_{E_{s}}^{E_{0}} \frac{\sigma(E)}{d E / d x} d E
$$

Donde

$R=$ Número de núcleos formados por segundo.

$n=$ Densidad del material en núcleos $/ \mathrm{cm}^{2}$.

$I=$ Flujo de las partículas incidentes relativo a la corriente del haz.

$\lambda=$ Constante de decaimiento del radionúclido producido.

$t=$ Tiempo de irradiación.

$\sigma=$ Sección eficaz como una función de la energía (E).

$-d x / d E=$ Poder de frenado de la partícula incidente.

$\int_{E_{s}}^{E_{0}}$

largo de su trayectoria.

Se le conoce como función de excitación a la relación que existe entre la sección transversal y la energía. Cada una de las reacciones nucleares posee su función de excitación tratándose de su "huella digital". La función de excitación para F-18 comienza justo en $2.5 \mathrm{MeV}$ (energía umbral) teniendo su máximo en $5 \mathrm{MeV}$ o la máxima probabilidad de producción (figura 2.4). 


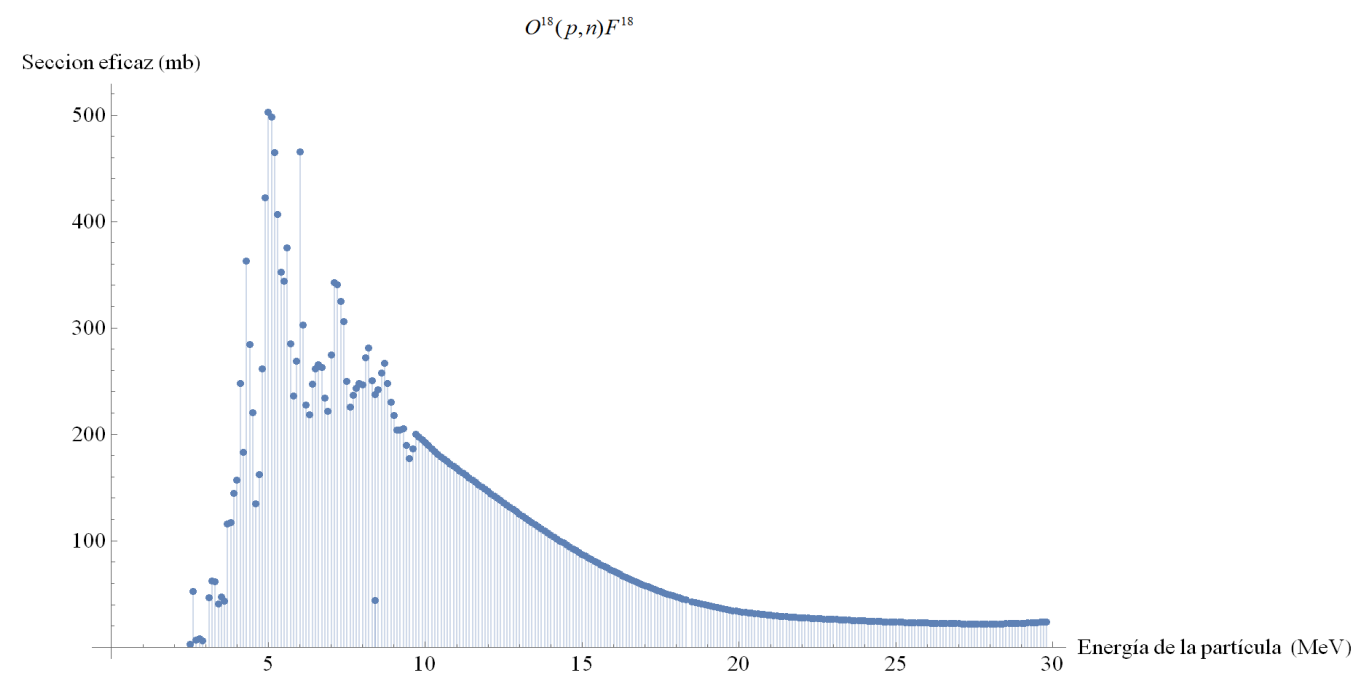

Figura 2.4.Función de excitación de la reacción $O^{18}(p, n) F^{18}$ en el cual la máxima probabilidad de producción se presenta en un rango de energía de 4-6 MeV. El umbral de energía para esta reacción es de $2.5 \mathrm{MeV}$.

\subsubsection{Actividad Específica}

La actividad específica (SA) de una muestra es la medida del número de átomos radiactivos comparados con el total de átomos de la misma muestra, su unidad es $\mathrm{GBq} / \mathrm{mol}$. La actividad específica del radiofármaco de interés es de vital importancia dado que los posibles efectos químicos o biológicos pueden ser estudiados en un determinado sistema [OIEA, 2008].

\subsubsection{Factores de saturación}

Tomando en cuenta la velocidad a la que una reacción nuclear se produce y considerando al mismo tiempo la variación en el número de núcleos en el transcurso de tiempo, la actividad específica del radionúclido es [Azorín, 1997]:

$$
A=\lambda N\left(1-e^{-\lambda t}\right)
$$

El factor de saturación definido por el término $\left(1-e^{-\lambda t}\right)$ es el punto de equilibrio donde la actividad del radionúclido en producción es constante para tiempos de irradiación más largos que su vida media (figura 2.5), en pocas palabras una vez superado este punto no se producirá más actividad ya que esta compite con el decaimiento del propio material. 


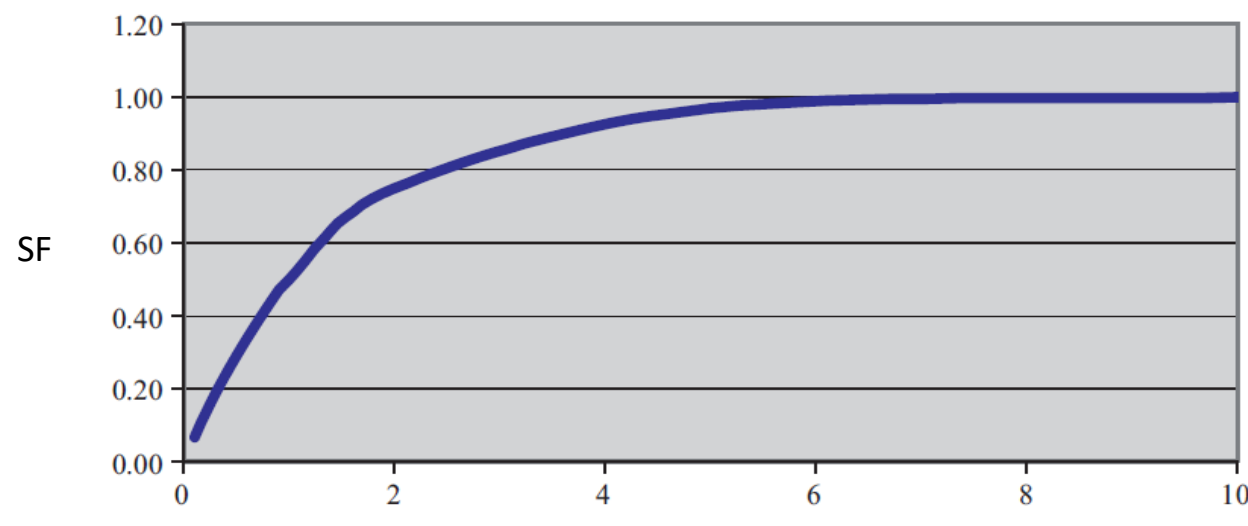

Tiempo de irradiación /vida media

Figura 2.5. Factor de saturación. En situaciones prácticas, el tiempo de irradiación no supera las tres vidas medias (SF: 90\%)

\subsubsection{Rendimiento de una reacción}

Es el valor que nos indica la cantidad de actividad producida por unidad de corriente dependiente de la energía y del tiempo de irradiación. Para el caso de la reacción nuclear $O^{18}(p, n) F^{18}$ la tabla 2.2 resume algunos de los rendimientos a determinadas energías.

Tabla 2.2 Rendimientos típicos obtenidos para diferentes energías de la partícula incidente.

\begin{tabular}{cccc}
\hline Energía $(\mathbf{M e V})$ & $\mathbf{Y}_{\text {físico }}(\mathbf{G B q} / \boldsymbol{\mu A})$ & $\mathbf{A}_{\mathbf{1}}{ }^{*}(\mathbf{G B q} / \boldsymbol{\mu A})$ & $\mathbf{A}_{\mathbf{2}}{ }^{*}(\mathbf{G B q} / \boldsymbol{\mu A})$ \\
$\mathbf{2 . 5}$ & 0.0593 & 0.000175 & 0.000563 \\
$\mathbf{1 0}$ & 777 & 2.33 & 7.38 \\
$\mathbf{1 5}$ & 1280 & 3.82 & 12.1 \\
$\mathbf{2 0}$ & 1540 & 4.61 & 14.6 \\
$\mathbf{2 9 . 8}$ & 1850 & 5.56 & 17.6
\end{tabular}

Datos obtenidos de la base de datos del Brookhaven National Laboratory. A1 ${ }^{*}:$ Actividad a $1 \mu$ A durante $1 \mathrm{~h}$. A2 ${ }^{*}:$ actividad de saturación a $1 \mu \mathrm{A}$. 


\subsection{Tipos de Blancos \\ 2.2.1.Consideraciones generales}

Para la producción de radioisótopos, el material blanco puede ser líquido, sólido o gaseoso. El cuerpo del blanco alberga al material en cuestión y pueden ser internos o externos. El objetivo de estos es mantener el material blanco sobre un haz de protones para después extraer el radionúclido producido de forma rápida y eficiente [Cárcamo, 2013]. Hay que considerar aspectos físicos y químicos que repercuten en la vida útil del cuerpo tales como [OIEA, 2012]:

- La temperatura en el interior del cuerpo del blanco

- La forma química del radionúclido

- Impurezas radionúclidas

- Frecuencia de mantenimiento

Cuatro son los elementos que constituyen en general la forma de un blanco y son:

- Cuerpo del blanco

- Ventana

- Rejilla

- Colimador

Cuerpo del blanco. Algunas de las características que deben cumplir los materiales con los que se elabora el cuerpo es que tengan una buena conductividad térmica y que sean resistentes a esfuerzo mecánico y altas presiones [OIEA, 2012]. Materiales que cumplen tales criterios son: Aluminio, Titanio, Níquel, Niobio, Tantalio y Plata. La tabla 2.3 muestra algunas propiedades físicas de tales materiales.

Tabla 2.3. Materiales de uso común en la elaboración del cuerpo del blanco para los tres estados.

Tabla modificada de [OIEA 2012]:

\begin{tabular}{|c|c|c|c|c|c|c|}
\hline Propiedades & Aluminio & Titanio & Níquel & Niobio & Tantalio & Plata \\
\hline $\begin{array}{l}\text { Conductividad Térmica } \\
\left(\mathrm{W} \cdot \mathrm{m}^{-1} \cdot \mathrm{K}^{-1}\right)\end{array}$ & 167 & 21.9 & 90.9 & 53.7 & 57 & 429 \\
\hline Punto de Fusión $\quad\left({ }^{\circ} \mathrm{C}\right)$ & 582 & 1725 & 1453 & 2410 & 3290 & 961 \\
\hline \multicolumn{7}{|l|}{ Capacidad calorífica } \\
\hline$\left(\mathrm{J} \cdot \mathrm{mol}^{-1} \cdot \mathrm{K}^{-1}\right)$ & 24.2 & 24.9 & 26.1 & 24.6 & 25.3 & 25.4 \\
\hline
\end{tabular}

Ventana. Es una laminilla delgada que alberga al material blanco y requerido en blancos líquidos y gaseosos. Detalles como su punto de fusión, su conductividad térmica, la degradación de la energía y la intensidad de la tensión a la que estén sometidos dichas ventanas se consideran al momento del diseño de un blanco. El espesor de dichas láminas es del orden de unas cuantas micras y pueden ser de Aluminio, Niobio, Titanio o Havar; una aleación de cobalto.

Rejillas. Da soporte a la ventana y cuyos arreglos pueden ser hexagonales o circulares. Para arreglos hexagonales, la transmisión del haz mejora. 
Colimadores. Diseñados para tener un haz más "fino" y que al impactar sobre el blanco se tenga una región propiamente limitada aumentando la probabilidad de producción. Cuando el haz se encuentra en "desajuste" suele haber un daño en los colimadores y con ello su activación por lo que hace más complicada la operación de desmontar el cuerpo en un mantenimiento preventivo.

Blancos sólidos. Generalmente el cuerpo de los blancos es más pequeño debido a que la trayectoria del haz es corta. Un ejemplo de blanco sólido es como el que se muestra en la figura 2.6:

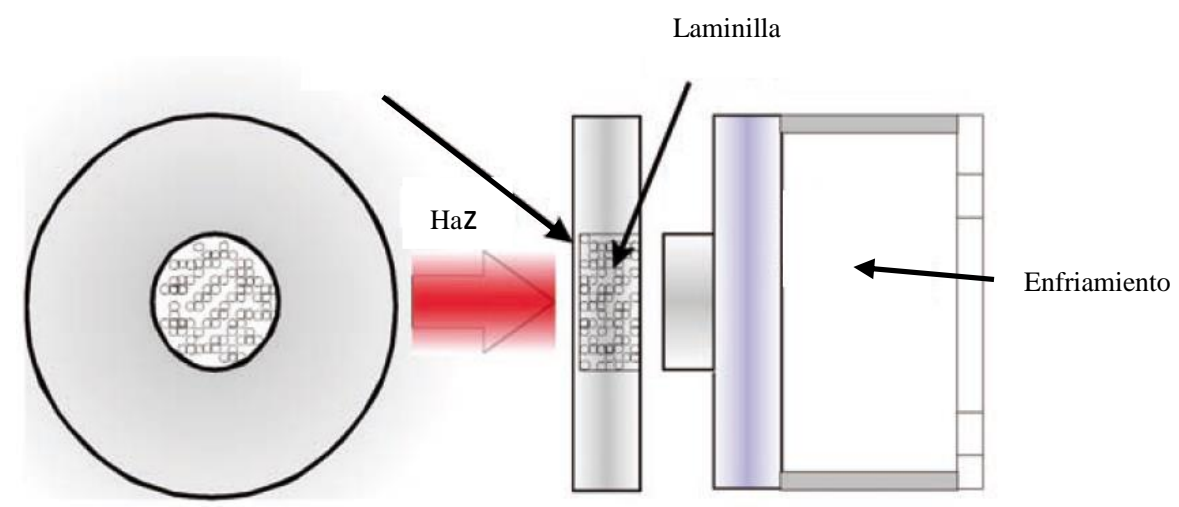

Figura 2.6, Blanco sólido. Imagen modificada de [OIEA, 2012].

Blancos líquidos. Con dimensiones parecidas a los blancos sólidos. Una vez obtenido el radionúclido, es transportado a los módulos de síntesis. Un ejemplo típico es la producción de F-18 donde se irradia agua enriquecida con un haz de protones de $18 \mathrm{MeV}$. Se realiza una separación de los iones de ${ }^{18} \mathrm{~F}^{-}$para la posterior reutilización del ${ }^{18} \mathrm{O}$. La ventana que utiliza este tipo de blancos es un Havar con espesor aproximado de $50 \mu \mathrm{m}$, y que soporta presiones de hasta 40 bars.

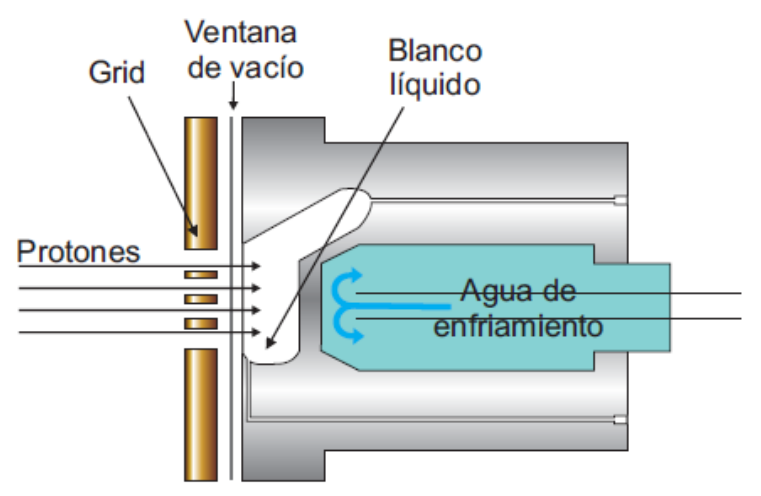

Figura 2.7 Ejemplo de blanco líquido. Imagen tomada de [Cárcamo, 2013].

Blancos Gaseosos. La configuración de este tipo de blanco es cilíndrica y ligeramente más largo con una ventana un poco más delgada que los otros blancos. La principal limitante en el uso de blancos gaseosos es la disipación del calor durante el proceso de irradiación dado que su conductividad térmica es baja. Ejemplo de un blanco gaseoso es como el que se muestra en la figura 2.8. 


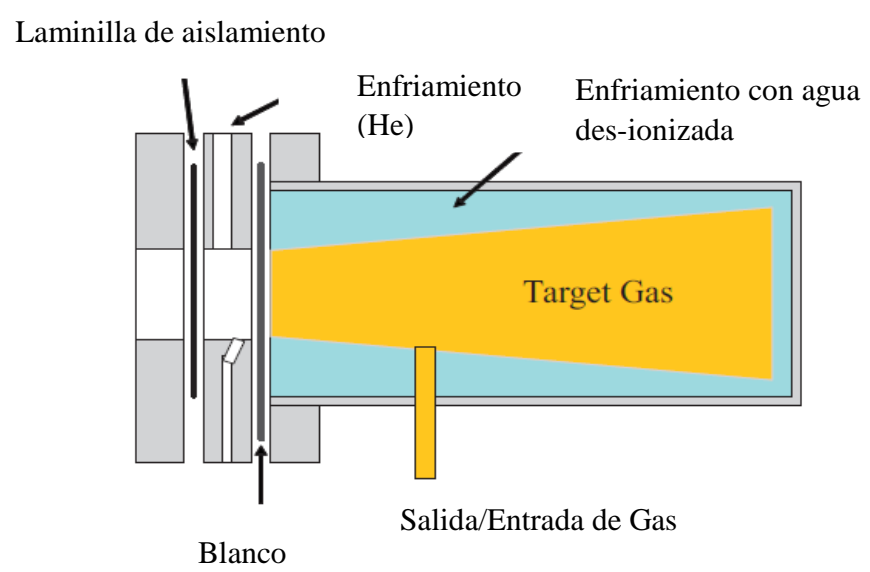

Figura 2.8. Blanco Gaseoso.

Un punto clave en la utilización de cualquier tipo de blanco es la obtención de altos rendimientos, este dependerá en primera instancia de la calidad del haz de irradiación que involucra la energía nominal y la forma del perfil. Un perfil centrado y alineado ayudará a tener la máxima probabilidad de producción al momento de la irradiación dado que se tiene una menor pérdida de haz en los colimadores. Por otra parte, obtener el ancho del haz permitirá a conocer las dimensiones necesarias para irradiar materiales sólidos (electrodeposición). En cuanto a la caracterización de la energía, conocer su valor nominal ayuda de igual manera a la optimización de los rendimientos de los radionúclidos que se quieran producir, dado que su función de excitación es una función de la energía [Cabrera, 2011].

\subsubsection{Transporte del haz de radiación. Perfiles.}

Conservar una reproducibilidad en el valor del rendimiento significa primeramente mantener adecuados los valores de los cuales depende el haz de radiación tales como: el amperaje de la fuente de iones y del imán, el valor de la radiofrecuencia, la posición del material de extracción del haz y una buena colocación del material blanco. A este proceso se le denomina tuning del haz. Realizar el tuning al inicio de una producción asegura la localización de impacto del haz en el blanco con la intensidad deseada. Existen técnicas para monitorear la intensidad del haz de radiación llamados monitores de perfil de haz. Son complemento para ayudar al operador a obtener una mejor distribución en intensidades y formas del haz.

Otra técnica utilizada en el monitoreo de la forma del haz es mediante el uso de películas de tinte radiocrómico; el método consiste en colocar en la entrada de un blanco prueba llamado beam dump una serie de láminas de material degradador seguido de una película con la intención de reducir la intensidad del haz. Una vez que la película es impactada por dicho haz, su tonalidad cambia debido al proceso de interacción físico-químico de su capa activa. Este cambio de intensidad es proporcional a la dosis absorbida y puede cuantificarse mediante la digitalización de la película en un escáner en modo transmisión. Detalles de este proceso se describen en el capítulo 3. 


\section{MÉTODOS PARA LA CARATERIZACIÓN DEL PERFIL DE UN HAZ DE PROTONES EN UN CICLOTRÓN}

\subsection{Método Dosimétrico}

Como anteriormente se mencionó, la importancia de caracterizar el perfil de un haz de cualquier ciclotrón radica en la mejora de los rendimientos de los radionúclidos que se estén produciendo. Sansaloni F. y colaboradores [Sansaloni et al., 2012], reportan la distribución del perfil del haz (una distribución 2D) mediante el uso de películas EBT2, mientras que Vadrucci M. y colaboradores [Vadrucci et al., 2015] hacen un estudio del comportamiento del haz de protones sobre películas EBT3 a bajas energías $(5 \mathrm{MeV}$ ) en un equipo para terapia con haces de protones. El cálculo de la dosis absorbida en el filme se basó en el monitoreo de la fluencia y la energía mediante el uso de detectores SSBD (Silicon Surface Barrier Detector).

\subsubsection{Películas de tinte radiocrómico: EBT3}

Las películas de tinte radiocrómico o filmes radiocrómicos son un tipo de dosímetros que comúnmente se utilizan en dosimetría de haces clínicos (tanto de fotones, electrones y protones). Distribuciones de dosis en 2D con alta resolución espacial, un proceso de post irradiación no requerido, baja sensibilidad a la luz y baja dependencia energética son algunas de las ventajas que ofrecen este tipo de dosímetros [Vadrucci et al., 2015]. Una de las principales desventajas de estas películas es que ya no son reutilizables pero la información almacenada se mantiene por un determinado periodo de tiempo.

Dentro de las aplicaciones clínicas se pueden encontrar: dosimetría en braquiterapia, radiocirugía estereotáctica, dosimetría en proton-terapia entre otras [Blackwell et al., 1998].

Estas películas se basan en polidiacetileno y están compuestas por hidrógeno, carbono, nitrógeno, oxígeno, litio, cloro, sodio, entre otros, que varían de acuerdo al lote que se esté manejando. La película EBT3 utilizada en este trabajo tiene la misma composición química en su capa activa que su predecesora la película EBT2, pero una de las razones por las cuales se eligió trabajar con la última generación de películas EBT fué por la capa especial del sustrato de poliéster que se añadió para prevenir los anillos de Newton (interferencia creada por el reflejo de la luz de una superficie plana sobre una superficie esférica) al momento de su digitalización y que interferiría al momento de visualizar el patrón perfil del haz. Tiene un $\mathrm{Z}_{\mathrm{eff}}$ de 6.84 comparado al del agua el cual corresponde a $\mathrm{Z}_{\mathrm{eff}}=7.3$ [Reinhardt et al., 2012].

Está compuesta de una capa activa con un grosor aproximado de $28 \mu \mathrm{m}$ que contiene el componente activo, el colorante marcador que hace a la película menos sensible a la luz, estabilizadores y otros componentes que dan la baja dependencia de energía aunque para bajas energías en fotones de $50 \mathrm{keV}$ se presenta una dependencia de hasta el $11 \%$ [Aragón, 2015]. Dicha capa activa se encuentra entre dos capas de poliéster (Mylar) de $120 \mu \mathrm{m}$ de espesor (figura 3.1) y compuesta de partículas de sílice para la prevención de los anillos de Newton [Escarcia, 2016]. 


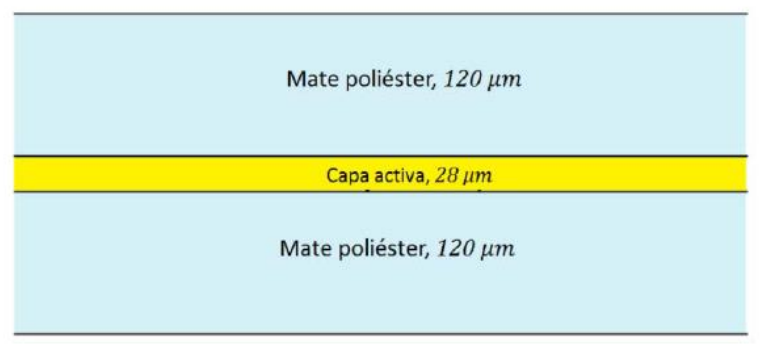

Figura 3.1. Composición de la película EBT3.

Cuando el filme es expuesto a una fluencia de partículas, se inicia una polimerización en la capa activa del material, resultando en un cambio de color que es dependiente de la dosis absorbida [Reinhardt et al., 2012]. Posteriormente su digitalización se puede hacer en densitómetros o escáneres de cama plana.

Estos últimos por su fácil forma de conseguir son los rutinarios para el escaneo de filmes radiocrómicos. El efecto de la radiación de las películas se mide en términos de la opacidad a la luz en el filme y definida como el cociente de la intensidad de la luz medida en ausencia de la película entre la intensidad de la luz transmitida en una película expuesta a la radiación [Escarcia, 2016]. La respuesta de la película en un determinado intervalo de dosis se cuantifica mediante la densidad óptica o transmitancia $\mathrm{T}$ de la luz mediante:

$$
A=-\log T
$$

Su curva de calibración se basa en la relación de la respuesta con respecto a la dosis a la que fue expuesta la película. De esta manera se puede conocer la dosis absorbida. Durante la digitalización y dependiendo la dosis a la que se haya trabajado, el filme se analizará en la descomposición de los llamados canales de sensibilidad: rojo, verde y azul. El canal rojo es el más sensible (un rango de 575$675 \mathrm{~nm}$ ) y se trabajan dosis de hasta $10 \mathrm{~Gy}$. Para un amplio rango de dosis se puede escoger el verde o azul. La absorción de la luz sobre la película en el cristal del escáner se da en una longitud de onda de $636 \mathrm{~nm}$ para películas EBT3 por lo que el fabricante recomienda digitalizarlas empleando el canal rojo.

Cabe mencionar que existen diversos aspectos fundamentales que deben considerarse al emplear un escáner; tales como: dependencia de la respuesta con la orientación relativa de la película, falta de homogeneidad en el área útil de escaneo, estabilidad del escáner, incertidumbre del escáner y curvas de calibración. Todos estos factores deben ser tomados en cuenta para minimizar la incertidumbre al momento de calcular la dosis [León-Marroquín et al., 2013]. 


\subsubsection{Dosimetría con películas EBT3}

Como lo descrito en la sección anterior, la curva de calibración de las películas se basa en la respuesta que se obtiene en el intervalo de dosis a la que es expuesta. Conociendo la curva de calibración es posible utilizar esas mismas películas en un equipo diferente al de referencia y conocer la dosis absorbida (reproduciendo las mismas condiciones de irradiación a las que se calibraron las películas). En un acelerador tipo ciclotrón, la fluencia del haz es dependiente de la corriente que se tenga en la fuente de iones, pero no hay manera de conocer la tasa de dosis a la que se está irradiando el blanco, por tanto no es posible construir una curva dosis-respuesta pero se puede hacer una estimación teórica de la dosis absorbida en dicho material o para este caso sobre la película EBT3 a partir de un análisis dosimétrico descrito en el anexo A.

\subsection{Método con lector de distribución de actividad usado en cromatografía de capa fina (TLC) \\ 3.2.1. Principios de funcionamiento de lector de tiras usadas en un TLC}

Los controles de calidad que los radiofármacos deben aprobar son estrictamente rigurosos dado que son administrados a pacientes. La pureza radioquímica, radionuclídica, $\mathrm{pH}$, y pureza química son algunos de los principales puntos que se deben aprobar en un control de calidad del radiofármaco de interés.

La pureza radioquímica se define como la fracción de la radiactividad total en la forma química deseada presente en el radiofármaco. Las impurezas pueden ser causadas por la acción del solvente utilizado, temperatura, luz etc. El método analítico más usado para determinar las impurezas radioquímicas en dicho radiofármaco es la cromatografía de capa fina. En esta técnica, una pequeña cantidad de la muestra de la preparación del radiofármaco $(1-5 \mu \mathrm{L})$ se coloca sobre una tira de soporte cromatográfico (sílica gel). La cromatografía se lleva a cabo introduciendo el soporte en un recipiente que contenga un solvente apropiado. Durante dicho proceso, diferentes componentes de la muestra se distribuyen entre el absorbente y el solvente dependiendo de sus coeficientes de distribución. El absorbente es la fase estacionaria y el solvente es la fase móvil.

Las fuerzas electrostáticas de la fase estacionaria tienden a retener varios componentes de la muestra, mientras que la fase móvil los transporta hacia el frente por lo que se tienen diferentes velocidades de migración apareciendo en diferentes distancias a lo largo del soporte. Dichas componentes se caracterizan por un valor de $\mathrm{Rf}$ definido como la relación de la distancia recorrida por cada componente y la distancia recorrida por el solvente:

$$
R f=\frac{d_{\text {muestra }}}{d_{\text {solvente }}}
$$

Cuando el solvente migra hasta la distancia deseada, se remueve la tira, se seca y se mide la radioactividad en un escáner de radio cromatografía. La impureza radioquímica se mide en función de la relación de la radiactividad del componente no deseado y la actividad total de la muestra. [OIEA, 1999]. 
Raytest posee una variedad de escáneres útiles para los controles de calidad mediante la técnica de TLC tales como el escáner miniGita (figura 3.2). Este instrumento posee un área de escaneo de $400 * 200 \mathrm{~mm}$ donde muestras pueden colocarse para la determinación de la distribución de la radiactividad. Uno de los detectores estándar es un cristal de BGO con su respectivo tubo fotomultiplicador. Puede detectar radiación beta y gamma de isotopos tales como $\left({ }^{68} \mathrm{Ga},{ }^{18} \mathrm{~F}\right){ }^{99 \mathrm{~m}} \mathrm{Tc},{ }^{123} \mathrm{I},{ }^{32} \mathrm{I} \mathrm{y}{ }^{137} \mathrm{Cs}$.

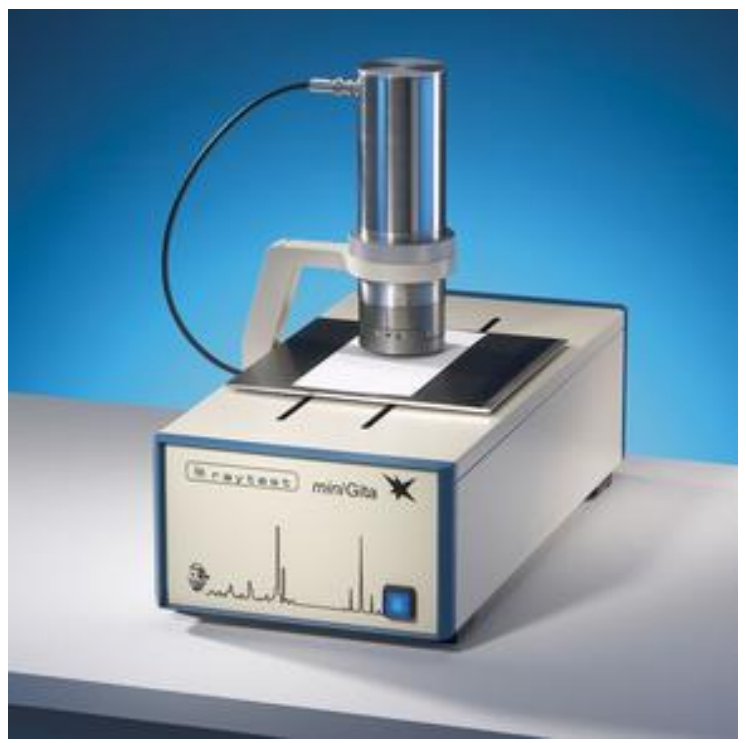

Figura 3.2. Escáner miniGita TLC.

En principio es posible colocar una muestra radiactiva de material muy delgado sobre este dispositivo para obtener picos de dicha distribución por unidad de longitud.

Un método para la caracterización del perfil del haz de protones del ciclotrón IBA 18/9 MeV, radica en la visualización del perfil mediante el impacto de este sobre filmes de tinte radiocrómico EBT3. Posteriormente su digitalización es posible a través de un software de procesamiento de imágenes con el objeto de obtener las dimensiones del perfil.

La película EBT3 está constituida de una serie de componentes (tabla 3.1). Entonces si se analizan las reacciones nucleares posibles debido al impacto de protones de alta energía (18 MeV) se obtienen elementos inestables que pueden ser detectados por el escáner TLC.

Tabla 3.1 Elementos de la película EBT3

\begin{tabular}{|c|c|c|c|c|c|c|c|c|}
\hline & \multirow{2}{*}{$\begin{array}{c}\text { Grosor } \\
\text { nominal } \\
{[\boldsymbol{\mu m}]}\end{array}$} & \multirow{2}{*}{$\begin{array}{c}\text { Densidad } \\
{\left[\boldsymbol{g} / \mathbf{c m}^{2}\right]}\end{array}$} & \multicolumn{4}{|c|}{ Composición Atómica (\%) } & \multirow{2}{*}{ Z efectivo } \\
\cline { 5 - 8 } & 125 & 1.35 & 36.4 & 0 & 45.5 & 18.2 & 0 & 6.64 \\
\hline $\begin{array}{c}\text { Matte: base de } \\
\text { poliéster de la } \\
\text { película }\end{array}$ & 28 & 1.2 & 56.8 & 0.6 & 27.6 & 13.3 & 1.6 & 7.26 \\
\hline $\begin{array}{c}\text { Activa (se asume } \\
7.5 \% \text { de humedad) }\end{array}$ & 125 & 1.35 & 36.4 & 0 & 45.5 & 18.2 & 0 & 6.64 \\
\hline $\begin{array}{c}\text { Matte: base de } \\
\text { poliéster de la } \\
\text { película }\end{array}$ & 125 & & & & & & & \\
\hline
\end{tabular}


Las reacciones nucleares posibles son:

- $\quad{ }^{12} \mathrm{C}(\mathrm{p}, \mathrm{n})^{12} \mathrm{~N}$

- ${ }^{16} \mathrm{O}(\mathrm{p}, \alpha)^{13} \mathrm{~N}$

- $\quad{ }^{27} \mathrm{Al}(\mathrm{p}, \mathrm{n})^{27} \mathrm{Si}$

La base de datos de Brookhaven National Laboratory proporciona información básica de los esquemas de decaimiento de los diversos radionúclidos existentes. Para el caso de ${ }^{12} \mathrm{~N},{ }^{13} \mathrm{~N} \mathrm{y}{ }^{27} \mathrm{Si}$ (figura 3.3):

7-NITROGEN-12

\begin{tabular}{|c|c|c|c|}
\hline Radiations & $\begin{array}{c}\mathbf{y}(\mathbf{i}) \\
(\mathbf{B q}-\mathbf{s})^{-1}\end{array}$ & $\begin{array}{c}\mathbf{E}(\mathbf{i}) \\
(\mathrm{MeV})\end{array}$ & $\mathbf{y}(\mathbf{i}) \times \mathbf{E}(\mathbf{i})$ \\
\hline$\beta+1$ & $4.40 \times 10^{-05}$ & $4.952 \times 10^{-01 *} \mathrm{k}$ & $2.18 \times 10^{-05}$ \\
\hline$\beta+2$ & $3.10 \times 10^{-03}$ & $1.625 *$ & $5.04 \times 10^{-03}$ \\
\hline$\beta+3$ & $4.60 \times 10^{-03}$ & 2.804 & $1.29 \times 10^{-02}$ \\
\hline$\beta+4$ & $2.70 \times 10^{-02}$ & 4.113 & $1.11 \times 10^{-01}$ \\
\hline$\beta+5$ & $1.90 \times 10^{-02}$ & 5.712 & $1.08 \times 10^{-01}$ \\
\hline$\beta+6$ & $9.45 \times 10^{-01}$ & 7.923 & 7.49 \\
\hline$\gamma^{ \pm}$ & 2.00 & $5.110 \times 10^{-01}$ & 1.02 \\
\hline$\gamma 1$ & $1.50 \times 10^{-02}$ & 3.215 & $4.82 \times 10^{-02}$ \\
\hline$\gamma_{2}$ & $2.73 \times 10^{-02}$ & 4.439 & $1.21 \times 10^{-01}$ \\
\hline K X-ray & $1.61 \times 10^{-10}$ & $2.000 \times 10^{-04 *}$ & $3.21 \times 10^{-14}$ \\
\hline Auger-K & $8.01 \times 10^{-08}$ & $2.600 \times 10^{-04 *}$ & $2.08 \times 10^{-11}$ \\
\hline \multicolumn{3}{|c|}{ Listed $\mathrm{X}, \gamma$, and $\gamma^{ \pm}$Radiations } & 1.19 \\
\hline \multicolumn{3}{|c|}{ Listed $\beta$, ce, and Auger Radiations } & 7.73 \\
\hline \multicolumn{3}{|c|}{ Listed Radiations } & 8.92 \\
\hline \multicolumn{2}{|c|}{ * Average Energy (MeV) } & \multicolumn{2}{|c|}{$\begin{array}{l}\text { Halflife }=11.000 \text { Millisec } \\
\text { Decay Mode: } E C+\beta+\end{array}$} \\
\hline
\end{tabular}

7-NITROGEN-13

\begin{tabular}{|c|c|c|c|}
\hline Radiations & $\begin{array}{c}\mathbf{y}(\mathbf{i}) \\
(\mathbf{B q}-\mathrm{s})^{-1}\end{array}$ & $\begin{array}{c}\mathbf{E}(\mathbf{i}) \\
(\mathrm{MeV})\end{array}$ & $\mathbf{y}(\mathbf{i}) \times \mathbf{E}(\mathbf{i})$ \\
\hline$\beta+1$ & $9.98 \times 10^{-01}$ & $4.918 \times 10^{-01 *}$ & $4.91 \times 10^{-01}$ \\
\hline$\gamma^{ \pm}$ & 2.00 & $5.110 \times 10^{-01}$ & 1.02 \\
\hline $\mathrm{K} X-\mathrm{r}$ & $3.72 \times 10^{-06}$ & $2.000 \times 10^{-04 *}$ & $7.44 \times 10^{-10}$ \\
\hline Auger- $\mathrm{K}$ & $1.86 \times 10^{-03}$ & $2.600 \times 10^{-04 *}$ & $4.83 \times 10^{-07}$ \\
\hline
\end{tabular}

Listed X, $\gamma$, and $\gamma^{ \pm}$Radiations $\quad 1.02$

Listed $\beta, \mathrm{ce}$, and Auger Radiations $\quad 4.91 \times 10^{-01}$

Listed Radiations

1.51

* Average Energy $(\mathrm{MeV})$

Halflife $=9.965$ Minutes Decay Mode: $\mathrm{EC}+\beta+$

Carbon-13 Daughter is stable.

14-SILICON-27

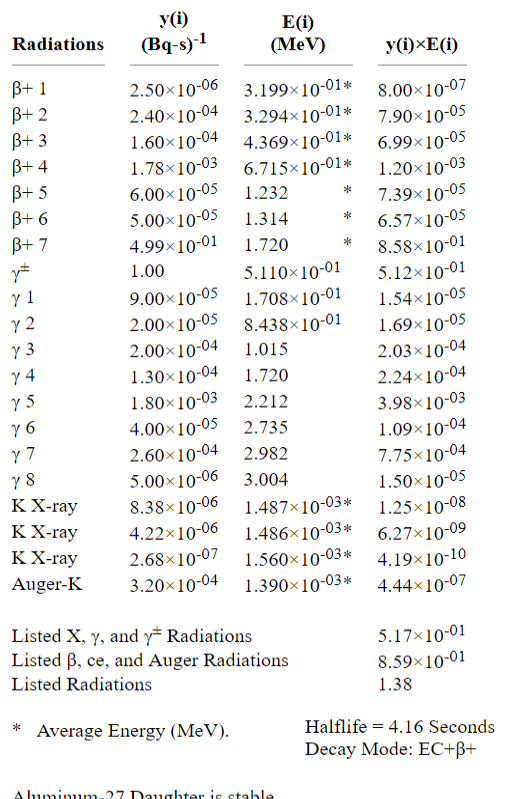

Aluminum-27 Daughter is stable.

Figura 3.3. Esquemas de decaimiento de los posibles productos de activación de los componentes de la película al momento de su irradiación con protones de $18 \mathrm{MeV}$. Es posible la detección del ${ }^{13} \mathrm{~N}$ con vida media aproximada de 10 minutos en un escáner TLC 


\section{CAPÍTULO 4 \\ METODOLOGÍA}

\subsection{Materiales}

\section{- Ciclotrón IBA 18/9 MeV}

Las irradiaciones se realizaron en un acelerador tipo ciclotrón perteneciente a la unidad de Ciclotrón y Radiofarmacia del Instituto Nacional de Cancerología (figura 4.1).

Este acelerador es apto para producir algunos de los radionúclidos convencionales (Flúor-18, Cobre64, Nitrógeno-13, Carbono-11) utilizados en técnicas de diagnóstico por imagen como PET. Cuenta con dos fuentes de iones de $\mathrm{H} \cdot \mathrm{Se}$ alcanza una energía de $18 \mathrm{MeV}$ para protones y $9 \mathrm{MeV}$ para deuterones. La forma de irradiación puede ser de manera simple o dual con una corriente en haz validada en $70 \mu \mathrm{A}$. No cuenta con auto blindaje.

Alrededor del equipo se tienen en total 8 puertos, dos de los cuales se emplean para realizar pruebas de aceptación (Beam Dump). Cada puerto cuenta con dos sistemas de extracción (laminillas de carbono) de espesor $30 \mu \mathrm{m}$. En los blancos restantes, se tiene la disponibilidad de producir los radionúclidos PET mencionados anteriormente.

El plano de aceleración de la partícula es horizontal sometida a un potencial oscilante de $34 \mathrm{kV}$ y radiofrecuencia de $46 \mathrm{MHz}$ en un campo magnético de $1.3 \mathrm{~T}$.

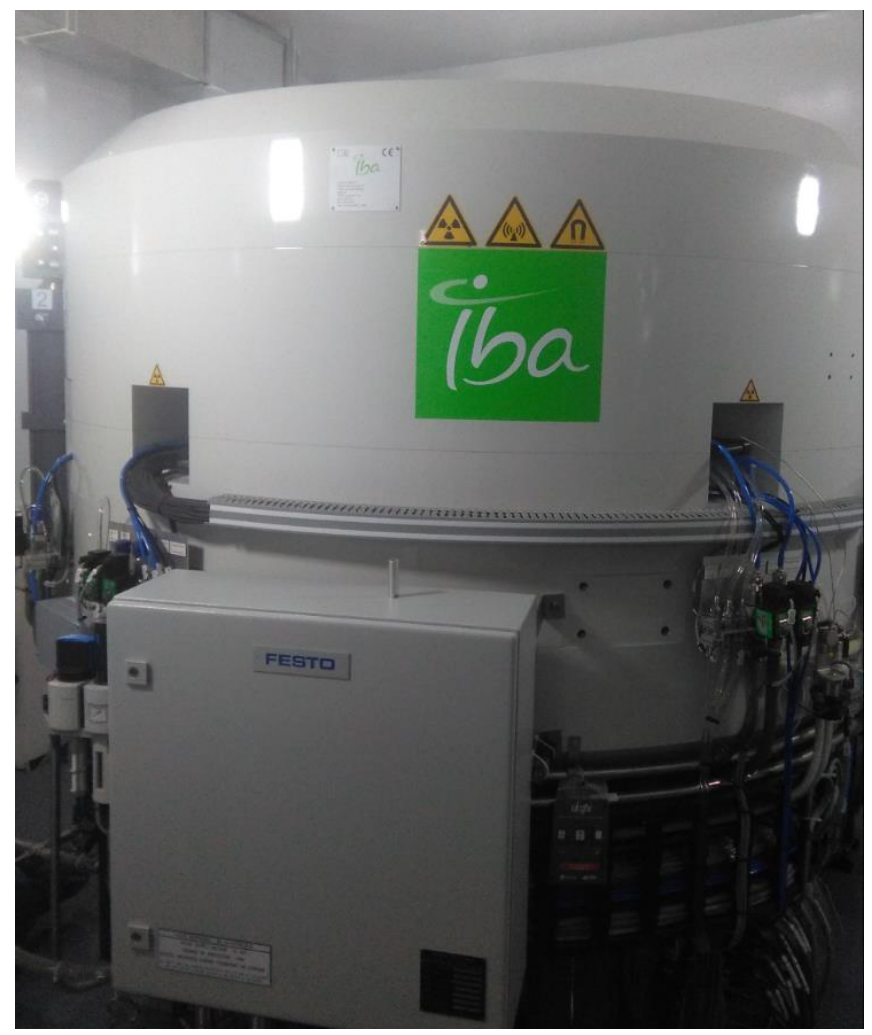

Figura 4.1. Ciclotrón del INCan. 


\section{- Películas Gafchromic EBT3}

Las películas fueron proporcionadas por el departamento de radioterapia del INCan. Ampliamente utilizadas en controles de calidad de IMRT, las películas son una buena referencia para la cuantificación de la dosis. En este trabajo, las películas se utilizaron para la comprobación del centrado y tamaño del perfil del haz.

Algunas de las características importantes de dichos filmes son las siguientes:

- Su digitalización se puede hacer mediante un escáner de cama plana.

- Baja dependencia energética y número atómico equivalente con el tejido.

- Revelado en tiempo real.

- Incorpora una capa activa de colorante amarillo para la dosimetría multicanal y la sensibilidad a la luz.

- Revestido en poliéster para la anti formación de los anillos de Newton.

Se cortaron películas circulares de $18 \mathrm{~mm}$ de diámetro (figura 4.2) para su posterior colocación en la entrada del blanco de prueba.
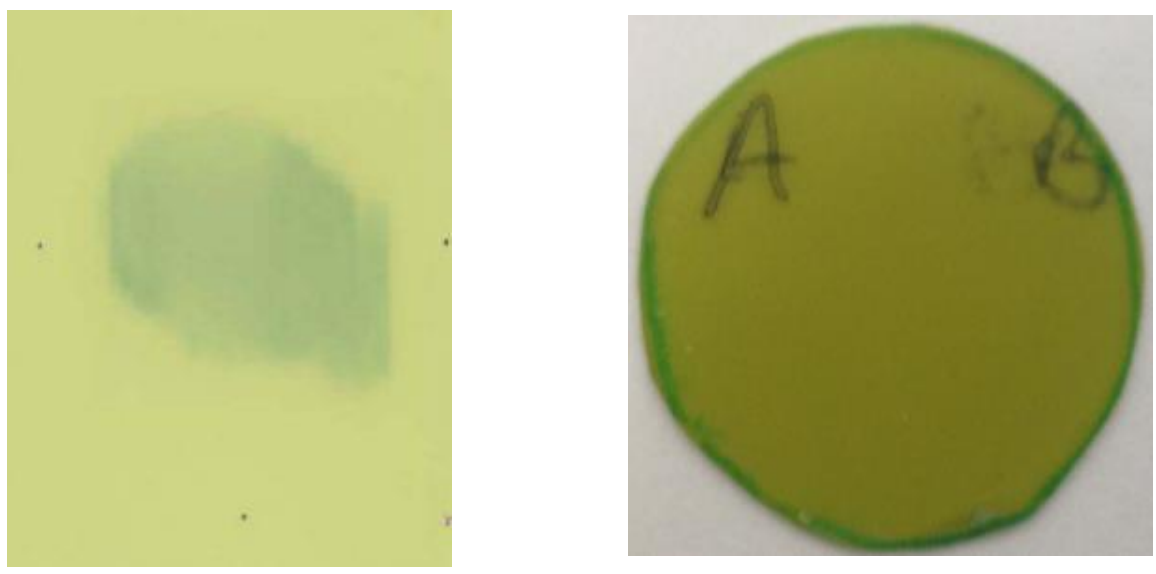

Figura 4.2. Películas Gafchromic EBT3 utilizadas en este trabajo. 


\section{- Escáner de cama plana Epson Expression 11000XL}

Para la digitalización de las películas se utilizó un escáner de cama plana perteneciente al Departamento de Radioterapia del Instituto Nacional de Cancerología (figura 4.3). La máxima resolución de este escáner es de 2000x 4800 dpi, con una profundidad de color de 48 bits (que determina el número máximo de colores que puede tomar cada uno de los pixeles en la imagen [Zúñiga, 2011]) y área de escaneo máximo de 12.2" x 7.2".

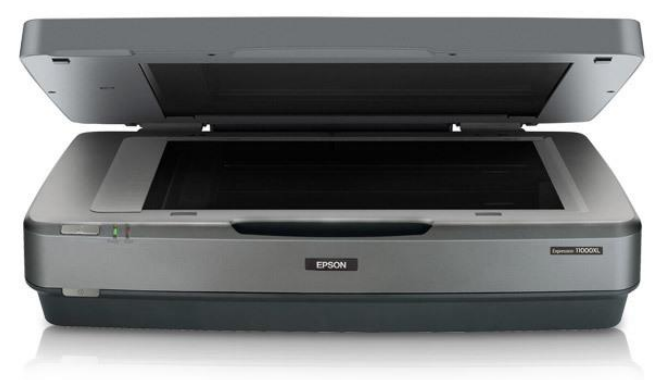

Figura 4.3. Escáner EPSON Expression 11000 XL

\section{- Escáner TLC miniGita}

Los espectros de activación de las películas se obtuvieron al término de su irradiación mediante un escáner de cromatografía de capa fina. Este cuenta con tres tipos de detectores (Tabla 4.1):

Tabla 4.1 Propiedades físicas de los tres detectores con los que cuenta el escáner TLC

\begin{tabular}{lccc}
\hline \multicolumn{1}{c}{ Características } & Detector $\mathbf{B G O}$ & Detector $\boldsymbol{G M}$ & Detector centellador \\
\hline Tipo de radiación & $\gamma(30-1600 \mathrm{keV})$ & $\beta+$ & $\beta+, \beta-$ \\
\hline Fondo $($ cps $)$ & $0.7 *$ & $0.1\left({ }^{18} \mathrm{~F}\right)$ & $<0.1\left({ }^{18} \mathrm{~F}\right)$ \\
\hline Sensibilidad $(\boldsymbol{B q})$ & 20 & $10^{*}$ & $15^{*}$ \\
\hline Resolución $(\boldsymbol{m m})$ & $2-3$ & $2-3$ & $1-2$ \\
\hline Máxima tasa de conteo $(\boldsymbol{c p s})$ & 100,000 & 35,000 & $<0.3$ \\
\hline Tiempo muerto $(\boldsymbol{\mu})$ & $<2$ & $<20$ & 30 \\
\hline Eficiencia $\boldsymbol{C s}-137(\%)$ & 10 & 30 & \\
\hline
\end{tabular}

* Para ${ }^{129} \mathrm{I}$

${ }^{*}$ Para ${ }^{18} \mathrm{~F}$ 

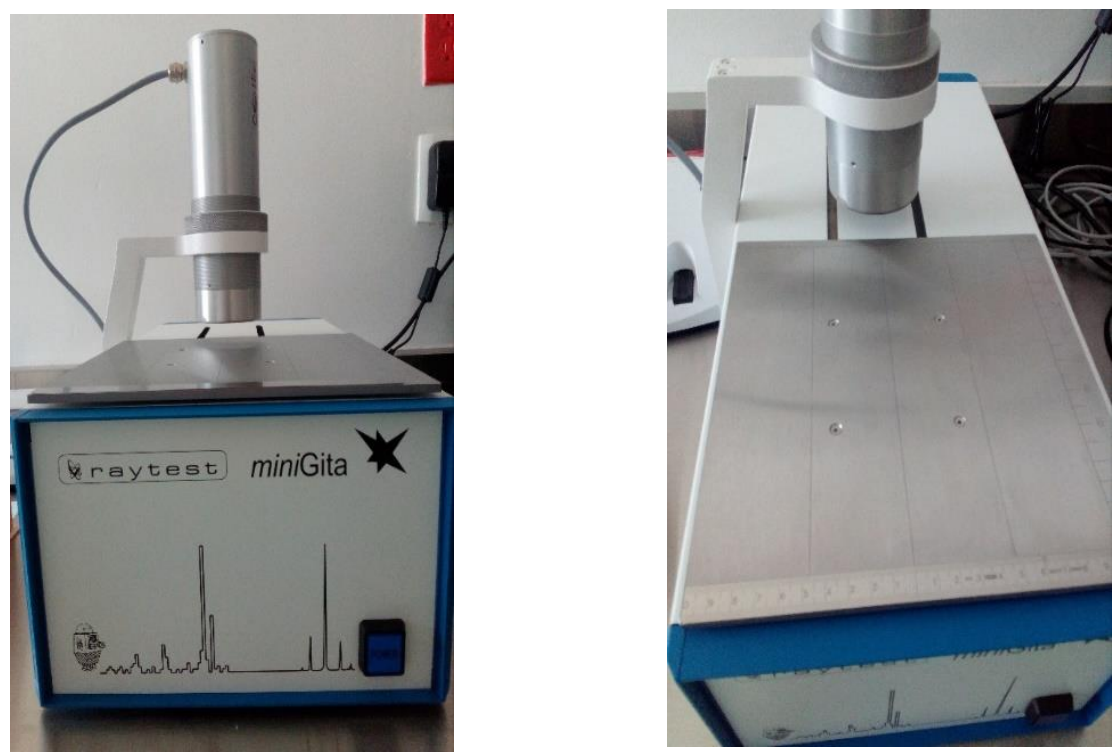

Figura 4.4. Escáner TLC.

- Software ImageJ y OriginLab 2018

El procesamiento de las imágenes de las películas digitalizadas se realizó en ImageJ versión 1.5 y en OriginLab 2018.

\section{- Calibrador de dosis}

Calibrador de dosis perteneciente a la Unidad de Ciclotrón y Radiofarmacia del INCan.

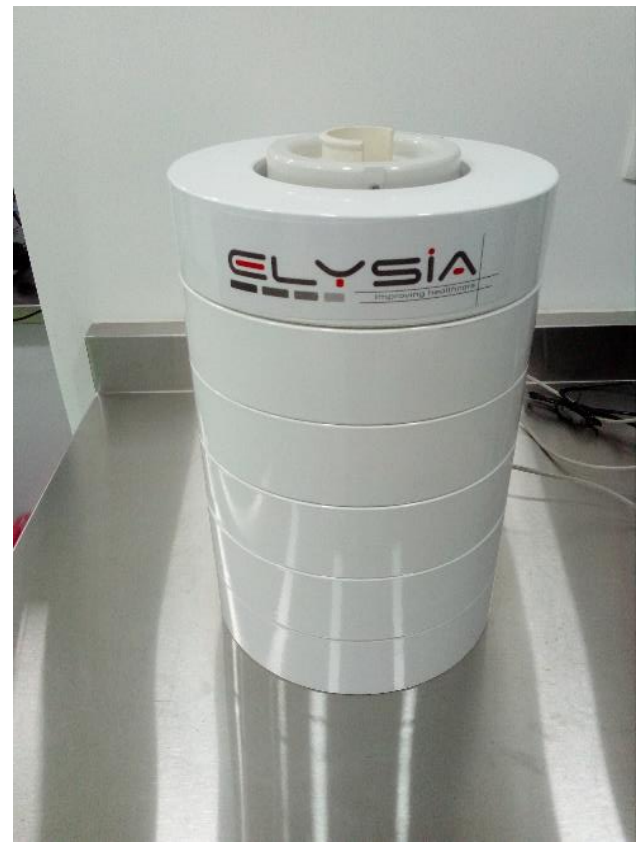

Figura 4.5. Calibrador de dosis. 


\subsection{Procedimiento experimental. \\ 4.2.1.Tuning de haz}

Antes de la colocación de las películas EBT3 sobre el blanco de prueba (beam dump) es necesario realizar un ajuste del haz conocido como tuning. Este proceso permite tener un centrado aproximado del haz que se corroborará con los siguientes parámetros:

- Máximo valor de la corriente en el sistema de extracción y posicionamiento del mismo (en grados).

- Máximo valor de la corriente en el blanco.

- Mínimo valor de la corriente en los colimadores.

Estos puntos se logran a partir de lo siguiente:

1. Sistema de gases abierto (H para la fuente de iones, Helio 6.0 para presurización del blanco).

2. En la consola de control (figura 4.6), se enciende el imán, la RF y al final la fuente de iones (por "default" la corriente manejada en el tuning es de $40 \mathrm{~mA}$ ). Se verifica que la punta de prueba esté deshabilitada. Posterior a esto, se debe seleccionar el blanco de prueba (para todas las irradiaciones se eligió el beam dump 2).

3. Se varía ligeramente el amperaje del imán para obtener una corriente máxima en el sistema de extracción. No se modifica parámetro alguno en la radiofrecuencia.

4. Después se modifica la posición del sistema de extracción para tener el máximo valor de corriente en el blanco.

5. El valor de la corriente en el colimador debe ser mínima para garantizar que la mayor parte del haz esté impactando al blanco. El cociente de la corriente en el colimador y el blanco no deberá ser mayor al $15 \%$.

6. La transmisión debe ser mayor al $50 \%$.

El sistema puede realizar este ajuste mediante la opción Fine Regulation ON.

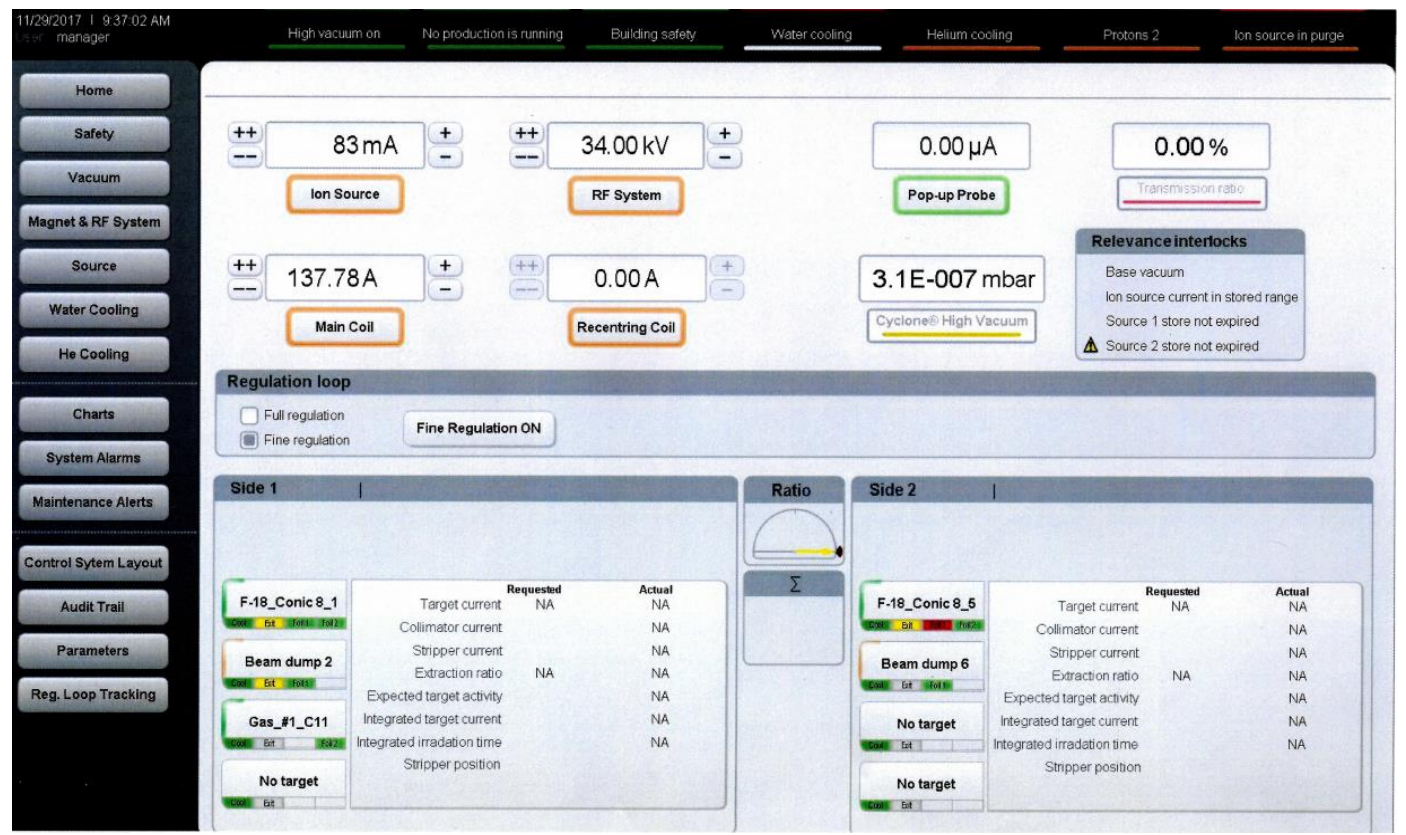

Figura 4.6. Interfaz del software del Ciclotrón IBA 18/9 


\subsubsection{Montaje de película EBT3 en blanco de prueba}

Una vez que se tiene una primera visión del centrado del haz, se procede a colocar la película en el blanco de prueba como a continuación se describe:

Se debe apagar el sistema de enfriamiento, no sin antes verificar que la fuente de iones, RF, mail coil y Pop-up Probe estén deshabilitadas. También se deshabilita el blanco de prueba.

En la opción "Vacuum" (figura 4.7) se procede a desconectar el beam dump llevándolo a presión atmosférica. Apagado el sistema de enfriamiento, se procede a cerrar el flujo de agua.
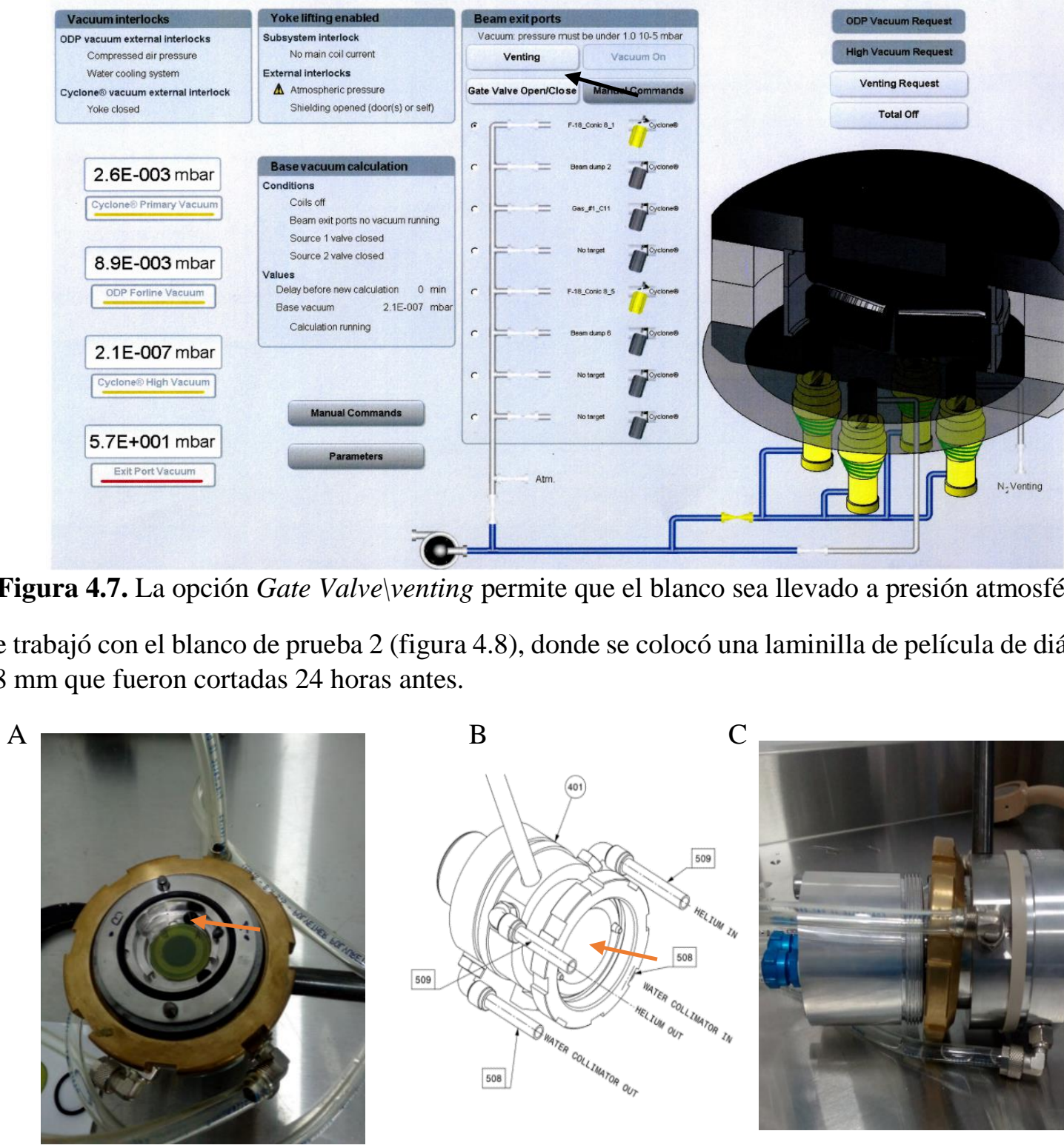

Figura 4.7. La opción Gate Valvelventing permite que el blanco sea llevado a presión atmosférica.

Se trabajó con el blanco de prueba 2 (figura 4.8), donde se colocó una laminilla de película de diámetro $18 \mathrm{~mm}$ que fueron cortadas 24 horas antes.
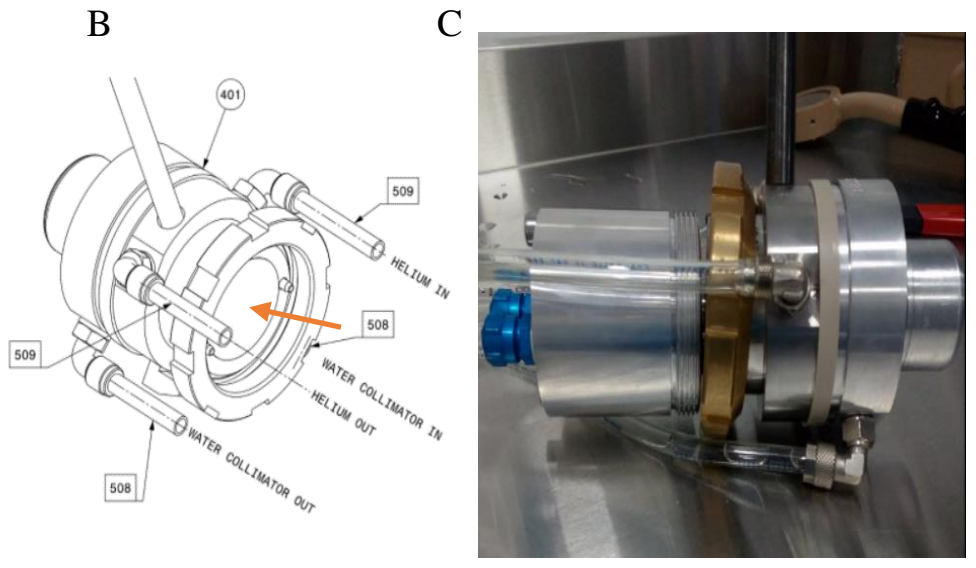

Figura 4.8. A) Vista frontal del beam dump donde se colocó la película para su irradiación. B) Cuerpo del blanco. La flecha marca el área nominal de irradiación que corresponde a $16 \mathrm{~mm}$. C) Blanco de prueba. 


\subsubsection{Proceso de Irradiación}

Una vez montado el blanco de prueba con la película se procede a la irradiación. Los parámetros a considerar son los siguientes:

- Corriente en el imán: para todas las irradiaciones el valor promedio fue de 137. 78 A.

- Radiofrecuencia: 34 kV.

- Posición del sistema de extracción: el intervalo óptimo para considerar no sobrepasar el $15 \%$ del daño al colimador va de $88.3^{\circ}-90.3^{\circ}$

- Vacío: $<2 \times 10^{-5}$ mbars.

A diferencia del proceso de tuning del haz, la punta de prueba es habilitada dado que registra la corriente efectiva del haz. La irradiación comienza justo cuando ésta se deshabilita. Algunas de las pruebas realizadas para comprobar la variación de tamaño de haz fueron las siguientes:

- Tiempo fijo a diferentes corrientes: se irradiaron 2 filmes para cada corriente en la fuente de iones de: 5, 10, 2030 y $40 \mathrm{~mA}$ a un tiempo de 3 segundos.

- Corriente fija a diferentes tiempos: para una corriente de $10 \mathrm{~mA}$, las irradiaciones se llevaron a cabo en un intervalo de tiempo de 3-8 segundos.

- Tiempo fijo a diferentes vacíos: para un tiempo de 3 segundos y una corriente en la fuente de iones de $10 \mathrm{~mA}$, se irradiaron filmes a valores de vacío: de $1.8 \times 10^{-5}$ mbars a $1.1 \times 10^{-5}$ mbars (los valores de vacío se tomaban conforme este se estabilizaba, en intervalos de aproximadamente $2 \mathrm{~min}$ ).

- Irradiación de diferentes materiales: se irradiaron también diferentes materiales (figura 4.9) bajo los siguientes parámetros: $34 \mathrm{kV}$ en la RF, 137.78 A para corriente en imán, $10 \mathrm{~mA}$ de corriente en la fuente de iones, $89.2^{\circ}$ en la posición del sistema de extracción, a un vacío de $1.5 \times 10^{-5}$ mbars durante 3 segundos.

Las irradiaciones no se realizaron en modo Fine Regulation ya que se presenta variación en los valores de la RF, corriente en la fuente y campo magnético conforme al tiempo de irradiación debido al calentamiento del imán. El sistema automáticamente balancea estos valores. Además de que en este modo también se busca un centrado de haz, no es conveniente colocar una película en el blanco de prueba.

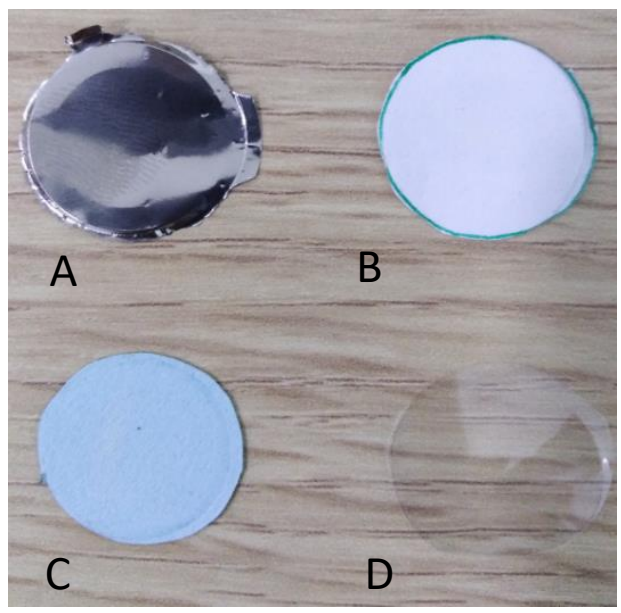

Figura 4.9. Materiales utilizados para la visualización del perfil del haz: A) laminilla de titanio, B) papel C) opalina y D) acetato. 


\subsubsection{Productos de activación. Lector de tiras de TLC y calibrador de dosis}

Posterior a la irradiación, se desmonta el blanco de prueba y se registra la rapidez de exposición tanto del cuerpo del blanco como el de la película.

Tanto los materiales prueba como las películas son transportados a control de calidad para su lectura en el lector de tiras de TLC (figura 4.10) bajo los siguientes parámetros (siguiendo el protocolo para la obtención de los espectros para F-18 y Ga-68):

- Tiempo de adquisición: 2 minutos

- Ancho de canal (resolución): $0.33 \mathrm{~mm}$

- Curva de suavizado de $10 \mathrm{~mm}$

A

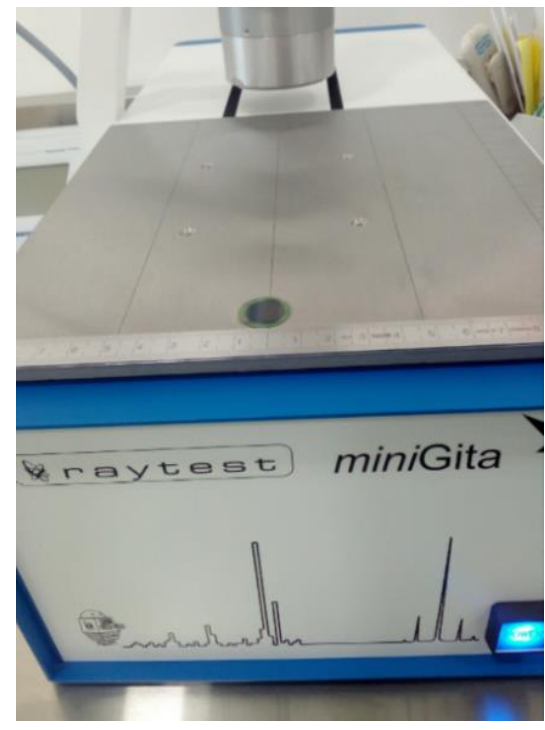

B

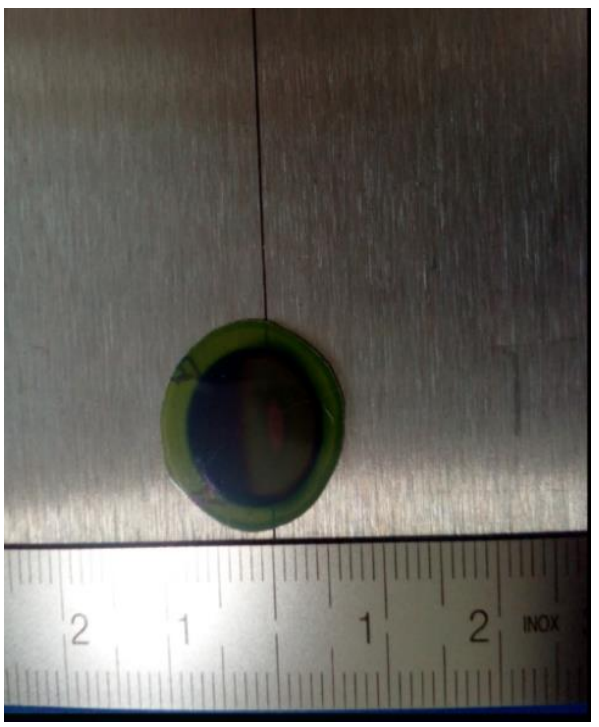

Figura 4.10. A) Película para su lectura en el lector de tiras de TLC. B) Dado que el proceso de obtención del espectro de la distribución de actividad depende del barrido del detector, la película se coloca en el origen del área de escaneo.

Se analizó el FWMH de la distribución de radiactividad obtenida para obtener el tamaño del eje horizontal de la elipse formada.

La curva de decaimiento se obtuvo en base a los posibles elementos que se activan. Posterior a la irradiación se obtuvieron mediciones de actividad de la película en el canal de Flúor-18 durante aproximadamente $20 \mathrm{~min}$. Siguiendo las posibles reacciones nucleares, el elemento probablemente formado es Nitrógeno-13, un emisor de positrones -al igual que Flúor-18- con un porcentaje de emisión de $99.8 \%$, es por ello que se decidió trabajar en este canal. 


\subsubsection{Proceso de Digitalización}

Previo a la adquisición de las imágenes primeramente se verificó que la cama del escáner no estuviera sucia o con manchas. Posterior a esto se comprobó la estabilidad del escáner y siguiendo el protocolo descrito por [Aragón, 2013], se digitalizó una película sin irradiar 15 veces para corroborar que la desviación estándar en las lecturas fuera menor a $0.3 \%$, de esta manera se asegura que la variación en la intensidad de las películas digitalizadas sea la menor posible.

Las películas fueron digitalizadas 24 horas después de la irradiación (se esperó un tiempo a que el estrés mecánico al que fue sometida la película al ser cortada disminuyera o desapareciera en su totalidad) en un escáner en modo transmisión (figura 4.11) a color de 48 bits, con resolución de 400 ppp (pixeles por pulgada) y se guardaron en formato .TIF para su posterior procesamiento con ImageJ. Se escogió un valor de 400 ppp como la mínima resolución a la que se podía visualizar el patrón del haz formado sobre la película.

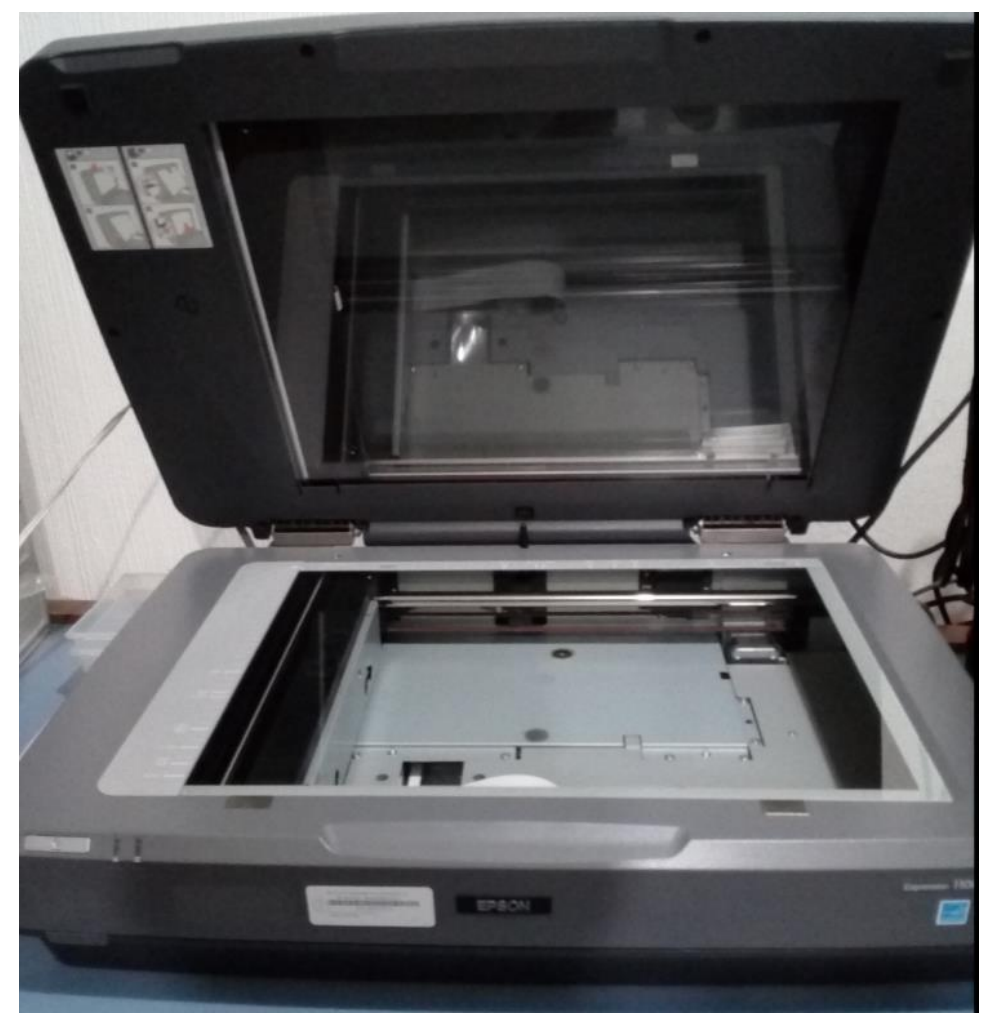

Figura 4.11. Escáner EPSON 1100XL 


\section{CAPÍTULO 5 \\ RESULTADOS, DISCUSIÓN Y CONCLUSIONES}

\subsection{Tamaño del haz. Técnica Dosimétrica y con lector de tiras de TLC}

Las siguientes imágenes presentan los perfiles elipse obtenidos para tres diferentes fuentes de iones.

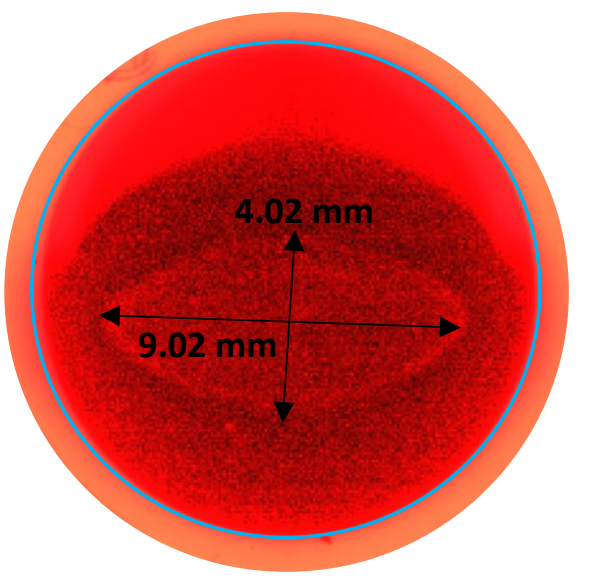

$\begin{array}{cc}\text { Parámetros de Irradiación } & \text { Valor } \\ \text { Corriente en fuente de iones } & 2 \mathrm{~mA} \\ \text { Corriente en el imán } & 137.72 \mathrm{~A} \\ \text { Posición del sistema de } & 89.3^{\circ} \\ \text { extracción } & \\ \text { Radiofrecuencia } & 34 \mathrm{kV} \\ \text { Tiempo de irradiación } & 3 \mathrm{segundos} \\ \text { Lado mayor } & 9.02 \mathrm{~mm} \\ \text { Lado menor } & 4.3 \mathrm{~mm}\end{array}$

Figura 5.1. Centrado de haz sobre la película EBT3 de la irradiación que se hizo para la primera fuente de iones comisionada.

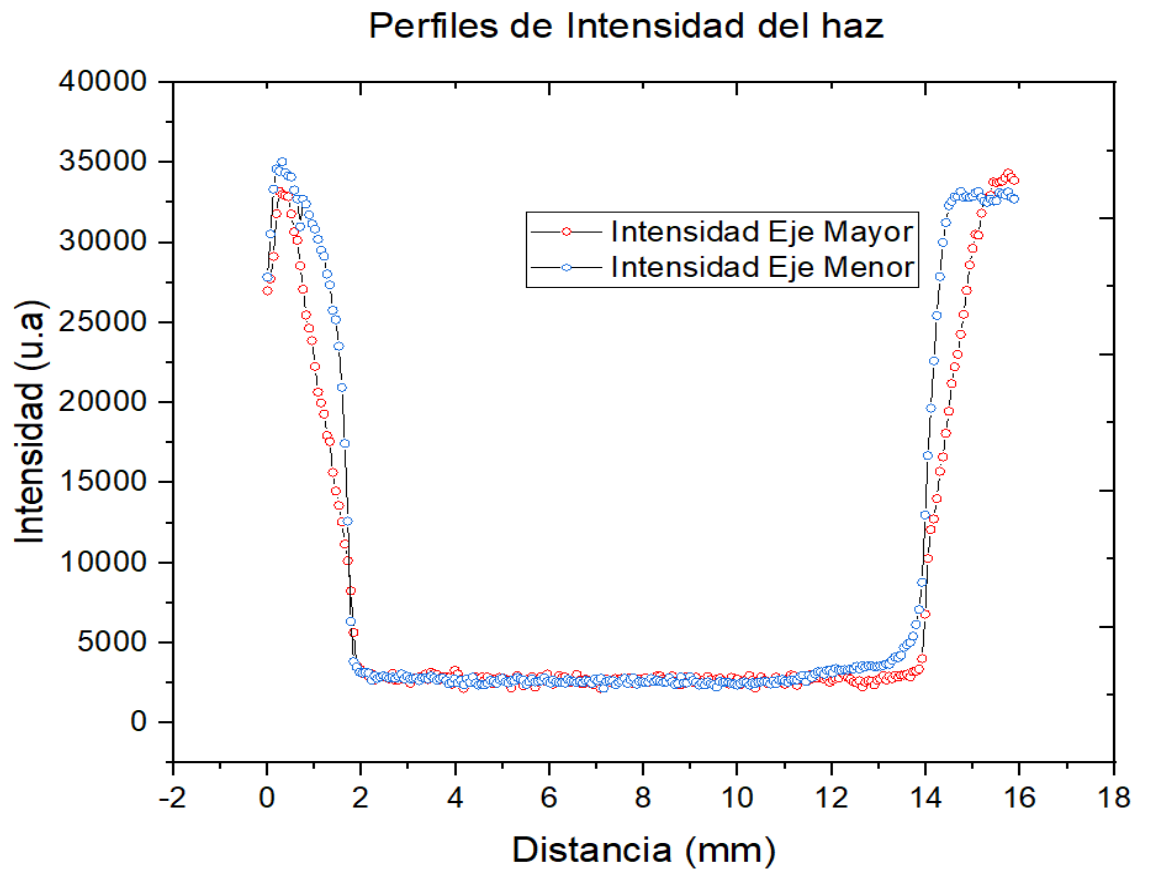

Figura 5.2. Perfiles del haz de radiación. Se observa un ligero aplanado sobre la región que contiene al área de la elipse. Cabe mencionar que la distancia de este aplanado en realidad tiene las dimensiones de la ventana útil del haz en el blanco de prueba (diámetro de la circunferencia azul) en la figura 5.1. 


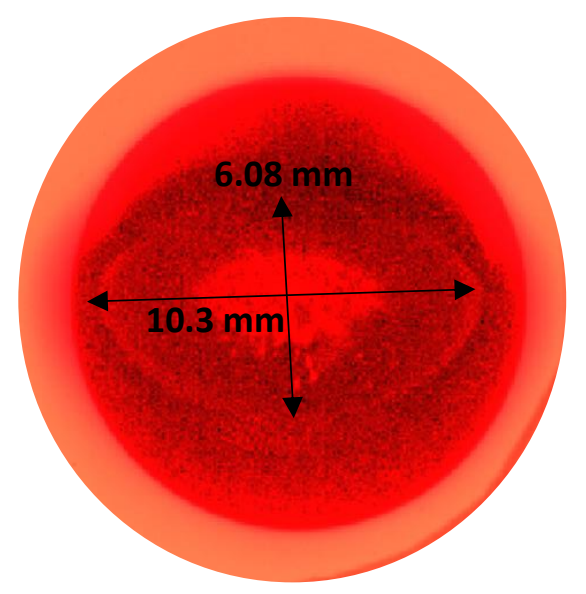

$\begin{array}{|cc|}\text { Parámetros de Irradiación } & \text { Valor } \\ \text { Corriente en fuente de iones } & 5 \mathrm{~mA} \\ \text { Corriente en el imán } & 137.78 \mathrm{~A} \\ \text { Posición del sistema de } & 89.2^{\circ} \\ \text { extracción } & \\ \text { Radiofrecuencia } & 34 \mathrm{kV} \\ \text { Tiempo de irradiación } & 3 \mathrm{segundos} \\ \text { Lado mayor } & 10.3 \mathrm{~mm} \\ \text { Lado menor } & 6.08 \mathrm{~mm}\end{array}$

Figura 5.2. Centrado de haz sobre la película EBT3 de la irradiación que se realizó con la fuente de iones 1.

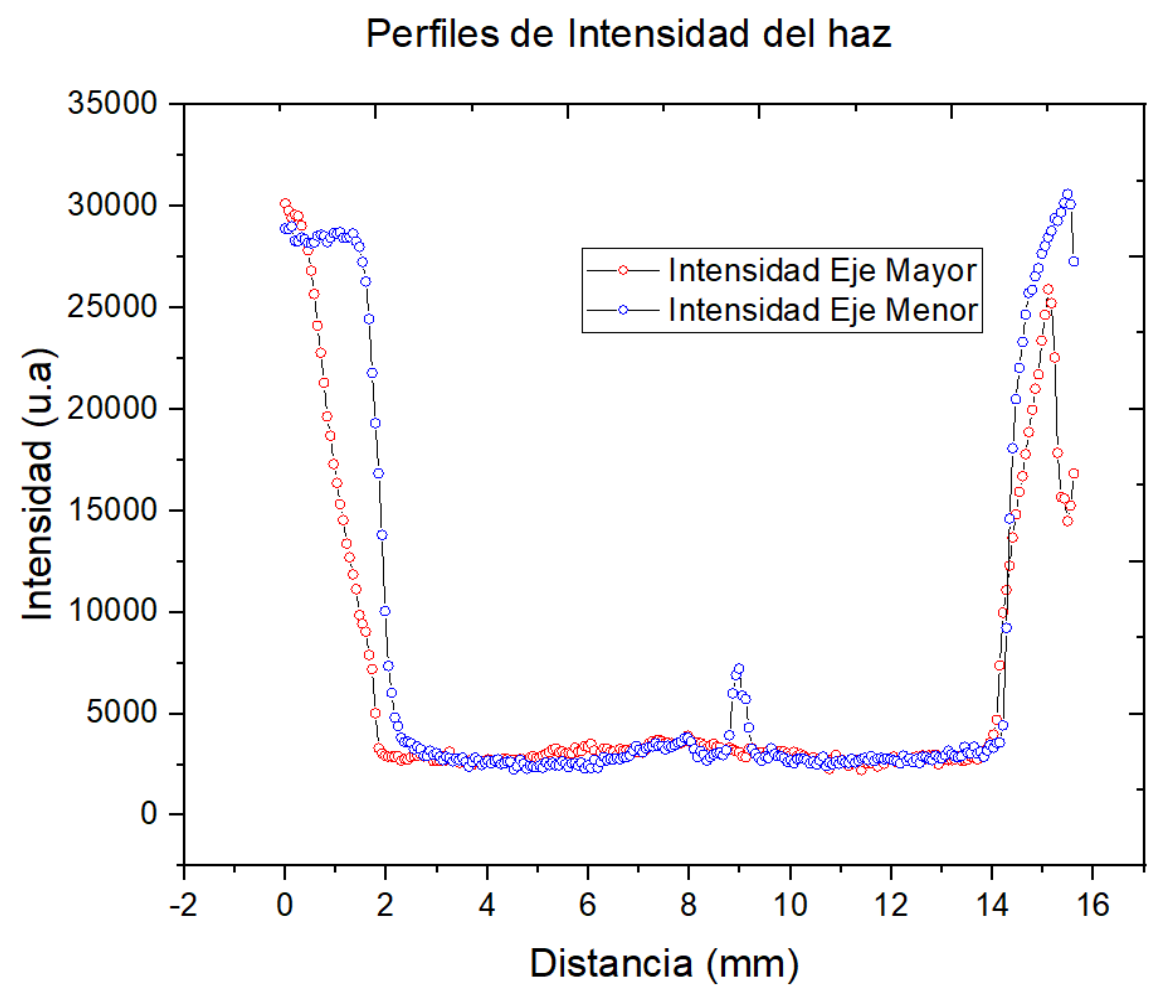

Figura 5.4. En la región correspondiente al aplanado de haz, se presenta una variación (picos de intensidad) debido al quemado de la película. 


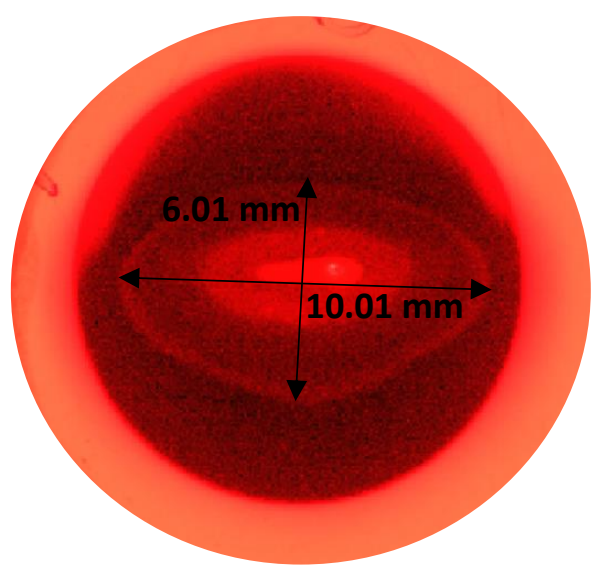

Figura 5.5. Centrado de haz obtenido para la fuente de iones 2 . La región más intensa en el centro de la elipse se debe a que la película fue perforada por el haz.

\begin{tabular}{|cc|}
\hline Parámetros de Irradiación & Valor \\
Corriente en fuente de iones & $40 \mathrm{~mA}$ \\
Corriente en el imán & $137.78 \mathrm{~A}$ \\
Posición del sistema de & $89.1^{\circ}$ \\
extracción & \\
Radiofrecuencia & $34 \mathrm{kV}$ \\
Tiempo de irradiación & $3 \mathrm{segundos}$ \\
Lado mayor & $10.01 \mathrm{~mm}$ \\
Lado menor & $6.01 \mathrm{~mm}$
\end{tabular}

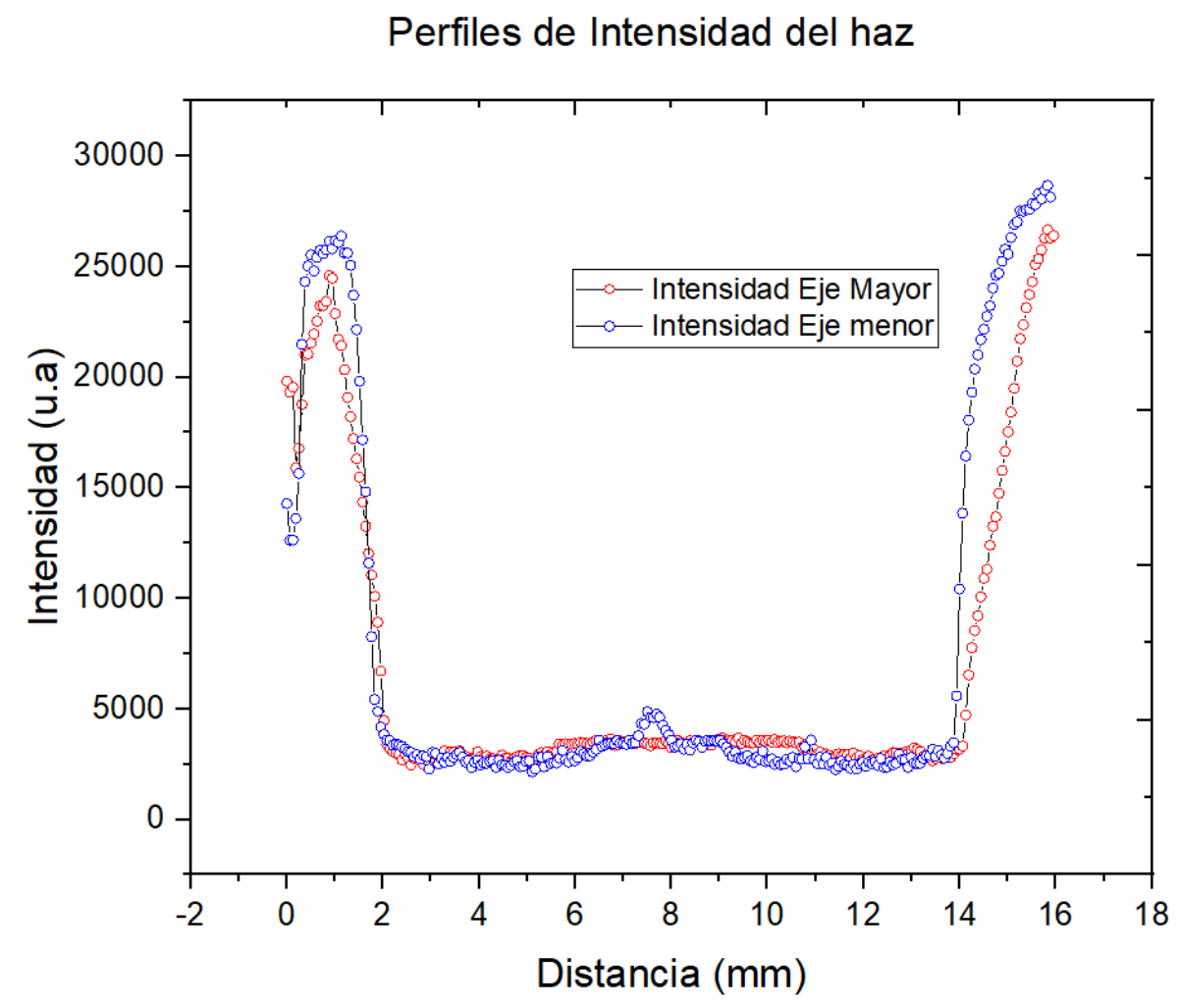

Figura 5.6. Perfiles de haz correspondientes a un tiempo de irradiación de 3 segundos a $40 \mathrm{~mA}$. Las regiones que caen abruptamente corresponden a la región de la película fuera de la ventana útil de haz (sin saturación). 


\subsection{Perfil de haz sobre Blanco de Flúor}

Nos interesa conocer el lugar exacto de donde impacta el haz de radiación sobre el blanco de flúor. Para esto se escaló la imagen de la forma del haz sobre la región de la cavidad a irradiar.

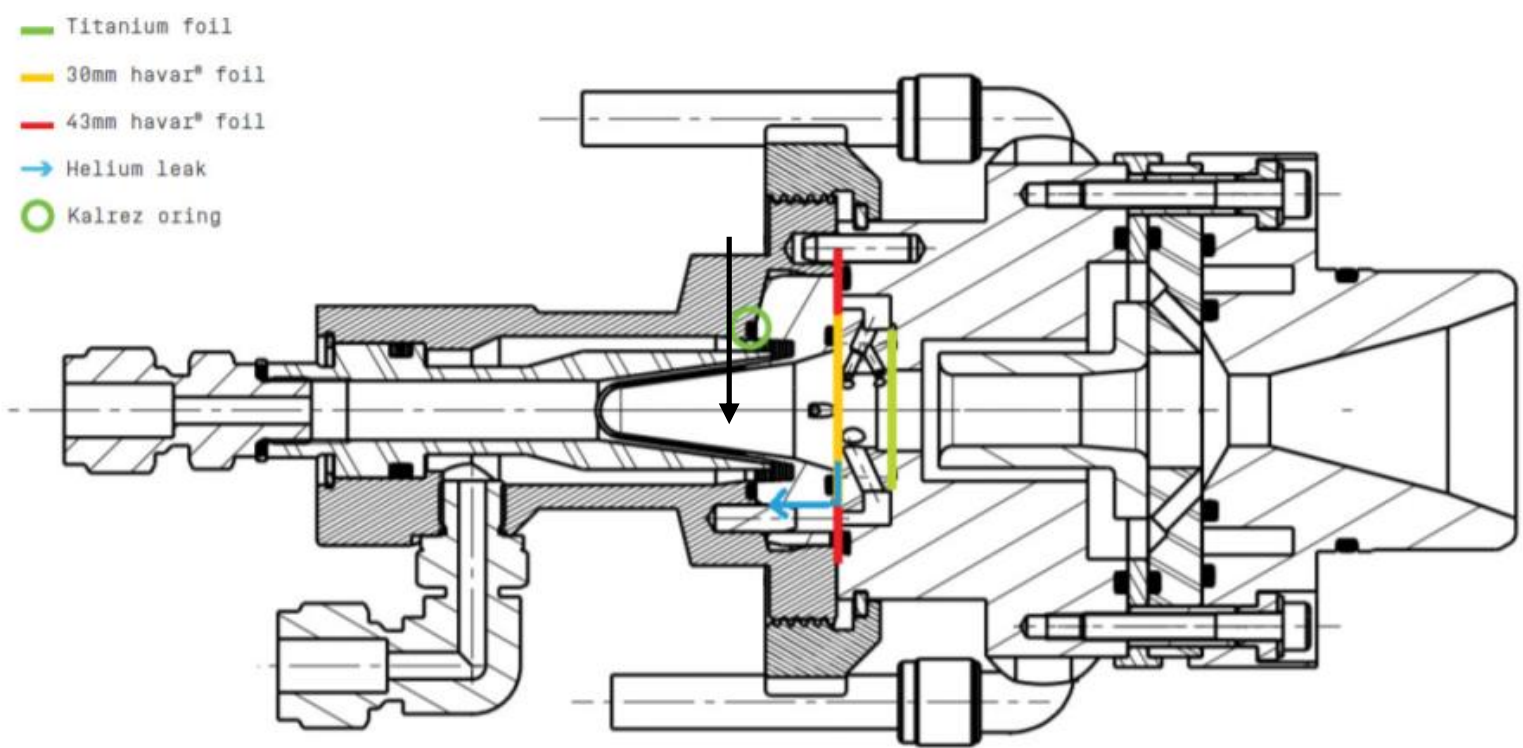

Figura 5.7. Esquema del Blanco para Flúor y sus diferentes ventanas La flecha marca la cavidad de irradiación del $\left[{ }^{18} \mathrm{O}\right] \mathrm{H}_{2} \mathrm{O}$.

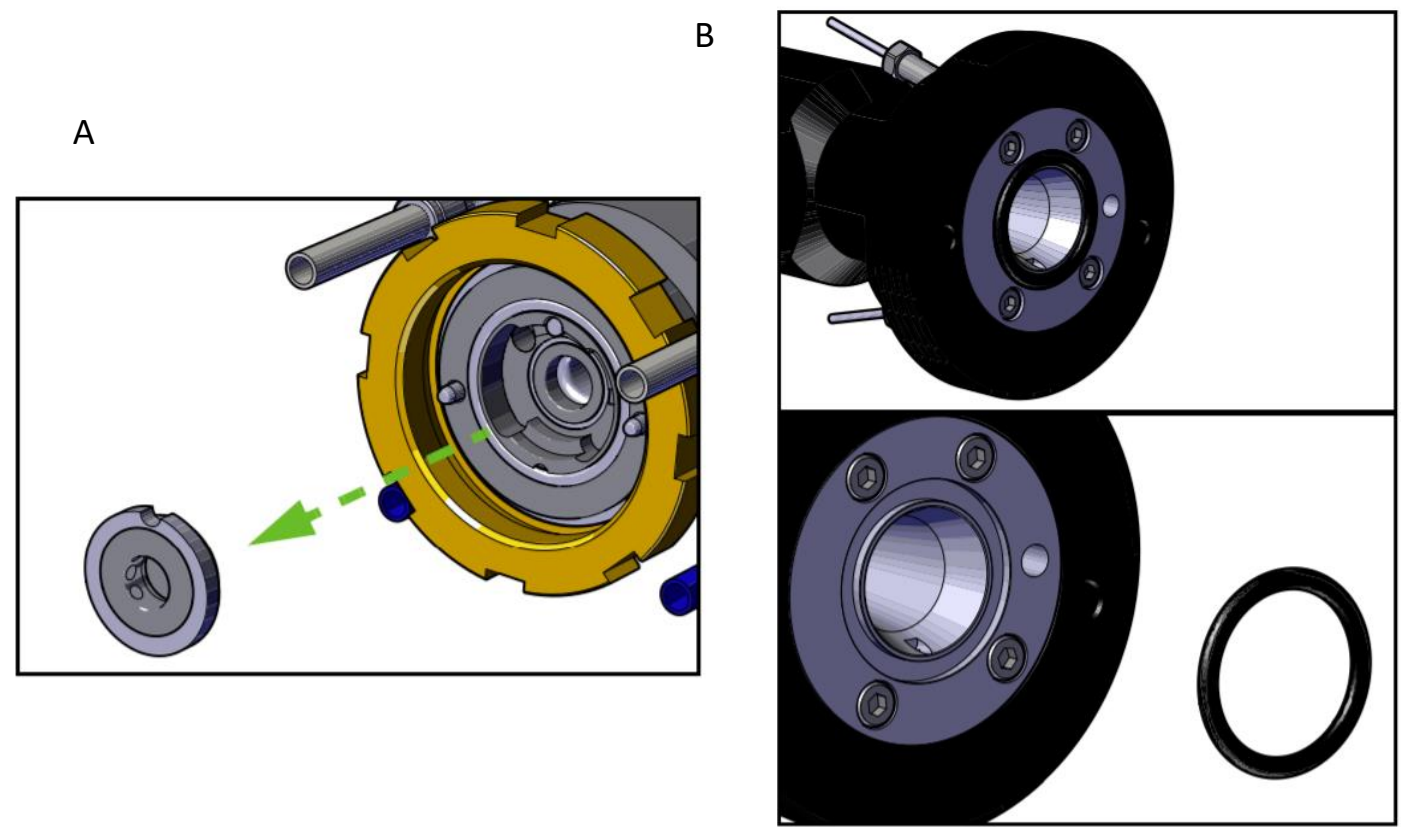

Figura 5.8. Sección de la cavidad del blanco de Flúor. A) sección del blanco (colimador). B) sección transversal de la cavidad de ${ }^{18} \mathrm{O}$ a irradiar. El diámetro de la cavidad es de $12 \mathrm{~mm}$. 


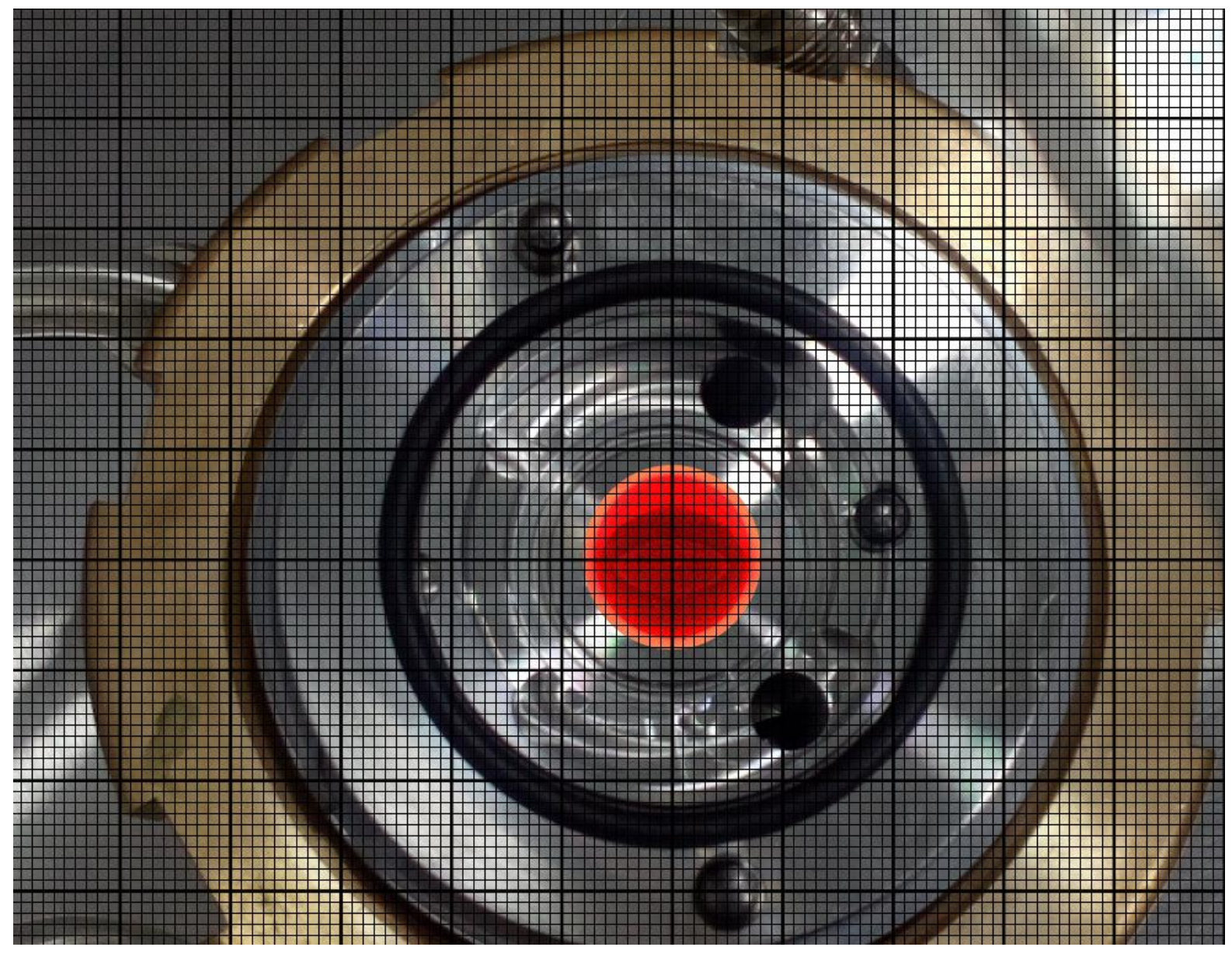

Figura 5.9. Forma del haz sobre la región de colimador correspondiente a la figura 5.8.A. La posición del perfil del haz se muestra con un ligero corrimiento desde el centro efectivo de la región de $12 \mathrm{~mm}$. Sobre la película, la región más intensa (color rojo) indica el área de la cavidad a irradiar. 


\subsection{Productos de Activación}

La figura 5.10 muestra la curva de decaimiento de los productos de activación de la película al término de la irradiación con protones de $18 \mathrm{MeV}$. Las reacciones nucleares posibles son: ${ }^{12} \mathrm{C}(\mathrm{p}, \mathrm{n}){ }^{12} \mathrm{~N},{ }^{16} \mathrm{O}(\mathrm{p}, \alpha){ }^{13} \mathrm{~N} \mathrm{y}{ }^{27} \mathrm{Al}(\mathrm{p}, \mathrm{n}){ }^{27} \mathrm{Si}$. La constante de decaimiento de la curva es de 0.071 resultando un valor de 9.90 min para la vida media que corresponde justo a la activación de ${ }^{16} \mathrm{O}$ en ${ }^{13} \mathrm{~N}$ que es un emisor de positrones con energía promedio $491 \mathrm{MeV}$ y emisor gamma (2\%) con fotones de $511 \mathrm{KeV}$. La vida media reportada para este radionúclido es de $9.965 \mathrm{~min}$.

Los valores correspondientes al ajuste exponencial son:

Para la actividad inicial de la muestra con valor de $(3.55 \pm 0.04) \mu \mathrm{Ci}$

Para la constante de decaimiento con valor de $(0.071 \pm 0.001) \mathrm{min}^{-1}$

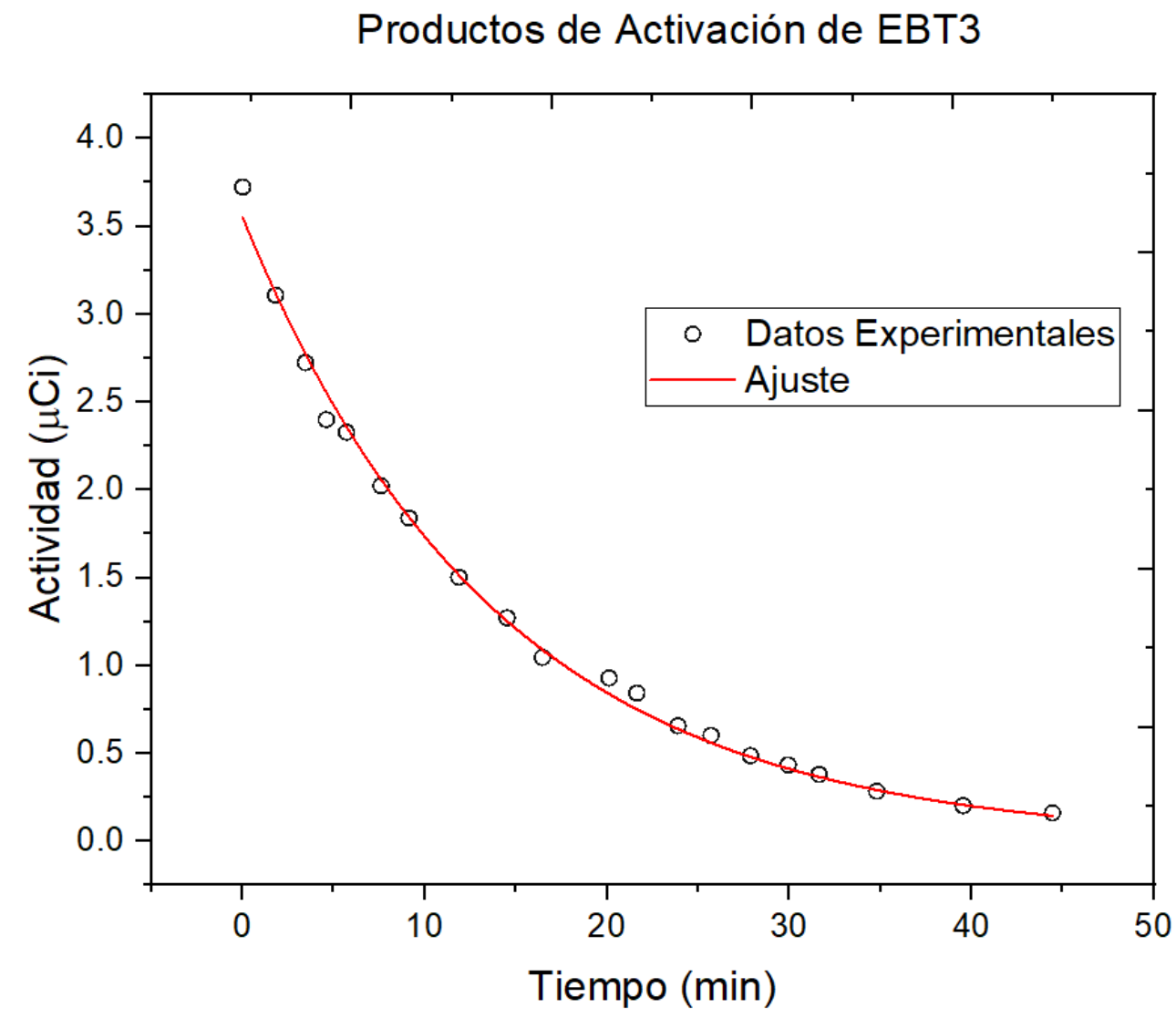

Figura 5.10. Curva de decaimiento de la película irradiada, cuyo ajuste a una función exponencial indica que fue activada con ${ }^{13} \mathrm{~N}$. 


\subsection{Tamaño del haz. Técnica con lector de tiras de TLC}

La distribución de la radiactividad sobre la película EBT3 debida a la activación de ${ }^{16} \mathrm{O}$ se muestran para la fuente de iones 1 y 2. El FWHM del perfil de actividad nos brinda información sobre el ancho del haz del eje mayor del patrón perfil que se forma (elipse). En todos los casos, el tamaño del haz resultó ser de $11 \mathrm{~mm}$.

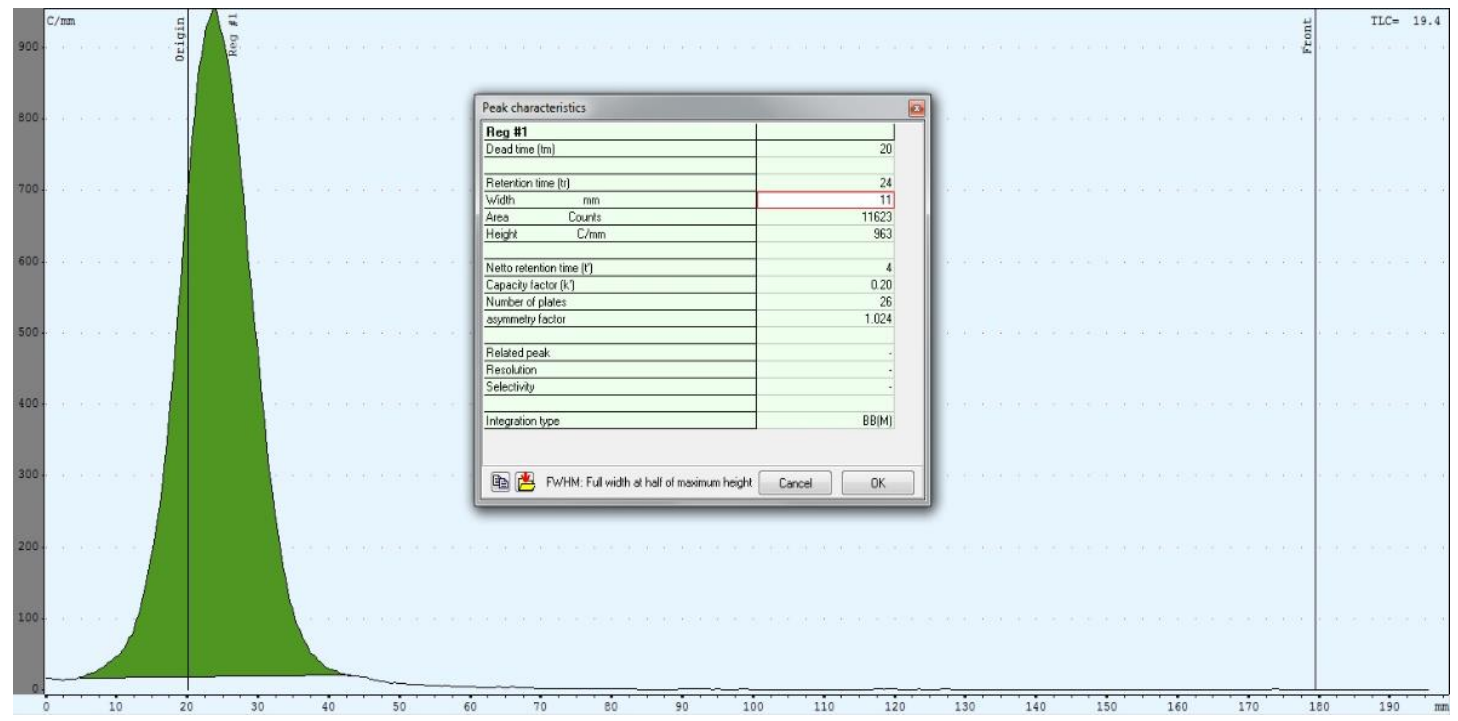

Figura 5.11. Espectro de distribución de radiactividad en la película EBT3 con un conteo máximo de 10835 cuentas para una irradiación de 3 segundos con 5 mA en la fuente de iones 1.

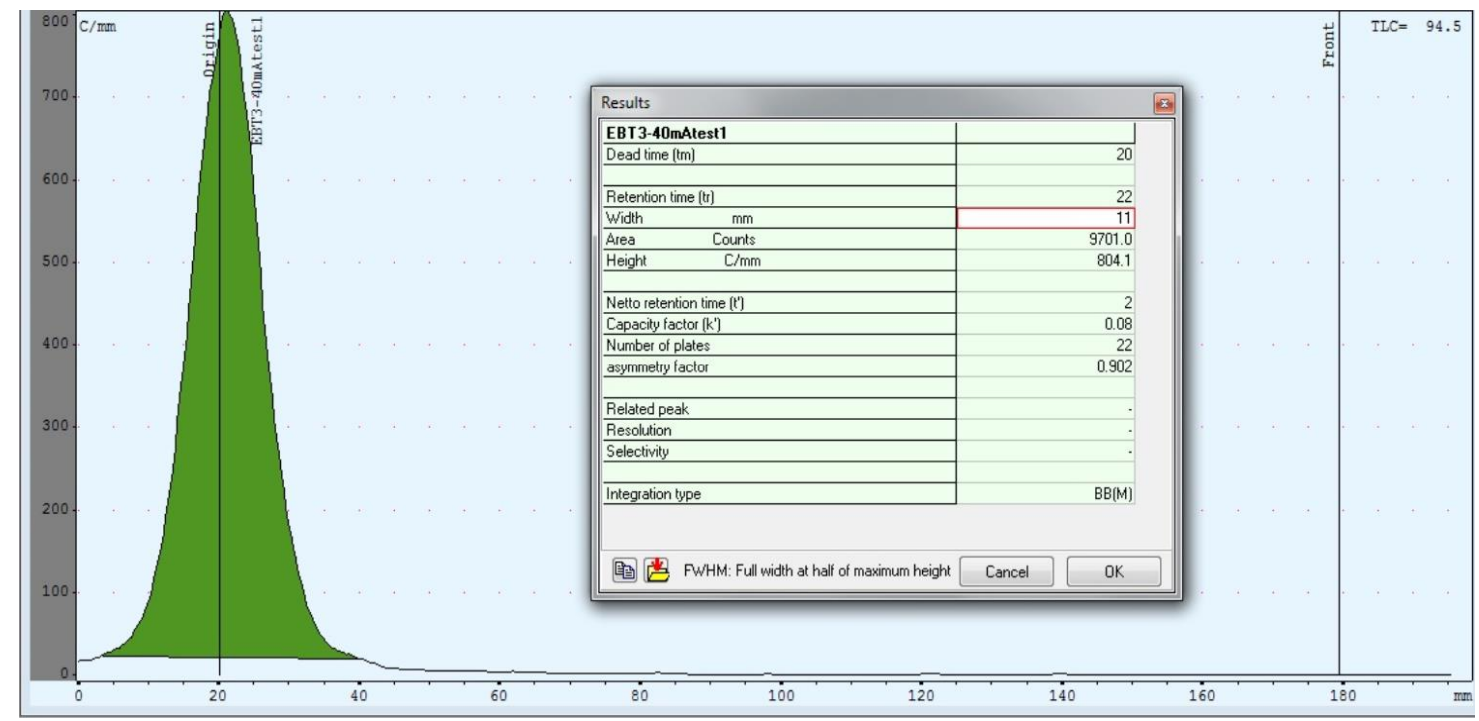

Figura 5.12. Espectro de distribución de radiactividad en la película EBT3 con un valor en corriente en la fuente de iones de $40 \mathrm{~mA}$. 


\subsection{Parámetros que influyen en el perfil del haz.}

\section{Intensidad de la corriente. Fuente de iones 1}

El tamaño promedio de haz (línea solida) para un tiempo de irradiación de 3 segundos a corrientes variables fue de $(10 \pm 1) \mathrm{mm}$ (figura 5.13). Los dos primeros puntos (5 y $10 \mathrm{~mA}$ ) corresponden a diámetros del haz para la fuente de iones 1 .

\section{Tamaño de haz vs Corriente}

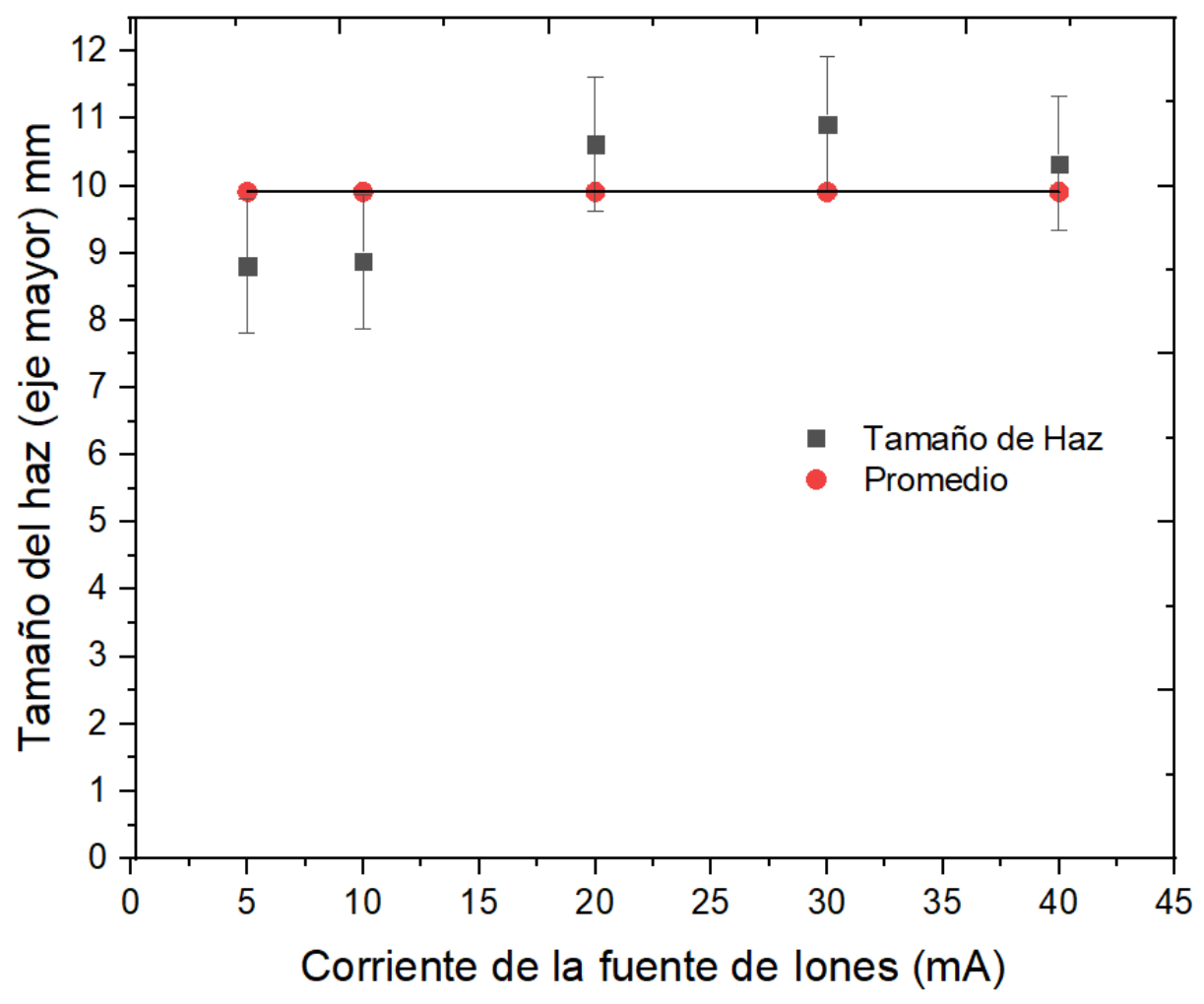

Figura 5.13. Los parámetros de irradiación considerados en todas las pruebas fueron: $34 \mathrm{kV}$ para la radiofrecuencia, $89.2^{\circ}$ para posición del sistema de extracción de haz, 137.78 A para la corriente en el imán a un vacío de $1.4 \times 10^{-5}$ mbars. 


\section{Fuente de iones 2}

La figura 5.14 muestra la tendencia de tamaño de haz que permanece constante $(10.5 \pm 0.5) \mathrm{mm}$. Todas las irradiaciones se realizaron utilizando la fuente de iones 2 .

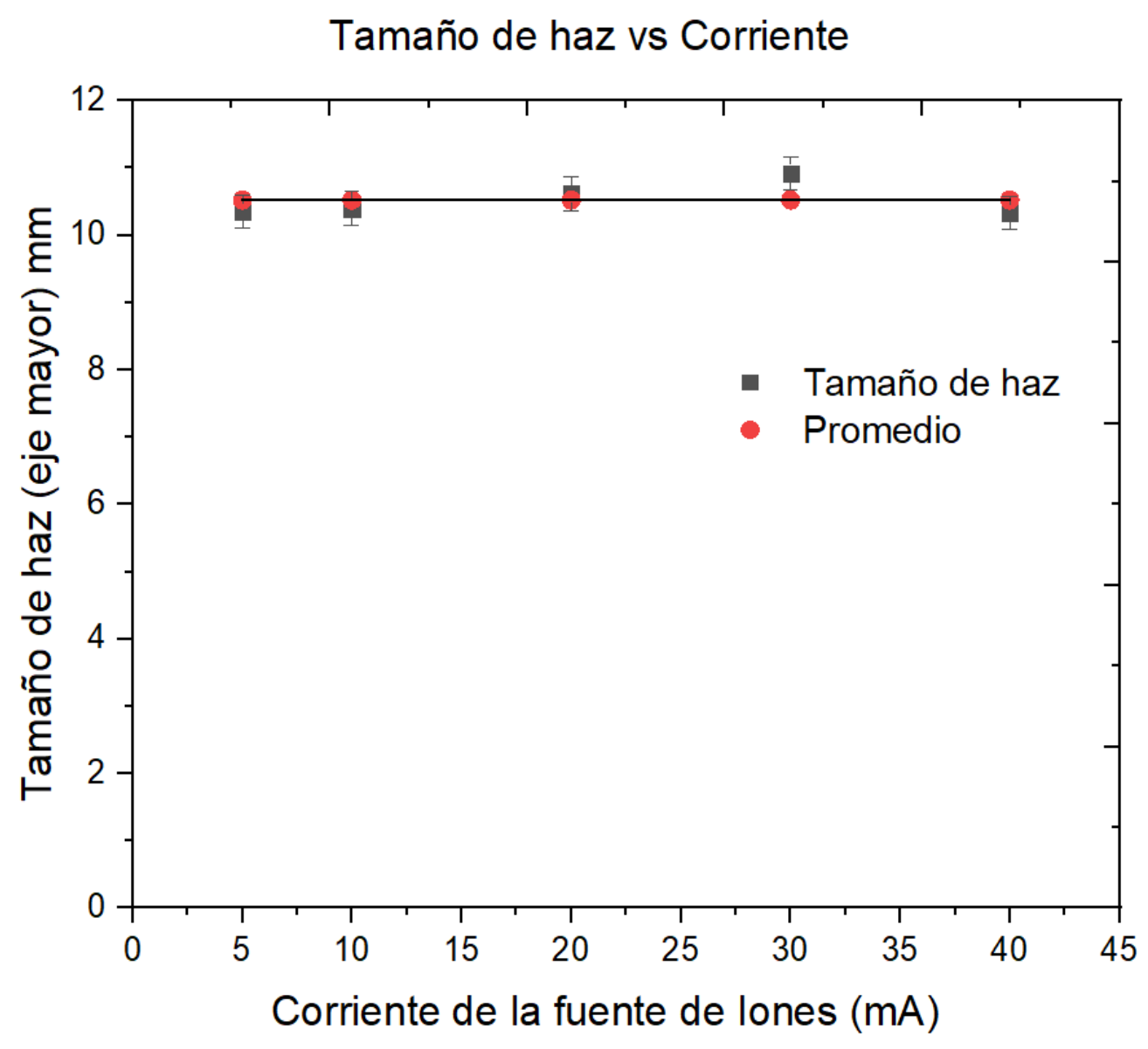

Figura 5.14. Tamaño de haz en función de la corriente. El vacío en todas las irradiaciones fue de 1.4 $\mathrm{x} 10^{-5}$ mbars. 


\section{Tiempo de Irradiación}

Como se muestra en el grafico 5.15, el tamaño de haz permanece constante a una corriente fija de 10 $\mathrm{mA}$ en un determinado intervalo de tiempo. El tamaño promedio de haz resultó ser de $(10 \pm 0.5) \mathrm{mm}$.

Tamaño de haz vs Tiempo

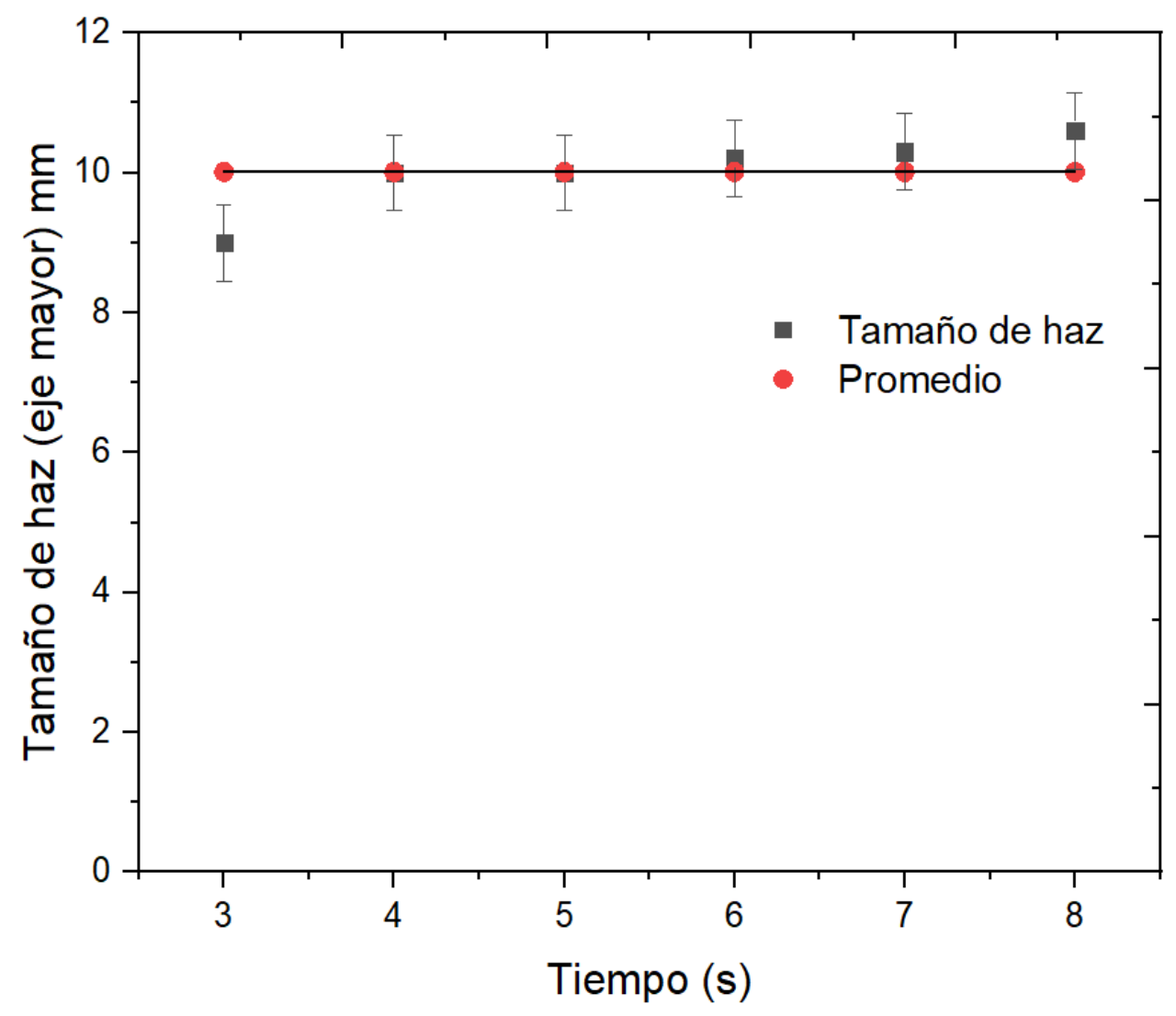

Figura 5.15. Tamaño de haz utilizando la fuente de iones 2 


\section{Vacío}

Para un tiempo de irradiación de 3 segundos, a una corriente de $10 \mathrm{~mA}$ en la fuente de iones, el tamaño de haz presenta variación por arriba de $1.6 \times 10^{-5}$ mbars. Dicho tamaño permanece constante (10.30 \pm 0.06$) \mathrm{mm}$ hasta un vacío de $1.1 \times 10^{-5}$ mbars.

Tamaño de haz vs Vacío

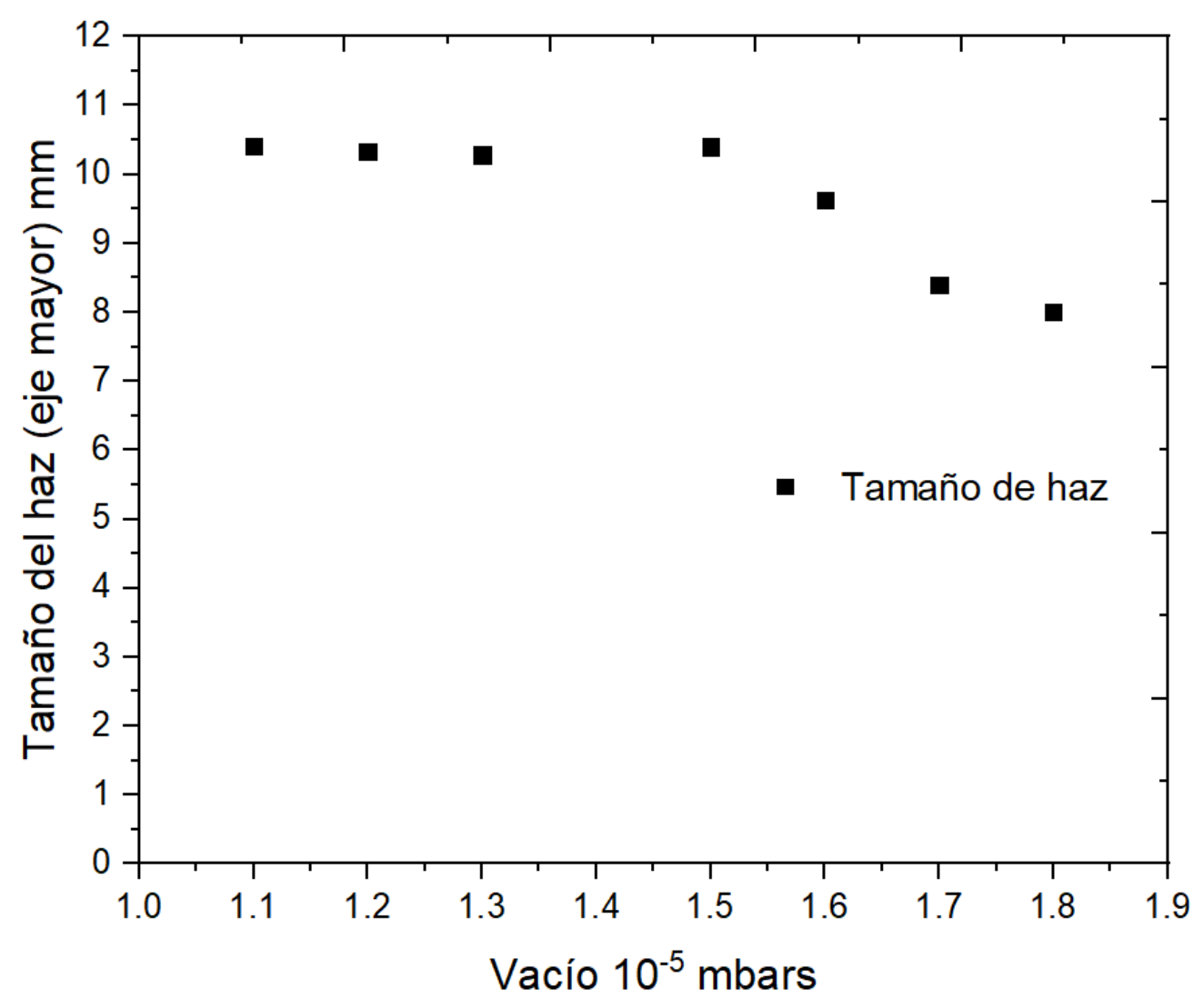

Figura 5.16. Variación de tamaño de haz con respecto al vacío. 


\subsection{Cálculo de la dosis absorbida}

El cálculo del poder de frenado se realizó analíticamente con lo descrito en el anexo A y con el software SRIM. La fluencia fue estimada a partir de la diferencia de corriente efectiva que se registraba en el target con y sin película (tabla 5.1). En el anexo B se muestran los resultados de las dosis para las pruebas de vacío, tiempo e intensidad de corriente.

Tabla 5.1 Parámetros obtenidos para el cálculo de la dosis de entrada en la película EBT3

\begin{tabular}{|c|c|c|c|}
\hline \multicolumn{4}{|c|}{$\begin{array}{l}\text { Haz de protones de } 18 \mathrm{MeV}, v=58 \times 10^{6} \mathrm{~m} / \mathrm{s} \\
\text { Material: Mylar }\left(1.397 \mathrm{~g} / \mathrm{cm}^{3}\right)\end{array}$} \\
\hline $\begin{array}{c}\text { Corriente en } \\
\text { fuente de } \\
\text { iones }(\mathrm{mA})\end{array}$ & $\begin{array}{c}\text { Corriente Efectiva } \\
(\mu \mathrm{A})\end{array}$ & $\begin{array}{c}\text { Poder de } \\
\text { Frenado Teórico } \\
\left(\mathrm{MeV} /\left(\mathrm{mg} / \mathrm{cm}^{2}\right)\right.\end{array}$ & $\begin{array}{l}\text { Poder de frenado con SRIM } \\
\left(\mathrm{MeV} /\left(\mathrm{mg} / \mathrm{cm}^{2}\right)\right.\end{array}$ \\
\hline 5 & 0.75 & \multirow[t]{5}{*}{25.88} & \multirow[t]{5}{*}{26.77} \\
\hline 10 & 1.28 & & \\
\hline 20 & 2.44 & & \\
\hline 30 & 4.06 & & \\
\hline 40 & 5.80 & & \\
\hline
\end{tabular}

\subsection{Tamaño de haz en diversos materiales}

El tamaño de haz para el caso de acetato, opalina y papel común resultó de $12 \mathrm{~mm}$. Para el caso de la ventana de titanio dicho tamaño resultó ser $1 \mathrm{~mm}$ más grande.

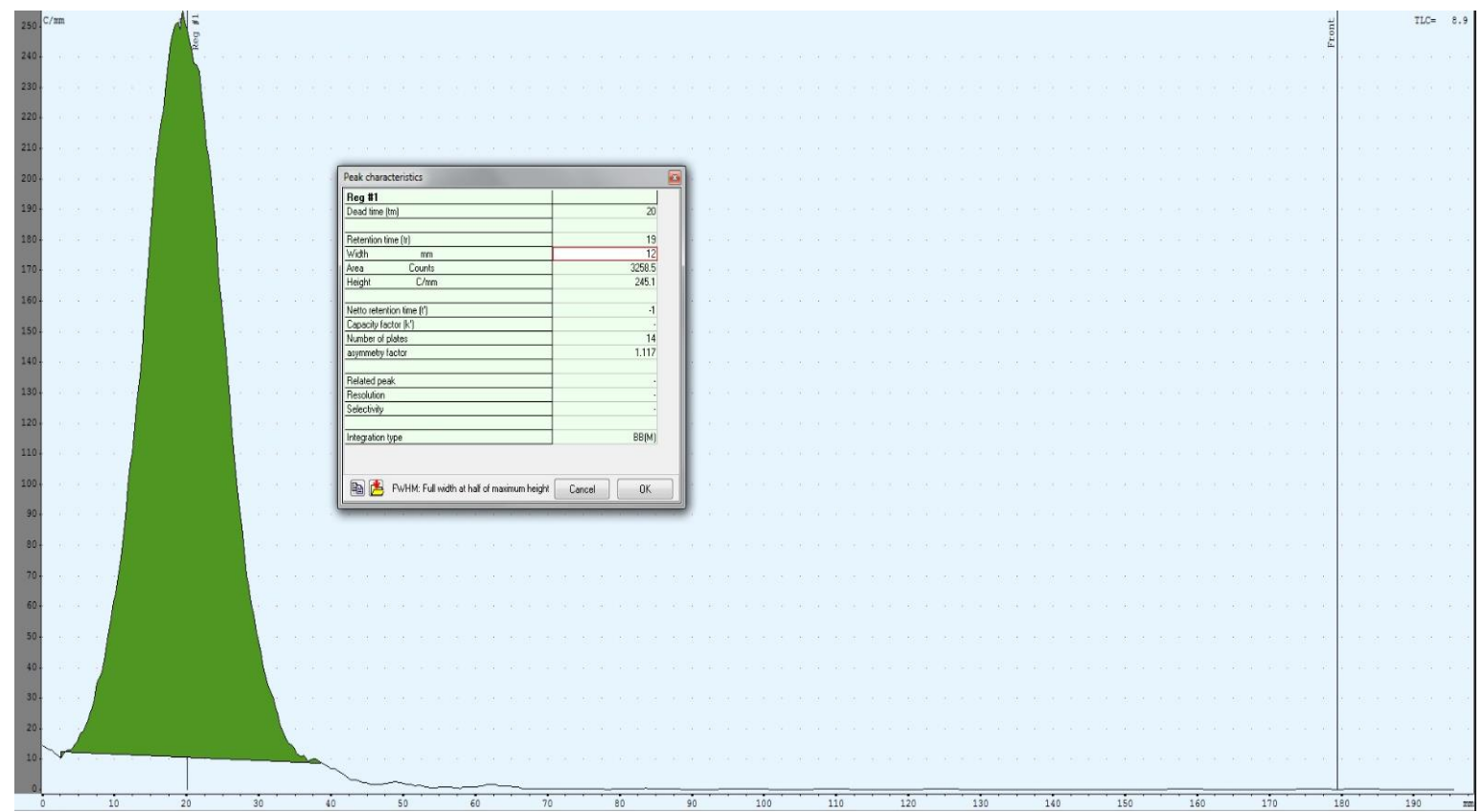

Figura 5.17.Espectro de distribución de actividad de ${ }^{13} \mathrm{~N}$ sobre acetato. El área corresponde a 3258.5 cuentas con un FWHM de $12 \mathrm{~mm}$. 


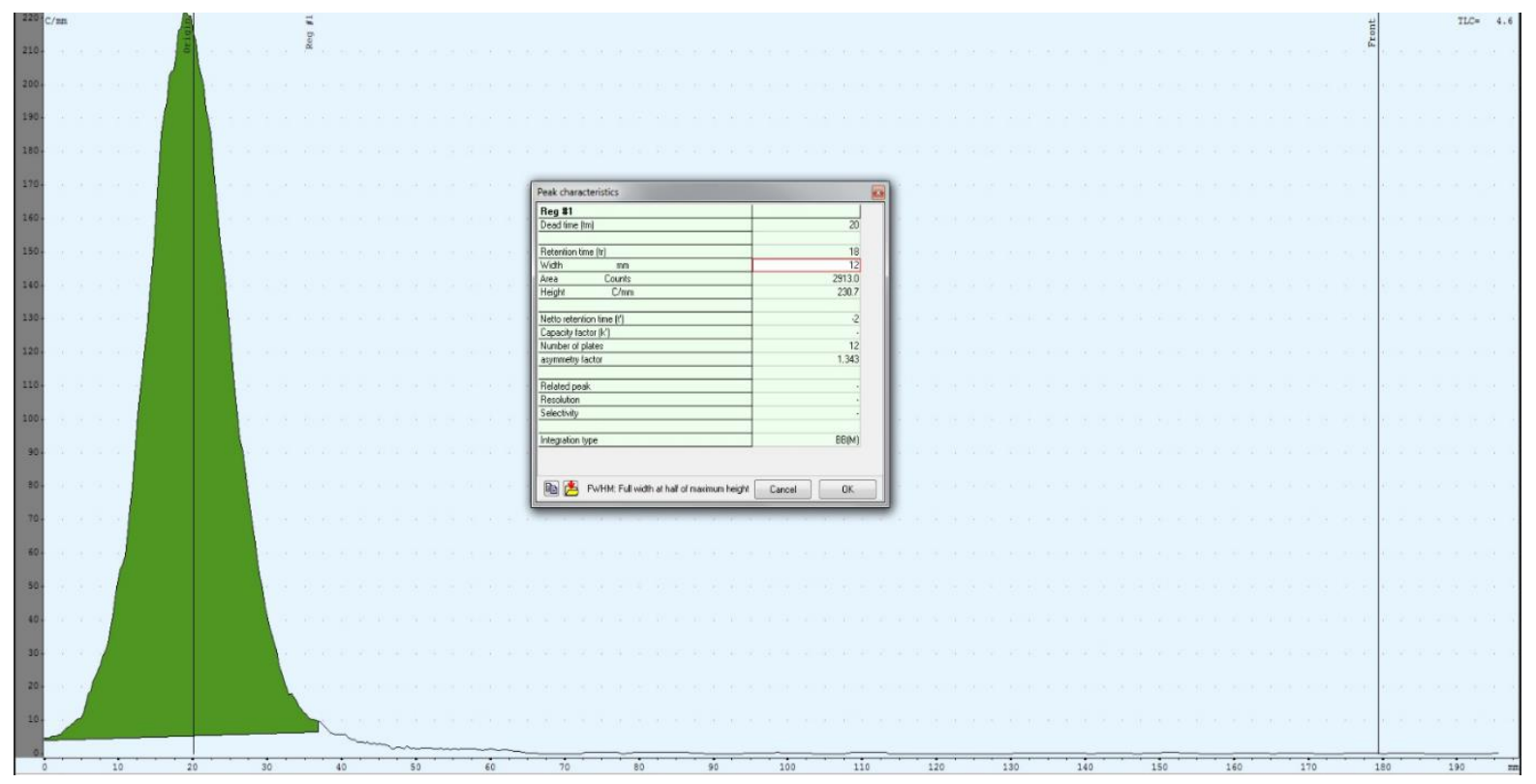

Figura 5.18. Perfil del haz sobre opalina. Con 2913 cuentas de área neta, el FWHM corresponde a 12 $\mathrm{mm}$.

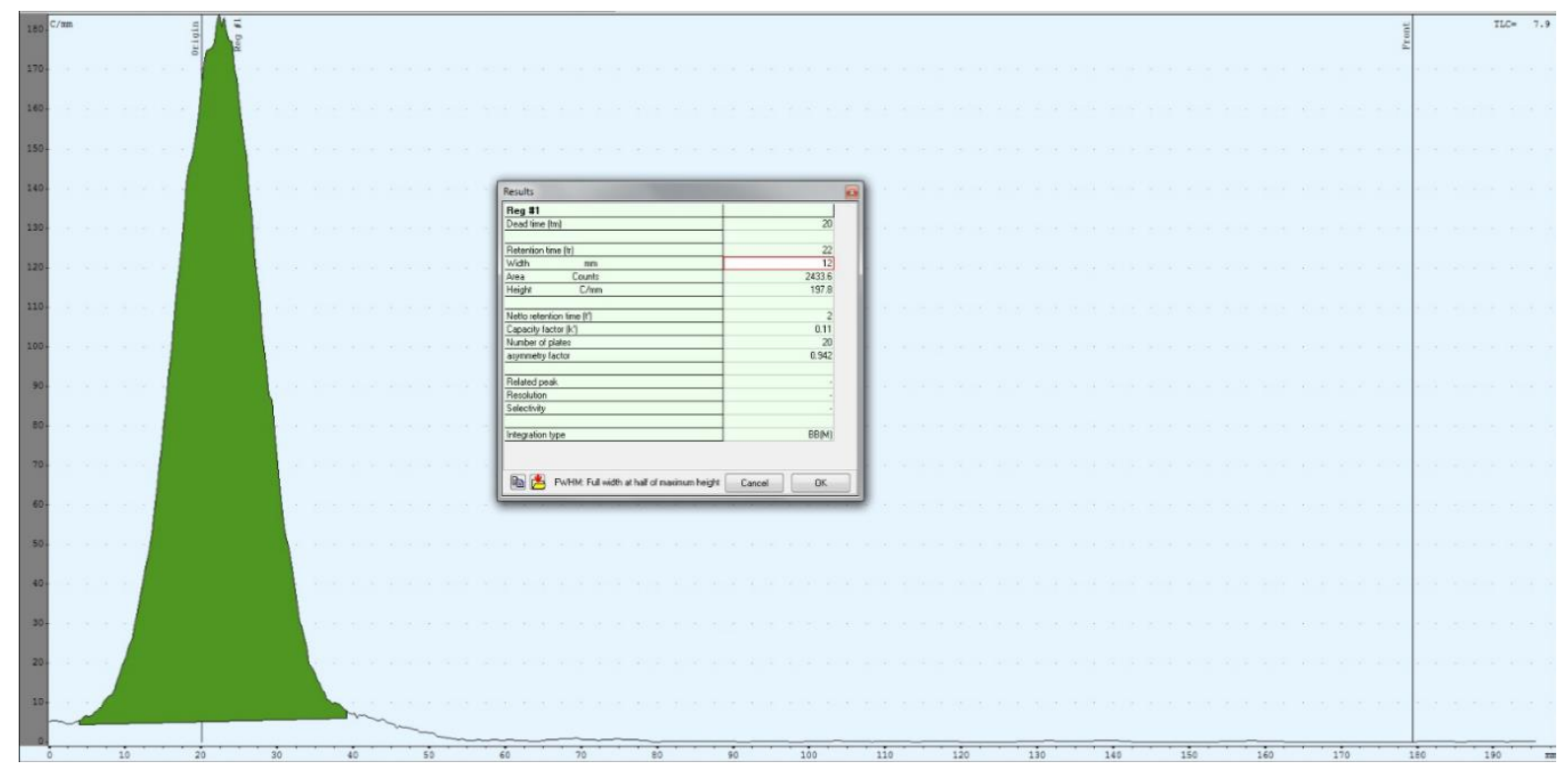

Figura 5.19. Prueba de haz sobre una superficie de papel. La superficie neta de la distribución corresponde a 2433 cuentas con un FWHM de $12 \mathrm{~mm}$. 


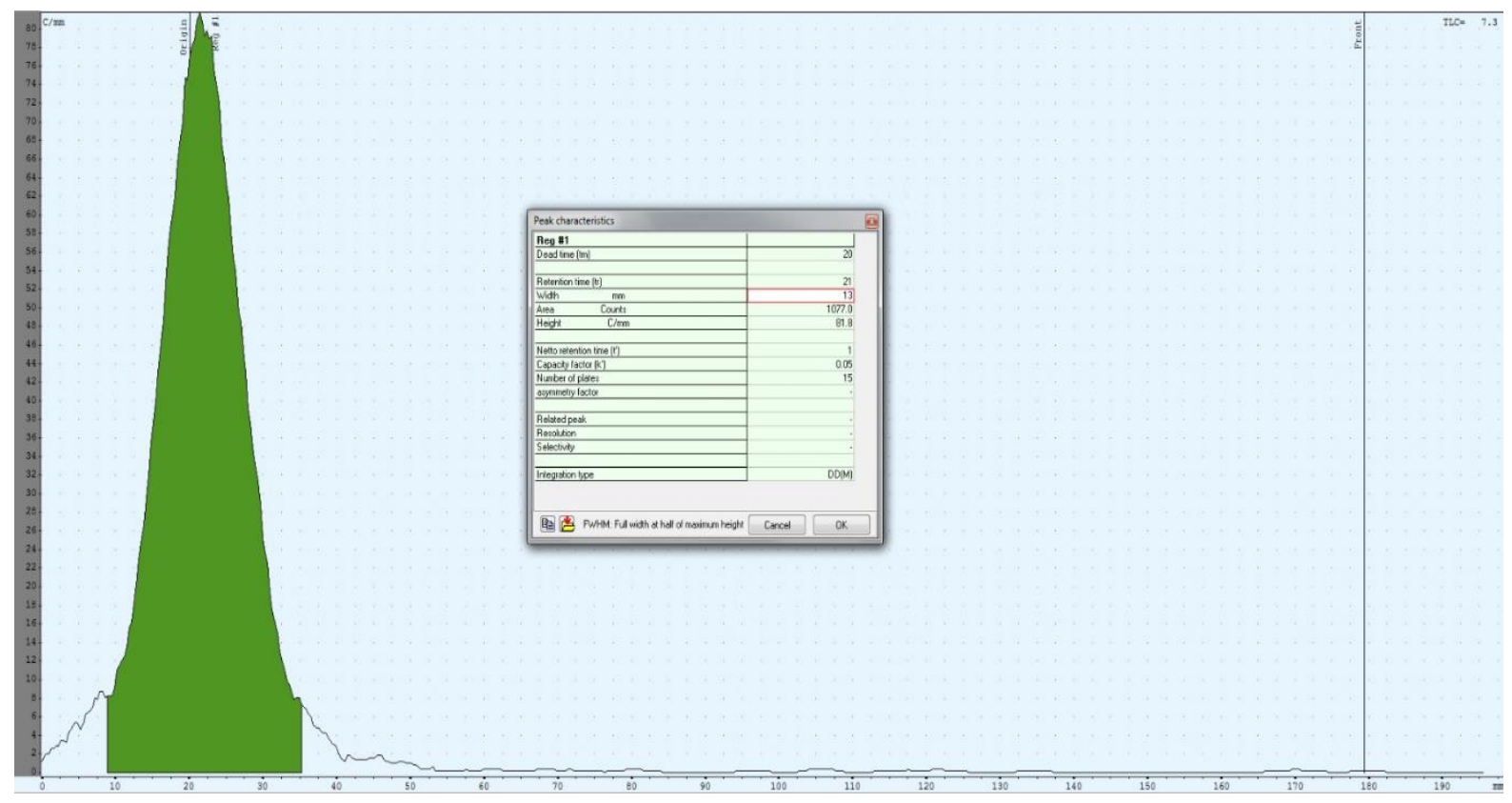

Figura 5.20. Prueba de haz sobre una ventana de titanio. El área neta del perfil de haz corresponde 1077 cuentas. El FWHM fue de $13 \mathrm{~mm}$. Una variación de $1 \mathrm{~mm}$ de tamaño de haz indica la forma de interacción del haz de partículas con el material blanco. La rapidez de exposición (a contacto) resultó al final de la prueba de $65 \mathrm{mR} / \mathrm{h}$. Este material no es práctico si se desea obtener de forma directa el tamaño de haz ya que permanece activo por más tiempo. (Asumiendo que la composición de la lámina es de titanio puro, la reacción posible para su activación es ${ }^{48} \mathrm{Ti}(\mathrm{p}, \mathrm{n}){ }^{48} \mathrm{~V}$, este radio-vanadio con una vida media de 16 días). 


\section{Discusión}

De acuerdo a la técnica con lector de tiras de TLC, el tamaño promedio del haz de protones (eje mayor) para las pruebas de variación de vacío, tiempo e intensidad de corriente y de diversos materiales es de $12 \mathrm{~mm}$ acorde al FWHM de la distribución del perfil obtenido de la activación de la película EBT3.

El tamaño promedio del ancho del haz mediante la digitalización de las películas y análisis en imageJ resultó ser de $(10 \pm 1) \mathrm{mm}$. El tamaño de haz no se ve modificado ni a tiempos ni corrientes variables. Donde sí se presenta variación significativa de dicho tamaño es para irradiaciones donde el valor del vacío sea bajo. Se encontró que para un vació de $1.8 \times 10^{-5}$ mbars, el tamaño de haz fue de $8 \mathrm{~mm}$. Esto se traduce en una mala transmisión de haz dado que se tiene una mayor cantidad de partículas en el interior de la cámara de aceleración y que interactúan con los iones de $\mathrm{H}$.

Tres parámetros que deben ser considerados en cuenta para pruebas con filmes son: tiempo, intensidad de corriente y vacío. Para tiempos mayores a 10 segundos, se presentaba una pérdida de vacío dado que el haz lograba perforar la película. A un tiempo de irradiación de 3 segundos con una corriente menor a $5 \mathrm{~mA}$, no se visualizaba la proyección del haz sobre la película por lo que dificultaba que en su digitalización también se percatara dicho perfil. Para una corriente mayor a $40 \mathrm{~mA}$, se presentaba también un daño a la película.

El Ciclotrón del INCan al ser un modelo 18/9 cuenta con 2 fuentes de iones: una para protones y otra para deuterones. En este equipo se tiene instaladas dos fuentes para protones. Al comienzo de las pruebas, se comenzó a trabajar con una de estas fuentes y para esto, el tamaño promedio del haz fue de aproximadamente $8 \mathrm{~mm}$. Posteriormente al mantenimiento del equipo, se tuvieron dos fuentes más de iones. Los tamaños reportados para estas fuentes fueron de $(9 \pm 0.1) \mathrm{mm}$ y $(10 \pm 1) \mathrm{mm}$ respectivamente. La variación de tamaño de haz con respecto a la fuente que se esté utilizando en ese momento se relaciona con la corriente efectiva que marque la punta de prueba antes de iniciar la irradiación. Una mala calidad de haz o restos de material producto del mismo desgaste de los cátodos modifica la corriente final que formará el haz de radiación. Para una irradiación de $10 \mathrm{~mA}$ en la fuente de iones 1 , la punta de prueba registró una corriente efectiva de $2.12 \mu \mathrm{A}$ y el beam dump de $0.75 \mu \mathrm{A}$. Para la fuente de iones 2, la punta registró una corriente de $2.59 \mu \mathrm{A}$ con $1.28 \mu \mathrm{A}$ en el beam dump.

El tamaño máximo de haz que se registra para la fuente actual de iones es de $11 \mathrm{~mm}$. Ávila- Rodríguez [Avila et al., 2009] realiza un procedimiento similar para la obtención de perfiles del haz de radiación en un Ciclotrón TR19/9 en el centro de cáncer Edmonton, Canadá. A comparación del método desarrollado en este trabajo, se irradian materiales como $\mathrm{Cu}$ y $\mathrm{Nb}$ a una energía de $15 \mathrm{MeV}$ con $15 \mu \mathrm{A}$ durante 5 minutos para posteriormente empalmar dichas laminillas de espesor $25 \mu \mathrm{m}$ sobre placas de películas EBT. Su correspondiente digitalización se realiza en un escáner de reflexión a 600 dpi a 8 bits. El tamaño que se reporta para el haz es de $19.7 \mathrm{~mm}$ y $9.6 \mathrm{~mm}$ para el eje mayor y menor respectivamente de la "elipse" formada. En este trabajo se decidió utilizar las películas EBT3 de última generación para evitar la formación de los anillos de Newton.

Tamburella [Tamburella et al., 2008], realiza una caracterización del haz de protones en un equipo similar al empleado en este trabajo. La forma del haz cuya posición de centrado es vital cuando se trabajan con blancos sólidos, la reportan con la emitancia de haz. También reportan la variación en mm ( $<1 \mathrm{~mm}$ ) que debe tener el haz en la posición vertical para no dañar y activar al colimador del blanco. Esto se puede corroborar al momento de realizar un tuning de haz, cuidando que el cociente de la corriente en el target y el colimador no sea mayor $15 \%$. 
La digitalización de las películas se realizó 24 horas después de la irradiación en un escáner de transmisión dado que en uno de reflexión no se visualizaba directamente la proyección del haz sobre la película. Los parámetros de escaneo que permitieron mostrar la forma del haz fueron: 400 dpi a 48 bits. No se tomó en cuenta la caracterización de los propios filmes dado que el objetivo no fue la cuantificación y/o verificación de dosis pero si del escáner para asegurar la uniformidad de la respuesta entre lecturas. Sansaloni [Sansaloni et al., 2012] obtiene perfiles de haz para un Ciclotrón IBA 18/9 $\mathrm{MeV}$ haciendo uso de películas EBT2. De igual manera, se irradian diferentes laminillas de Al con diferentes espesores que posterior a su activación son colocadas sobre las películas. La forma del perfil de haz que se encuentra corresponde al mismo patrón elipse formado. La tendencia del haz a presentar esta forma elíptica puede corresponder a la influencia del campo magnético en el eje vertical del haz de radiación haciendo que se tenga un ligero "aplanado" y que posea un menor tamaño comparado con el eje horizontal. Los tamaños de haz para el eje menor se muestran en el anexo C. El tamaño promedio para este eje fue de $(6 \pm 0.1) \mathrm{mm}$. No presenta variación ni a tiempos y corrientes variables.

Ahora bien, con los productos de activación de los filmes al término de la irradiación $\left({ }^{13} \mathrm{~N}, \mathrm{t}_{1 / 2} \sim 10 \mathrm{~min}\right)$, $\dot{\mathrm{X}} \sim 140 \mathrm{mR} / \mathrm{h}$ (a contacto) se encontraron distribuciones de actividad sobre su superficie mediante un lector de cromatografía de capa fina. Para todas las pruebas descritas, el tamaño de haz máximo que se registró fue de $12 \mathrm{~mm}$ al igual que las pruebas con los diferentes materiales alternos. Este método que se propone como una nueva forma de estimar el tamaño de haz es confiable porque el perfil se reconstruye a partir de los datos procesados (cuentas) de la región de activación o el área en donde impacta directamente el haz; es decir que no se utilizaron degradadores de haz.

Con algunas pruebas mediante el lector de tiras de TLC, el FWHM resultó ser máximo de $11 \mathrm{~mm}$ correspondiente a pruebas con un vacío cercano a $1.8 \times 10^{-5}$ mbars. El máximo tamaño de haz con técnica con un lector de tiras de TLC que fue $1 \mathrm{~mm}$ más grande que con la técnica de digitalización se debe solamente a la activación de la película más allá del área en donde impacta el haz por dispersión del mismo. En la figura 6.15a, se muestra el perfil de haz de protones en el Ciclotrón IBA 18/9 MeV. La figura 5.18B muestra el perfil de haz de protones en un ciclotrón SIEMENS eclipse HP de $11 \mathrm{MeV}$
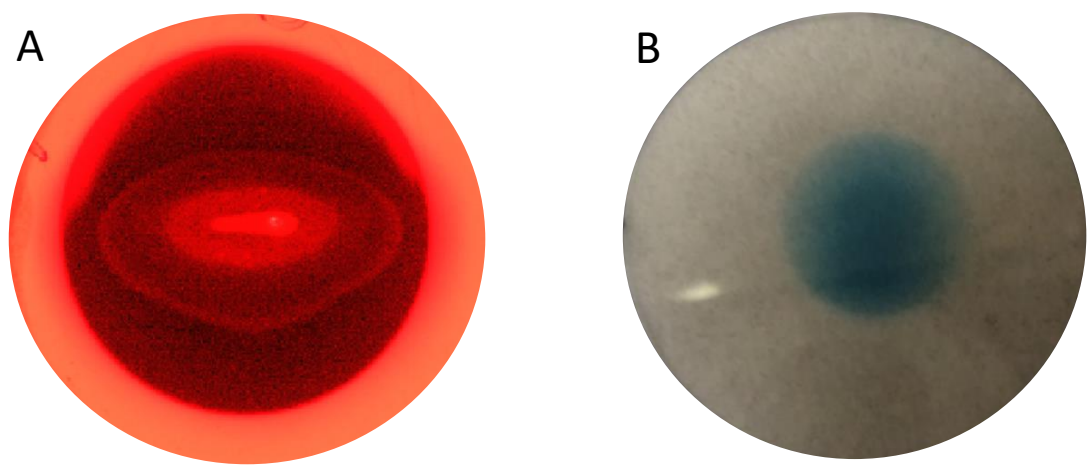

Figura 5.18. A) perfil elipsoide de un haz de protones sin degradador de haz. B) perfil obtenido de manera indirecta utilizando materiales degradadores de haz expuestos sobre una película. Imagen tomada de [Cárcamo, 2013]. 
Para el caso de la comprobación de tamaño de haz en el eje menor del perfil, no se tomaron medidas mediante el lector de tiras de TLC dado que se presentaba una pérdida de información de actividad en la película. El tiempo de vida media del producto de activación es de aproximadamente $10 \mathrm{~min}$. El proceso de desmonte del blanco de prueba y traslado a control de calidad de la película tomaba un tiempo aproximado de 7 minutos. El tiempo de escaneo en el lector fue de 2 minutos. La información obtenida en el perfil de distribución de haz pasado el tiempo de vida media, resultó en un FWHM menor a lo encontrado mediante digitalización y análisis en imageJ por lo que representaba pérdida de información.

En el anexo B se muestran los valores de las dosis absorbidas en los filmes. La caracterización de un haz de irradiación en un Ciclotrón involucra el centrado de haz, medición del perfil y energía. Vadrucci [Vadrucci et al., 2015] realiza una calibración de películas EBT3 con un haz de protones de $5 \mathrm{MeV}$ en un equipo de protonterapia con el objetivo de implementar un sistema de dosimetría para estudios radiobiológicos. La dificultad de implementarse en un Ciclotrón es el desconocimiento de la tasa de dosis con la que se está irradiando, pero con el cálculo estimado de la dosis que absorbe la película se podría comenzar con la caracterización de películas a altas energías y la dependencia que tendría en el cálculo como: LET, región de Bragg etc.

Una de las ventajas del método propuesto en este trabajo es que resulta adecuado y económico ya que con las pruebas de irradiación de distintos materiales se puede utilizar papel común y corriente. Marcas como GE e IBA utilizan la quema de papel para corroborar el centrado de haz. El utilizar películas de tinte radiocrómico ayuda de una mejor manera el obtener las dimensiones del perfil siempre y cuando se disponga de un escáner de transmisión para su digitalización. El utilizar papel común para obtener las dimensiones del haz requerirá de la utilización de un escáner de tiras de TLC.

Ahora bien, el tener un máximo tamaño de haz permitirá conocer la región de electrodeposición para el caso de la irradiación de blancos sólidos. Tomemos como caso la obtención del radio metal ${ }^{64} \mathrm{Cu}$ a partir de la irradiación de ${ }^{64} \mathrm{Ni}$ enriquecido. $\mathrm{El}{ }^{64} \mathrm{Cu}$ suele ser un importante agente teranóstico para algunos tipos de lesiones cancerígenas. Su función de excitación es favorable dado que la mayor probabilidad de producción se encuentra en un rango de energías de 10 a $12 \mathrm{MeV}$ teniéndose un incremento en el rendimiento para blancos menores a $100 \mathrm{mg} / \mathrm{cm}^{2}$. Conocer el tamaño máximo del haz de protones al cual impactará al blanco electrodepositado de ${ }^{64} \mathrm{Ni}$ implica una buena optimización de dicha superficie dado que el costo de este blanco suele ser de aproximadamente US \$25/mg debido a su abundancia natural de solo $0.925 \%$ [Valdovinos, 2017].El aumento del rendimiento se traduce a no tener pérdida del haz (corriente) al momento de realizar la estimación de la actividad esperada. 
Se obtuvieron los parámetros necesarios de tuning de haz en un ciclotrón IBA 18/9 MeV para garantizar el correcto centrado de haz lo que permitirá tener la máxima probabilidad de producción al momento de irradiar cualquier material blanco.

La caracterización de un haz de protones incluye primeramente el conocimiento del tamaño de haz por lo que se debe considerar los siguientes puntos:

La dimensión del haz se puede obtener irradiando prácticamente cualquier material (a excepción de la ventana de titanio) ya que mediante su activación puede obtenerse un perfil de distribución de actividad en un lector de cromatografía de capa fina como resultado del impacto directo de haz

El uso de las películas EBT3 como un material para verificar el tamaño de haz tiene especial ventaja dado que mediante su digitalización en un escáner de transmisión el análisis mediante imageJ facilita una mejor visualización del perfil obtenido. Con las pruebas de vacío, tiempo de irradiación y variación de intensidad de corriente se comprueba que existe un máximo tamaño de haz además de un correcto centrado.

Es necesario en caso de optar por películas EBT3, contar con un escáner de transmisión. Si se tiene disponible un escáner convencional, el patrón perfil formado es complicado de visualizar.

Puede obtenerse un perfil elipsoide más definido sobre papel común. A comparación de las películas donde se tiene un autorevelado por la indicencia de la radiación en su capa activa, el perfil en papel se logrará visualizar si se aumenta la intensidad de corriente a un tiempo mínimo (es decir $40 \mathrm{~mA}$ en la fuente de iones a 3 segundos).

Estas nuevas técnicas tienen especial ventaja sobre el uso de degradadores de haz en cuanto al costo que se requiere para adquirir tales laminillas. 


\section{ESTIMACIÓN DE LA DOSIS ABSORBIDA EN PELICULAS EBT3 DEBIDA A UN HAZ DE PROTONES DE 18 MEV EN UN CICLOTRÓN IBA 18/9 MEV}

\section{Calculo de la velocidad del haz de protones}

En un ciclotrón, la partícula sometida a aceleración en un potencial oscilante bajo la acción de un campo magnético se rige por la fuerza de Lorenz dada por:

$$
F_{L}=q v B=\frac{m v^{2}}{r}
$$

Donde:

$q=$ carga de la partícula

$v=$ velocidad máxima del haz de partículas

$B=$ campo magnético

$m=$ masa de la partícula

$r$ =radio de la órbita de la partícula en una revolución

Considerando la trayectoria o ciclo final de la partícula, el radio de la órbita corresponderá ahora al radio del electrodo o de la Dee, de esta manera partiendo de la ecuación (1) se tiene que:

$$
R=\frac{\sqrt{2 m E_{k}}}{q B}
$$

Primeramente se necesita conocer la ganancia de energía cinética de la partícula en cada proceso de aceleración para obtener la energía final adquirida que se requerirá para llevar a cabo la reacción nuclear en el blanco.

La ganancia de energía está descrita como:

$$
\Delta E_{K}=V_{D E E} N \bullet q \bullet \operatorname{sen}\left(\frac{h \varphi}{2}\right)
$$

En el caso del ciclotrón IBA 18/9 MeV se tiene que:

$\mathrm{V}_{\text {DEE }}=$ voltaje de amplitud $(34 \mathrm{kV})$.

$\mathrm{N}=$ número de brechas de aceleración, para 2 Dees= 4 .

$\mathrm{q}=$ carga de la partícula (para electrones $\mathrm{q}=\mathbf{1}$ )

h= modo armónico (2).

$\phi=$ longitud azimutal $\left(\mathbf{3 0}^{\circ}\right)$. 
La ganancia de energía de la partícula cada vez que se acelera es de $\mathbf{6 0} \mathrm{keV}$. La energía cinética final del haz es de $18000 \mathrm{keV}$.

\section{Cálculo del radio de la Dee}

Consideremos los valores para la carga y masa del protón. El valor de la energía cinética final del haz de protones en $\mathrm{MeV}$ es transformado a valores de energía expresados en Joules.

$q=1.602 \times 10^{-12} \mathrm{C}$

$\boldsymbol{m}=1.62726 \times 10^{-27} \mathrm{Kg}$

$\boldsymbol{B}=1.3 \mathrm{~T}$

$\boldsymbol{E}=2.88 \times 10^{-12} \mathrm{~J}$

De la relación (2), el radio de la Dee es de aproximadamente $47 \mathrm{~cm}$.

Calculo de la velocidad del haz de partículas

De la relación (1) se tiene una expresión inmediata para la velocidad:

$$
v=\frac{q B R}{m}
$$

Tomando los mismos valores para la carga y masa del protón en un campo magnético, la velocidad del haz de protones justo antes de impactar el blanco es de $\mathbf{5 8 . 5 2} \times \mathbf{x 1 0}$ m/s.

\section{Unidades dosimétricas}

Dosis absorbida. La dosis absorbida en cualquier punto $\mathrm{P}$ de un determinado volumen de masa $m$ se define como el cociente del valor esperado de la energía impartida por unidad de masa. La unidad de dosis es el gray $[\mathrm{J} / \mathrm{kg}]$.

$$
D=\frac{d \bar{\varepsilon}}{d m}
$$

Fluencia. Sea $\mathrm{N}$ el número de rayos impactando una esfera finita en un punto $\mathrm{P}$ durante un intervalo de tiempo. Si dicha esfera se reduce infinitesimalmente en ese mismo punto con área $d a$, entonces la fluencia es [Attix, 1986]:

$$
\phi=\frac{d N}{d a}
$$

La unidad de la fluencia se cuantifica en número de partículas $/ \mathrm{cm}^{2}$

Exposición. Es definida en el reporte ICRU de 1980 como el cociente de $d Q$ por $d m$, donde el valor de $d Q$ es el valor absoluto de la carga total de los iones de un solo signo producidos en una masa de aire, cuando los electrones liberados por partículas sin carga son frenados totalmente. 


$$
X=\frac{d Q}{d m}
$$

La unidad tradicional, el Roentgen $(\mathrm{R})$, se define como la cantidad de radiación electromagnética necesaria para producir una unidad electrostática de carga en $1 \mathrm{~cm}^{3}$ de aire en condiciones normales de presión y temperatura [Azorín, 2010].

Poder de Frenado. Es el valor esperado de la rapidez de pérdida de energía por unidad de longitud debido a una partícula cargada $\mathbf{Y}$ y energía cinética $\mathbf{T}$, en un medio de número atómico $\mathbf{Z}$. Dividiendo el poder de frenado por la densidad del medio absorbente se obtiene el denominado poder de frenado másico $\left[\mathrm{Jm}^{2} / \mathrm{kg}\right]$. La expresión para partículas cargadas (fórmula de Bethe) es:

$$
\left(\frac{d T}{\rho d x}\right)=0.3071 \frac{Z z^{2}}{A \beta^{2}}\left[13.8373+\operatorname{In}\left(\frac{\beta^{2}}{1-\beta^{2}}\right)-\beta^{2}-\operatorname{In}(I)\right]
$$

Dónde: $z$ representa la carga de la partícula incidente sobre el material, $Z$ el número atómico del absorbedor, $\beta=v / c$ como la fracción correspondiente de la velocidad de la partícula incidente con respecto a la velocidad de la luz e I es valor promedio de los potenciales de ionización y excitación de un átomo en el medio absorbedor [Attix, 1986].

\section{Calculo del poder de frenado}

El poder de frenado es el valor esperado de la rapidez de perdida de energía por unidad de longitud de una partícula cargada $\mathbf{Y}$, con una energía cinética $\mathbf{T}$ en un determinado medio de número atómico $\mathbf{Z}$. Cuando se habla del poder de frenado másico, se hace referencia al cociente del poder de frenado y el valor de la densidad del medio absorbedor. Sus unidades son: $\left[\mathrm{MeV} \mathrm{cm}^{2} / \mathrm{g}\right]$.

Debido al tipo de interacciones o colisión, el poder de frenado se divide en dos: poder de frenado radiativo y poder de frenado por colisión. El primero hace referencia basándose solo en la producción de bremsstrahlung que es despreciable para medios de $\mathrm{Z}$ bajo.

Para el poder de frenado por colisión, éstas a su vez, en base a la interacción coulombiana que puede llevar a cabo la partícula cargada cerca del núcleo o no (parámetro de impacto), se clasifican en colisiones suaves (soft) y fuertes (hard). De esta manera, el poder de frenado por colisión se expresa de la siguiente manera:

$$
\left(\frac{d T}{\rho d x}\right)_{c}=\left(\frac{d T_{s}}{\rho d x}\right)_{c}+\left(\frac{d T_{h}}{\rho d x}\right)_{c}
$$

El término colisión suave es obtenido en base a la aproximación de Bohr en el cual se asume que la velocidad de la partícula incidente (partículas pesadas o cargadas), $v=\beta c$ es mucho mayor que la velocidad de los electrones orbitales.

El término de Bethe para colisiones suaves es:

$$
\left(\frac{d T_{s}}{\rho d x}\right)_{c}=\frac{2 C m_{0} c^{2} z^{2}}{\beta^{2}}\left[\operatorname{In}\left(\frac{2 m_{0} c^{2} \beta^{2} H}{I^{2}\left(1-\beta^{2}\right)}\right)-\beta^{2}\right]=0.1535 \frac{Z z^{2}}{A \beta^{2}}\left[\operatorname{In}\left(\frac{2 m_{0} c^{2} \beta^{2} H}{I^{2}\left(1-\beta^{2}\right)}\right)-\beta^{2}\right] \frac{M e V}{g / c m^{2}}
$$


Donde:

$m_{0} c^{2}=$ masa en reposo del electrón

$\mathrm{H}=$ energía mínima entre colisiones suaves y fuertes en términos de la energía transferida al átomo o electrón en la interacción.

$\beta=$ cociente de la velocidad de la partícula incidente y el valor de la velocidad de la luz en el vacío.

I= potencial de ionización del medio

$\mathrm{Z} / \mathrm{A}=$ número de electrones por unidad de masa en el medio

z= carga de la partícula en cuestión

El término colisión fuerte dependerá del tipo de partícula incidente en el medio absorbedor. Se asume que la energía máxima que es transferida directamente en una colisión con un electrón atómico para una partícula pesada (por ejemplo protones), es mayor a la energía mínima que puede haber entre colisiones es decir:

$$
H<<T_{\max }=H<<2 m_{0} c^{2}\left(\frac{\beta^{2}}{1-\beta^{2}}\right)
$$

Por lo que el término de colisión es:

$$
\left(\frac{d T_{h}}{\rho d x}\right)_{c}=0.1535 \frac{Z z^{2}}{A \beta^{2}}\left[\ln \left(\frac{T_{\max }}{H}-\beta^{2}\right)\right]
$$

El poder de frenado másico total por colisiones es entonces:

$$
\left(\frac{d T}{\rho d x}\right)=2 \cdot 0.1535 \frac{Z z^{2}}{A \beta^{2}}\left[\ln \frac{2 m_{0} c^{2} \beta^{2}}{\left(1-\beta^{2}\right) I}-\beta^{2}\right]
$$

Se requiere calcular la perdida de energía promedio de un haz de protones de $18 \mathrm{MeV}$ impactando un medio material (película EBT3). La composición de dicha película se describe en el capítulo 4. El valor del poder de frenado másico se calcula para Mylar $\left(\mathrm{C}_{10} \mathrm{H}_{8} \mathrm{O}_{2}\right)$. Los parámetros para el cálculo se describen a continuación:

$\beta=v / c=0.19$

( Se consideran velocidades relativistas para $\beta>0.2$ )

$I=78.70 e V$ (Potencial de Ionización para Mylar), [Attix, 1986]

$Z / A=0.52$ (Densidad electrónica para Mylar). 
$m_{0} c^{2}=938.28 \mathrm{MeV}$ (Masa en reposo del protón).

El valor aproximado del poder de frenado másico debido a un haz de protones de $18 \mathrm{MeV}$ sobre la película EBT3:

$$
\left(\frac{d T}{\rho d x}\right)_{18 M e V} \approx 25.87 \frac{M e V c m^{2}}{g r}
$$

El cálculo del poder der frenado másico se corroboró con el software SRIM, una paquetería que permite la simulación de la interacción de iones en la materia. Tablas de poderes de frenado y gráficas de la simulación de daño a la materia son dos de sus principales funciones.

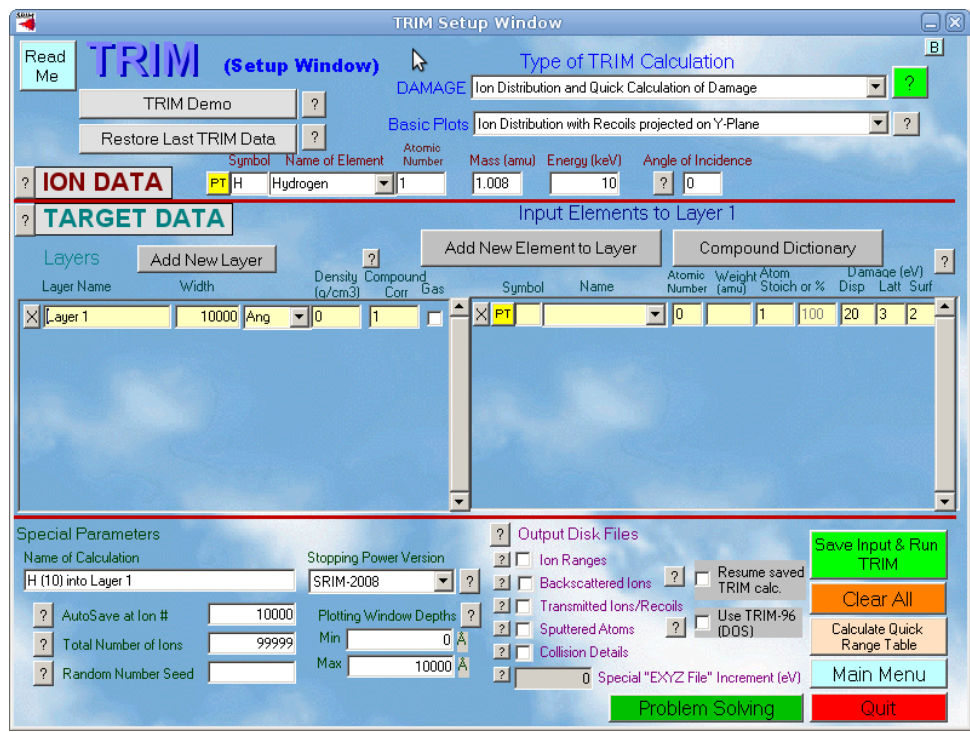

Figura 1.A. Software SRIM. 


\section{Calculo de la dosis absorbida}

Consideremos un haz de partículas cargadas de energía cinética $\mathbf{T}_{\mathbf{0}}$ perpendicular a un material de número atómico $\mathbf{Z}$ y considerando que el blanco es muy delgado se asume lo siguiente:

- El poder de frenado permanece constante a una energía cinética

- El flujo de partículas que atraviesan el material permanece constante, es decir, no hay dispersión.

- No se asume corrección por polarización o efecto de densidad

La pérdida de energía por colisión debido a una fluencia $\phi$ de partículas cargadas, de energía cinética T perpendicular al material target de espesor másico $\boldsymbol{\rho t}\left(\mathrm{g} / \mathrm{cm}^{2}\right)$ es:

$$
E=\phi\left(\frac{d T}{\rho d x}\right) \rho t\left(\frac{M e V}{c m^{2}}\right)
$$

Entonces la dosis absorbida puede ser obtenida dividendo (4.6) por unidad de masa y área del blanco

$$
D=\frac{\phi(d t / \rho d x) \rho t}{\rho t}=\phi\left(\frac{d T}{\rho d x}\right) \quad \text { Gy }
$$

\section{Propagación de incertidumbres para la dosis absorbida}

La forma general de la propagación de incertidumbres se define como:

$$
(\delta z)^{2}=\sum_{i=1}^{n}\left(\frac{\partial z}{\partial x_{i}}\right)^{2}\left(\delta x_{i}\right)^{2}
$$

Definiendo a $z$ como la variable dependiente (dosis absorbida) y $x_{i}$ como la variable a la que se le tiene asociada una incertidumbre debida al instrumento de medición. Desarrollando la propagación para la variable dosis absorbida se tiene lo siguiente:

La fluencia del haz de protones la denotaremos como: $\phi=\frac{\Gamma}{A} \mathrm{y}$ siendo $\Gamma=I(C / \mathrm{s})\left(6.24 \times 10^{18} e^{-} / C\right) t$

El área corresponde al de una elipse, el cual es el patrón formado en la película por el haz de protones.

El área de la elipse A corresponde a $\pi\left(a_{0} \pm \delta a\right)\left(b_{0} \pm \delta b\right)$, siendo $\left(\mathrm{a}_{0}, \mathrm{~b}_{0}\right)$ el valor de los semiejes obtenidos con el software imageJ en el perfil de cada película y $(\delta a, \delta b)$ las incertidumbres asociadas al objeto de medición. 
La dosis absorbida en la película radiocrómica se calcula como: $D(G y)=\varepsilon \phi\left(\frac{d E}{\rho d x}\right)$ y con $\varepsilon$ como un factor de conversión igual a $1.60 \times 10^{-10}$. La propagación de incertidumbres para la dosis absorbida siguiendo la relación 10, con $x_{1}=\phi$ y $x_{2}=\left(\frac{d E}{\rho d x}\right)$ es:

$$
\delta D=\sqrt{\left(\frac{\partial D}{\partial \phi}\right)^{2}(\delta \phi)^{2}+\left(\frac{\partial D}{\partial\left(\frac{d E}{\rho d x}\right)}\right)^{2}\left(\delta\left(\frac{d E}{\rho d x}\right)\right)^{2}}
$$

La incertidumbre asociada al poder de frenado másico es cero por lo que (11) se reduce a:

$$
\delta D=\frac{\partial D}{\partial \phi} \delta \phi, \frac{\partial D}{\partial \phi}=\varepsilon \frac{d E}{\rho d x} \therefore \quad \delta D=\varepsilon\left(\frac{d E}{\rho d x}\right) \delta \phi
$$

El cálculo para la incertidumbre de la fluencia es ahora:

$$
(\delta \phi)^{2}=\left(\frac{\partial \phi}{\partial A}\right)^{2}(\delta A)^{2}, \frac{\partial \phi}{\partial A}=\left|-\frac{\Gamma}{A^{2}}\right| \therefore \delta \phi=\frac{\Gamma}{A^{2}} \delta A
$$

La incertidumbre asociada al área de la elipse es:

$$
\delta A=\mid \pi a b\left(\frac{\delta a}{a}+\frac{\delta b}{b}\right) \quad \text { Con } a \text { y } b \text { los ejes mayor y menor de la elipse. }
$$

Se tiene finalmente una expresión general para la incertidumbre en la dosis absorbida dada por la siguiente expresión:

$$
\delta D=\varepsilon\left(\frac{d E}{\rho d x}\right)_{T_{0}, v_{0}} \frac{\Gamma}{A^{2}}|\pi a b|\left(\frac{\delta a}{a}+\frac{\delta b}{b}\right)(\mathrm{Gy})
$$




\section{DOSIS ABSORBIDA EN PELICULA EBT3}

Se muestran los valores de las dosis absorbidas por los filmes en tres de las diferentes pruebas: vacío, tiempo y corriente. El cálculo se realizó utilizando el poder de frenado másico obtenido con SRIM.

Tabla B.1 Dosis absorbida en EBT3 para prueba de vacío

$\begin{array}{cccccc}\begin{array}{c}\text { Vacío } \\ \left(\mathbf{1 0}^{-5} \mathbf{m b a r s}\right)\end{array} & \begin{array}{c}\text { Corriente de } \\ \text { entrada } \\ \boldsymbol{\mu A}\end{array} & \begin{array}{c}\text { Fluencia } \\ \mathbf{\Phi}\end{array} & \begin{array}{c}\boldsymbol{\Delta} \boldsymbol{\phi} \\ \left(\mathbf{1 0}^{\mathbf{1 3}} \mathbf{p} / \mathbf{c m}^{\mathbf{2}}\right)\end{array} & \begin{array}{c}\text { Dosis } \\ \left.\mathbf{( 1 3} \mathbf{p} / \mathbf{c m}^{\mathbf{2}}\right)\end{array} & \begin{array}{c}\Delta \text { Dosis } \\ \mathbf{k G y}\end{array} \\ \mathbf{1 . 8} & 0.87 & 7.40 & 3.04 & 317 & \\ \mathbf{1 . 7} & 0.82 & 6.84 & 2.82 & 294 & 130 \\ \mathbf{1 . 6} & 0.76 & 4.10 & 1.31 & 176 & 56 \\ \mathbf{1 . 5} & 0.70 & 2.43 & 0.62 & 104 & 26 \\ \mathbf{1 . 3} & 0.24 & 1 & 0.27 & 34 & 12 \\ \mathbf{1 . 2} & 0.47 & 1.84 & 0.49 & 79 & 21 \\ \mathbf{1 . 1} & 0.06 & 2.41 & 0.07 & 10 & 3\end{array}$

Tabla B.2 Dosis absorbida en EBT3 para prueba de intensidad de corriente

\begin{tabular}{|c|c|c|c|c|c|}
\hline $\begin{array}{c}\text { Corriente en } \\
\text { la fuente de } \\
\text { iones } \\
(\mathrm{mA})\end{array}$ & $\begin{array}{c}\text { Corriente de } \\
\text { entrada } \\
\mu \mathrm{A}\end{array}$ & $\begin{array}{c}\text { Fluencia } \\
\Phi \\
\left(10^{13} \mathrm{p} / \mathrm{cm}^{2}\right)\end{array}$ & $\begin{array}{c}\Delta \phi \\
\left(10^{13} \mathrm{p} / \mathrm{cm}^{2}\right)\end{array}$ & $\begin{array}{c}\text { Dosis } \\
\text { kGy }\end{array}$ & $\begin{array}{c}\Delta \text { Dosis } \\
\text { kGy }\end{array}$ \\
\hline 5 & 0.29 & 2.56 & 1.10 & 110 & 47 \\
\hline 10 & 0.41 & 3.60 & 0.89 & 154 & 38 \\
\hline 20 & 1.05 & 3.75 & 0.95 & 161 & 41 \\
\hline 30 & 1.51 & 5.19 & 1.29 & 223 & 56 \\
\hline 40 & 2.09 & 7.10 & 1.74 & 75 & 305 \\
\hline
\end{tabular}

Tabla B.3 Dosis absorbida en EBT3 para prueba de tiempo a una corriente de $10 \mathrm{~mA}$ en la fuente de iones

$\begin{array}{cccccc}\begin{array}{c}\text { Tiempo } \\ \text { (segundos) }\end{array} & \begin{array}{c}\text { Corriente de } \\ \text { entrada } \\ \boldsymbol{\mu A}\end{array} & \begin{array}{c}\text { Fluencia } \\ \mathbf{\Phi}\end{array} & \begin{array}{c}\boldsymbol{\Delta} \boldsymbol{\phi} \\ \left(\mathbf{1 0}^{\mathbf{1 3}}\right. \\ \left.\mathbf{p} / \mathbf{c m}^{\mathbf{2}}\right)\end{array} & \begin{array}{c}\text { Dosis } \\ \mathbf{k G y}\end{array} & \begin{array}{c}\boldsymbol{\Delta} \text { Dosis } \\ \mathbf{k G y}\end{array} \\ \mathbf{3} & & & & & \\ \mathbf{4} & 0.87 & 3.01 & 0.74 & 32 & 129 \\ \mathbf{5} & 0.64 & 2.71 & 0.75 & 32 & 117 \\ \mathbf{6} & 0.64 & 2.77 & 0.77 & 33 & 119 \\ \mathbf{7} & 0.47 & 1.99 & 0.55 & 24 & 86 \\ \mathbf{8} & 0.29 & 0.98 & 0.23 & 10 & 42 \\ & 0.35 & 1.26 & 0.32 & 14 & 60\end{array}$




\section{TAMAÑO DE HAZ (EJE MENOR)}

La figura C.1 muestra la tendencia del haz a diferentes vacíos durante la irradiación. Para valores por arriba de $1.5 \times 10^{-5}$ mbars, el tamaño de haz (eje menor) comienza a ser constante con un valor promedio de $(6 \pm 0.1) \mathrm{mm}$.

Tamaño de haz vs Vacío

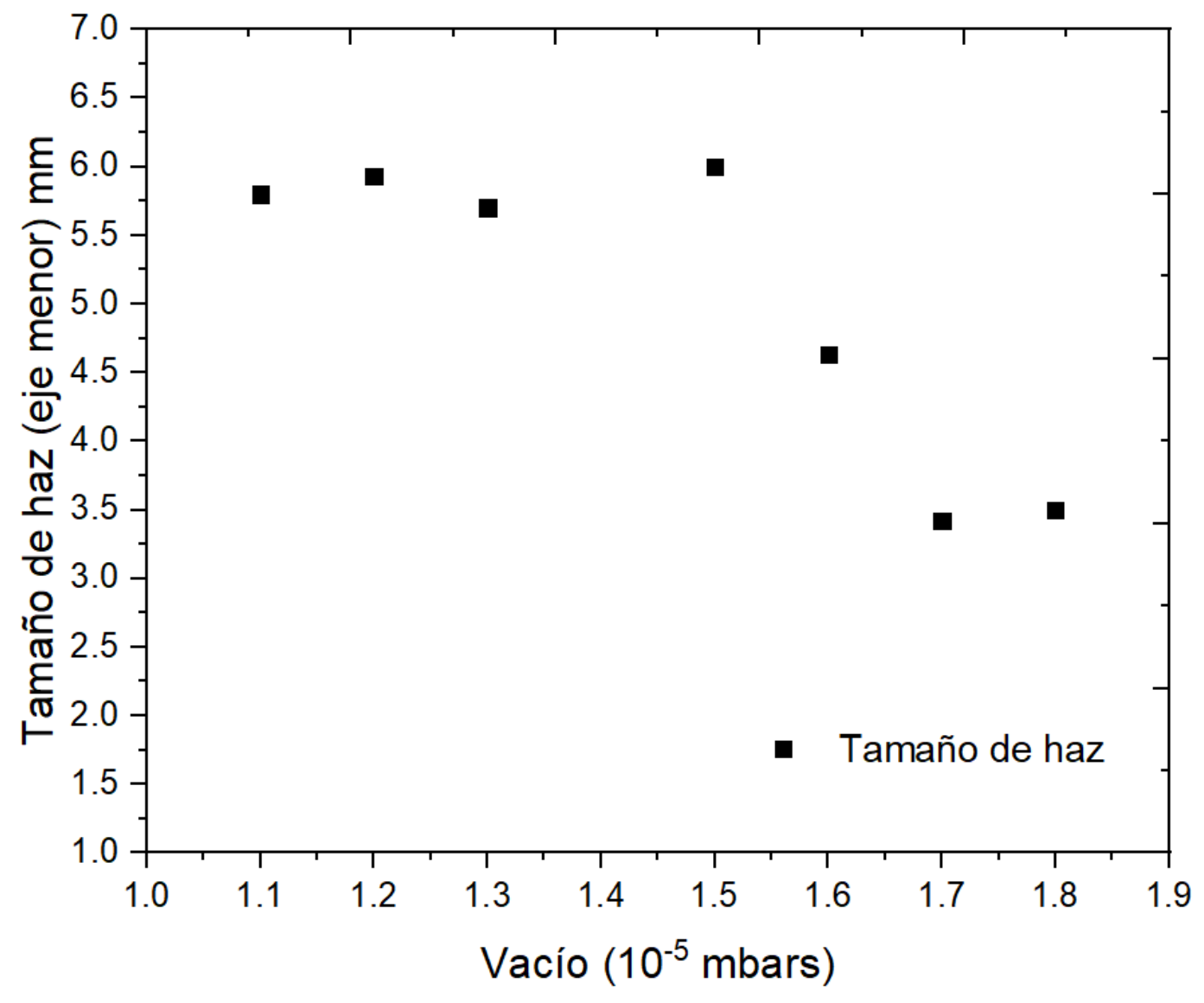

Figura C.1 Variación del eje menor del haz a vacíos variables. Para irradiaciones por debajo de 1.5 x $10^{-5}$ mbars, se tiene una disminución de fluencia de partículas traduciéndose en pérdida de corriente de haz. 
Para una corriente de $10 \mathrm{~mA}$ en la fuente de iones 2, el eje menor de la elipse presenta un tamaño promedio de $(6 \pm 0.1) \mathrm{mm}$ (línea sólida en figura C.2). No se manejaron tiempos menores a 3 segundos dado que el proceso de desactivar la punta de prueba para dar paso al flujo de partículas involucraba un tiempo mínimo de 3 segundos.

Tamaño de haz vs Tiempo

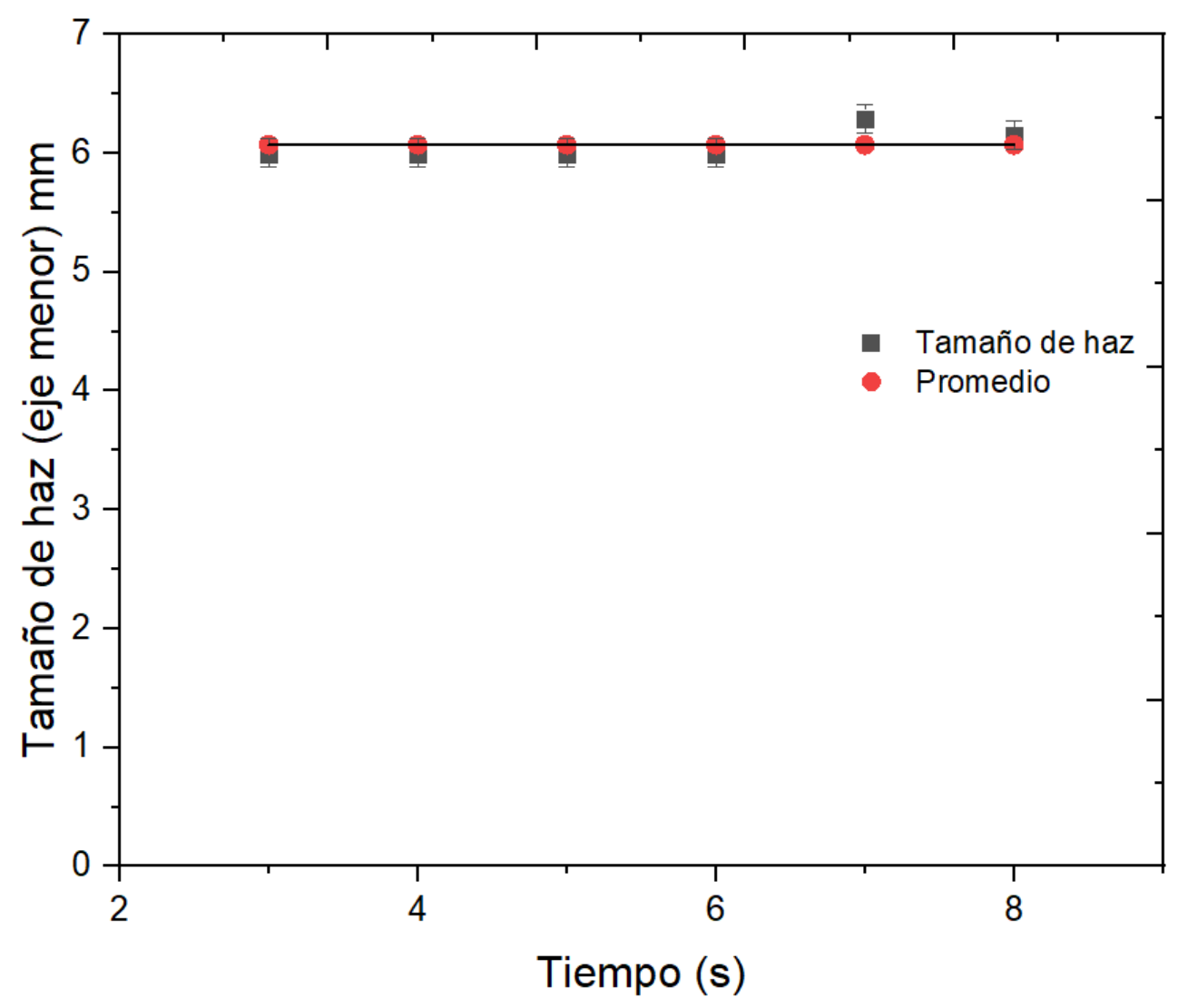

Figura C.2. Variación de tamaño de haz para el eje menor de la elipse a un tiempo variable. 
Durante un tiempo de irradiación de 3 segundos, con un máximo de $40 \mathrm{~mA}$ en la fuente de iones, el tamaño promedio del haz fue de $(6.2 \pm 0.2) \mathrm{mm}$

\section{Tamaño de haz vs Corriente}

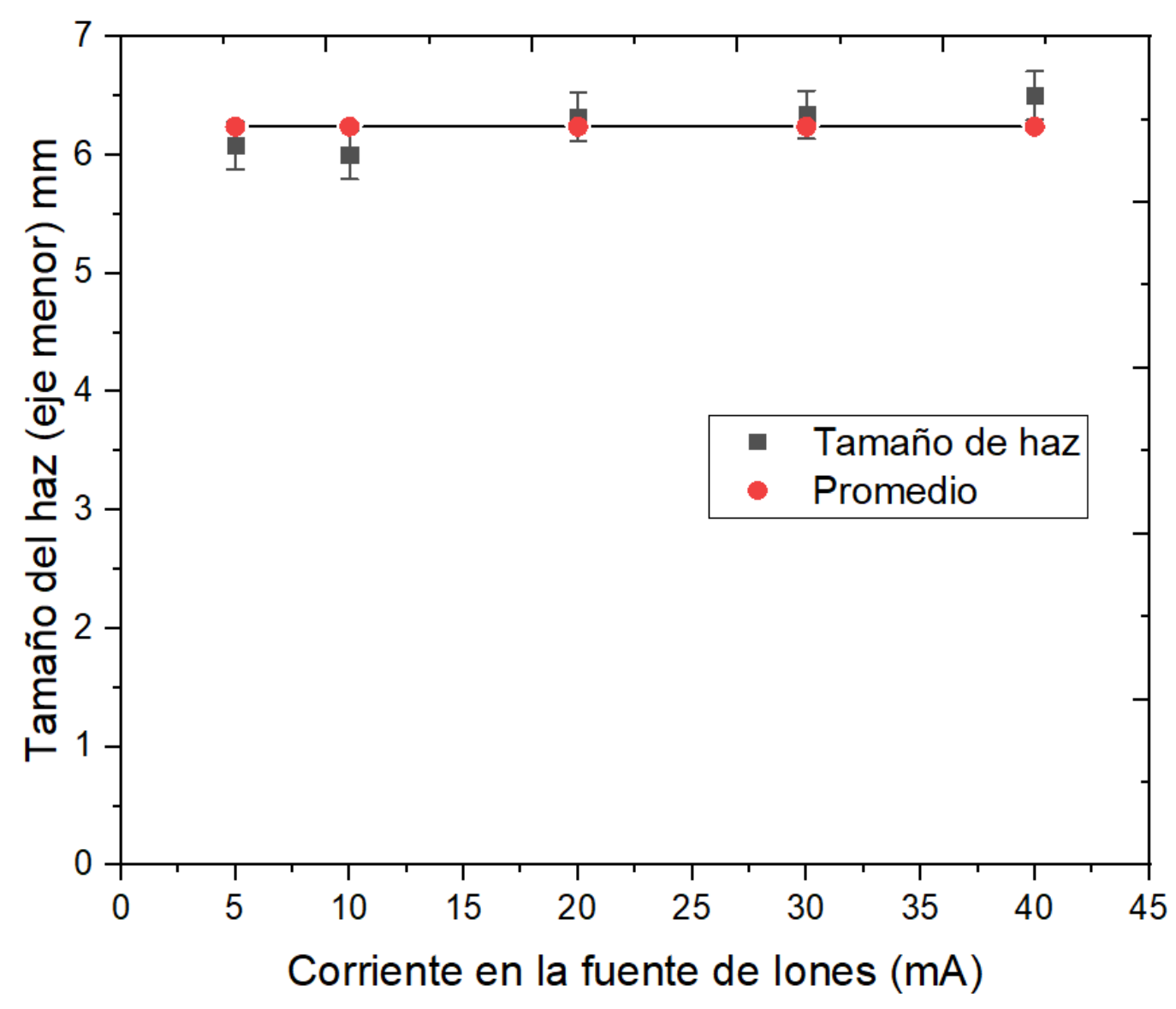

Figura C.2 Tendencia de haz constante a tiempos de irradiación fijos y corriente variable 
[Aragón, 2015]

[Attix, 1986]

[Ávila et al., 2009]

[Azorín, 1997]

[Azorín, 2010]

[Blackwell et al., 1998]

[Cabrera, 2011]

[Cárcamo, 2013]

[Cherry et al., 2012]

[Cristerna, 1995]

[Escarcia, 2016]

[Evans, 1955]
Aragón, N. (2015). Dosimetría de referencia en una unidad de Cyberknife (Tesis de maestría). UNAM, México, D.F.

Attix, F. (1986), Introduction to radiological physics and radiation dosimetry, USA: Jhon Wiley \&Sons.

Avila-Rodriguez, M. A., Wilson, J. S., \& McQuarrie, S. A. (2009). The use of radiochromic films to measure and analyze the beam profile of charged particle accelerators. Applied Radiation and Isotopes, 67(11), 2025-2028.

Azorín, J. (1997), Introducción a la física nuclear, México, D.F: ediciones científicas AZVEG.

Azorín, J. (2010), Protección Radiológica, México, D.F: Universidad Autónoma Metropolitana.

Blackwell, C. R., Coursey, B. M., Gall, K. P., Galvin, J. M., Mclaughlin, W. L., Meigooni, A. S., \& Soares, C. G. (1998). Radiochromic Film Dosimetry, 25(63).

Cabrera, J. (2011). Determinación de la energía del haz de protones de un ciclotrón biomédico compacto mediante el uso de diferentes reacciones monitor (Tesis de licenciatura). UNAM, México, D.F.

Cárcamo, R. (2013). Implementación de un sistema de blancos sólidos en el ciclotrón de la UNAM (Tesis de maestría). UNAM, México, D.F.

Cherry, S., Sorenson J., \& Phelps M. (2012). Physics in Nuclear Medicine. New York. E.U.A: Saunders.

Cristerna, R. (1995), Imagenología Médica, México, DF, UAM-Iztapalapa.

Escarcia, F. (2016).Influencia de tamaño de campo en la respuesta de la película radiocrómica EBT3 y su impacto en la medición de los factores totales de dispersión de campos pequeños (Tesis de maestría). UNAM, México D.F.

Evans, R. (1955), The Atomic Nucleus, New York: McGraw-Hill. 
[Kenneth, 1988]

[Leon- Marroquín et al., 2013]

[NCRP, 2003]

[OIEA, 2012]

[OIEA, 1999]

[OIEA, 2010]

[OIEA, 2008]

[Powsner.R \& Powsner.E, 2006]

[Sansaloni et al., 2012]
Krane. Kenneth, 1988). Introductory Nuclear Physics. Oregon State University: Jhon Waley \& Sons.

León-Marroquín, E.Y., Camacho-Lopez, M.A., GarcíaGarduño, O.A., Herrera-Gonzalez, J.A., Villareal-Barajas, J.E., Martinez-Quiroz, C., De la Cruz-Perez, D., \& Jimenez-Aviles, G. (2016).Analysis of the absorption spectra of EBT2 and EBT3 kradiochromic films. Revista Mexicana de Ingeniería Biomedica, 28 (1), 363-371.

National Council On Radiation Protection and Measurements. (2003). Radiation Protection.

Organismo Internacional de Energía Atómica. (2012). Ciclotrón Produced Radionuclides: Operation and Manteinance of Gas and Liquid Targets $\mathrm{N}^{\circ} 4$. Recuperado de http://www-pub.iaea.org/books/

OIEA. (1999). Manual de Protocoles de Calidad de Radiofármacos. Viena, Austria.

Organismo Internacional de Energía Atómica. (2010). El físico médico: Criterios y recomendaciones para su formación académica, entrenamiento clínico y certificación en América Latina $\mathrm{N}^{\circ}$ 1. Recuperado de: http://wwwpub.iaea.org/books/

Organismo Internacional de Energía Atómica. (2008). Ciclotrón produced radionuclides: principles and practice $\mathrm{N}^{\circ}$ 465. Recuperado de http://www-pub.iaea.org/books/

Powsner R. \& Powsner E. (2006). Essential Nuclear Medicine Physics. Malden, MA: Blackwell Publishing.

Sansaloni, F., Lagares, J. I., Arce, P., Llop, J., \& Perez, J. M. (2012). Characterization of the proton beam from an IBA Cyclone 18/9 with radiochromic film EBT2. AIP Conference Proceedings, 1509, 46-50. 
[Reinhardt et al., 2012]

[Resnick et al., 1994]

[Tamburella et al., 2008]

[Vadrucci, 2015]

[Valdovinos, 2017]

[Zuñiga, 2011]
Reinhardt, S., Hillbrand, M., Wilkens, J.J., \& Assmann, W., (2012). Comparison of Gafchromic EBT2 and EBT3 films for clinical photon and proton beams. Med, Phys. 39 (8), 5257.

Halliday, D., Resnick, R. \& Krane., K. (1992). Física Vol.2.Seattle, Washington: Continental.

Tamburella, C., Giles, T. J., Beyer, G.J. \& Soloviev, D. (2008). Beam diagnostics for an $18 \mathrm{MeV}$ medical cyclotron. Nuclear Instruments and Methods in Physics Research, Section B: Beam Interactions with Materials and Atoms, 266(19-20), 4678-4681.

Vadrucci, M. (2015). Calibration of GafChromic EBT3 for absorbed dose measurements in $5 \mathrm{MeV}$ proton beam and 60 Co $\gamma$-rays, 42(August), 4578-4684.

Valdovinos, H. (2017). Production, labeling and in vivo studies with the theranostic positron-emmiting radiometals ${ }^{44} \mathrm{Sc}, \quad{ }^{55 / 58 m / 58 g} \mathrm{Co},{ }^{61 / 64} \mathrm{Cu},{ }^{86} \mathrm{Y}$ and ${ }^{69} \mathrm{Ge}$. (Tesis de Doctorado). Universidad de Wisconsin, Madison.

Zuñiga, L. (2011). Respuesta de películas radiocromicas EBT a radionúclidos emiosres de positrones. Tesis de Licenciatura. UNAM, México, D.f. 
Caracterización del Perfil del

Haz de un Ciclotrón IBA 18/9

con Películas Radiocrómicas de EBT3.
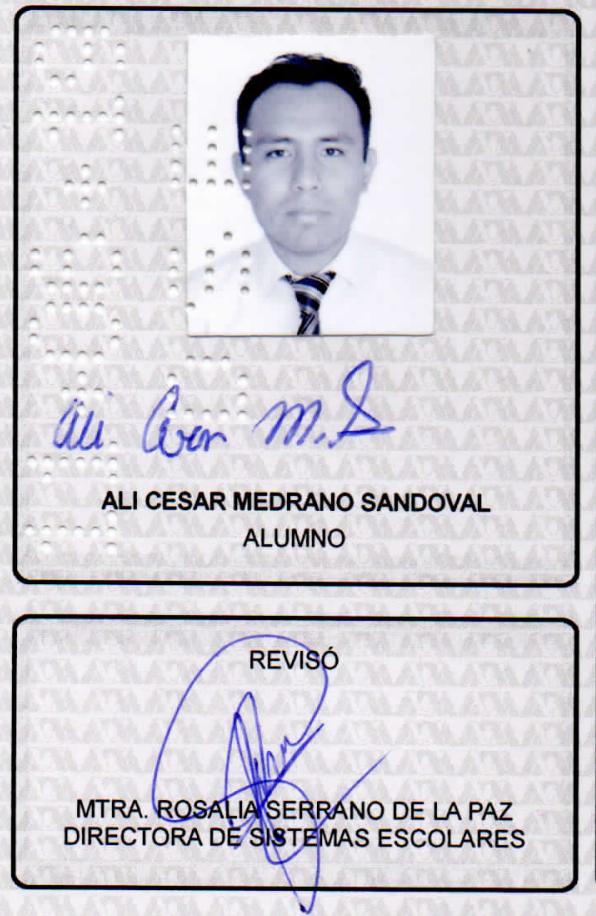

DECTOR DE LA DIVISIÓN DE CBI

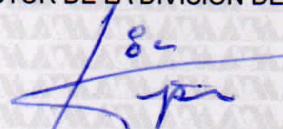

DR. JESUS ALBERTO OCHOA TAPIA
En la Ciudad de México, se presentaron a las $12: 00$ horas del día 7 del mes de junio del año 2019 en la unidad Iztapalapa de la Universidad Autónoma Metropolitana, los suscritos miembros del jurado:

DR. HECTOR FRANCISCO VALDOVINOS URIBE

MTRO. JOSE ALFREDO HERRERA GONZALEZ

MTRO. ADOLFO ZARATE MORALES

DR. JUAN AZORIN NIETO

Bajo la Presidencia del primero y con carácter de Secretario el último, se reunieron a la presentación de la Idónea Comunicación de Resultados cuya denominación aparece al margen, para la obtención del diploma de:

ESPECIALIZACION EN FISICA MEDICA CLINICA

DE: ALI CESAR MEDRANO SANDOVAL

y de acuerdo con el artículo 79 fracción II del Reglamento de Estudios Superiores de la Universidad Autónoma Metropolitana, los miembros del jurado resolvieron:

\section{APROBAR}

Acto continuo, el presidente del jurado comunicó al interesado el resultado de la evaluación $y$, en caso aprobatorio, le fue tomada la protesta.

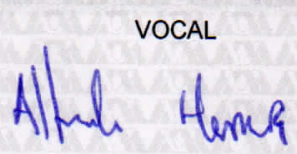

MTRO. JOSE ALFREDO HERRERA GONZALEZ

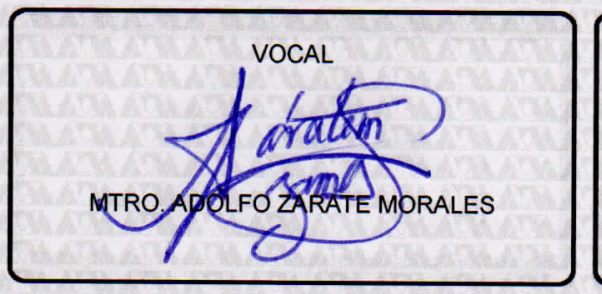

SECRETARIO

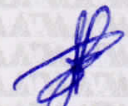

DR. JUANSAZORIN NIETO 